\title{
Stem Cells and Cell Therapies in Lung Biology and Lung Diseases
}

\author{
Daniel J. Weiss ${ }^{1}$, Jay K. Kolls ${ }^{2}$, Luis A. Ortiz ${ }^{3}$, Angela Panoskaltsis-Mortari ${ }^{4}$, and Darwin J. Prockop ${ }^{5}$ \\ ${ }^{1}$ Department of Medicine, University of Vermont College of Medicine, Burlington, Vermont; ${ }^{2}$ Division of Pulmonary Medicine, Allergy, and \\ Immunology, Children's Hospital of Pittsburgh, Pittsburgh, Pennsylvania; ${ }^{3}$ University of Pittsburgh, Pittsburgh, Pennsylvania; ${ }^{4}$ Department of \\ Pediatrics, Division of Pulmonary, Allergy/Critical Care Medicine, and Division of Hematology/Oncology, Blood and Marrow Transplant Program, \\ University of Minnesota, Minneapolis, Minnesota; and ${ }^{5}$ Center for Gene Therapy, Tulane University Health Sciences Center, New Orleans, Louisiana
}

\section{EXECUTIVE SUMMARY}

The University of Vermont College of Medicine and the Vermont Lung Center, with support from the National Heart, Lung, and Blood Institute (NHLBI), the American Thoracic Society, the Alpha-1 Foundation, and the Pulmonary Fibrosis Foundation, convened a workshop, "Stem Cells and Cell Therapies in Lung Biology and Lung Diseases," to review our current understanding of the role of stem and progenitor cells in lung repair after injury and to review the current status of cell therapy approaches for lung diseases. These are rapidly expanding areas of study that both provide further insight into and challenge traditional views of mechanisms of lung repair after injury and pathogenesis of several lung diseases. The goals of the conference were to summarize the current state of the field, discuss and debate current controversies, and to identify future research directions and opportunities for both basic and translational research in cellbased therapies for lung diseases.

This workshop was a follow-up to an inaugural workshop held at the University of Vermont in 2005, "Adult Stem Cells, Lung Biology, and Lung Disease," sponsored by the NHLBI and the Cystic Fibrosis Foundation, together with the Vermont Lung Center and the University of Vermont College of Medicine (1). That workshop was instrumental in helping guide research and funding priorities.

Since the 2005 workshop, investigations of stem cells and cell therapies in lung biology and diseases have continued to rapidly expand. However, there have been several distinct changes in focus and direction, particularly with respect to cell-based therapy approaches. For example, engraftment of airway or alveolar epithelium by stem or progenitor cells originating from outside of the lung is now viewed to be a rarer occurrence than previously described and of unclear physiologic or therapeutic significance. In contrast, circulating endothelial progenitor cells (EPCs) can contribute to regeneration of diseased pulmonary

\footnotetext{
(Received in original form April 8, 2008; accepted in final form May 13, 2008)

The Alpha-1 Foundation, American Thoracic Society, Pulmonary Fibrosis Foundation, University of Vermont College of Medicine, University of Vermont Department of Medicine, and the Vermont Lung Center provided financial support for the conference. The conference was also supported in part by R13HL088903 from the NHLBI (D.J.W.).

Correspondence and requests for reprints should be addressed to Daniel J. Weiss, M.D., Ph.D., Associate Professor of Medicine, Department of Medicine, University of Vermont College of Medicine, 149 Beaumont Avenue, HSRF 226, Burlington, VT 05405. E-mail: daniel.weiss@uvm.edu

This article has an online supplement, which is accessible from this issue's table of contents at www.atsjournals.org

Proc Am Thorac Soc Vol 5. pp 637-667, 2008

DOI: $10.1513 /$ pats.200804-037DW

Internet address: www.atsjournals.org
}

vasculature and are being investigated in patients with pulmonary hypertension in a clinical trial being conducted at the University of Toronto and in one recently completed at Zhejiang University, China. Circulating EPCs may also play roles in both acute lung injury and in fibrotic lung diseases. Furthermore, increasing evidence suggests that circulating fibrocytes can contribute to the pathophysiology of fibrotic lung diseases and thus may be a potential therapeutic target.

In addition, novel areas of investigation have developed that include increasing exploration of three-dimensional culture systems and bioengineering approaches to generate functional lung tissue ex vivo and in vivo. Mesenchymal stem cells (MSCs) have been found to exert profound suppressive effects on immune cells and pathways and have demonstrated both safety and efficacy in phase 1 and 2 trials in immune-mediated diseases such as graftversus-host disease (GVHD) and Crohn's disease. Recent publications and several abstracts presented at the workshop demonstrate that MSCs suppress lung injury and inflammation in several mouse models of inflammatory and immune-mediated lung diseases. These areas are predicted to be of intense investigation over the next several years.

Progress continues to be made in investigations of local (endogenous) stem and progenitor cells resident in the lungs. Further understanding of the identity and lineage expansion properties of previously identified endogenous progenitor populations, including variant Clara cells, bronchoalveolar stem cells (BASCs), and side population cells, suggests an increasingly complex network of cellular repair after injury. Most recently, embryonic origin Oct- $4^{+}$Clara cell secretory protein $\left(\mathrm{CCSP}^{+}\right)$ cells have been identified in neonatal mouse lungs and have been postulated to play a progenitor role in adult lung. However, study of endogenous lung stem and progenitor cells is complicated by the role of specific microenvironmental niches in which these cells reside. Alteration of the niches with experimental protocols or removal of cells from the niches can change their identifying characteristics and biologic activities. One of the challenges facing the field is to devise lineage tracing and other study mechanisms to define, characterize, and explore potential therapeutic and/or pathologic properties of endogenous lung progenitor cells. Notably, the existence of lung cancer stem cells is an area of increasing focus and high interest but remains poorly understood. Another challenge is that most studies of endogenous progenitor cells have used mouse models. Correlative information in human lungs remains poorly defined. Comparably, most studies of exogenous cells in lung repair have used mouse models, with relatively limited data in patient models.

A continuing issue of confusion is that of terminology. Precise definitions and characterizations of specific cell populations, notably MSCs and EPCs, are not agreed upon. The terms "stem cell" and "progenitor cell" are still used with varying 
degrees of clarity and precision by different investigators and in recent publications. This continues to complicate comparison of different investigative approaches. A glossary of relevant working definitions applicable to lung is depicted in Table 1. This glossary does not necessarily reflect an overall consensus for the definition of each term and will undergo continuing revision as overall understanding of the cell types and mechanisms involved in lung repair continues to be elucidated. Nonetheless, it is a useful framework.

In the first session, after an overview of the field by Diane Krause (Yale University), respective presentations by Wellington Cardoso (Boston University), Barry Stripp (Duke University), Ivan Bertoncello (Australian Stem Cell Center), and Douglas Ball (Johns Hopkins University School of Medicine) reviewed the current state of knowledge of endogenous stem cell populations and their potential to initiate or augment repair. This included lessons learned from lung development, the role of the local microenvironmental niches, and consideration of lung cancer progenitor cells. Key points made during this session were that stem cells are operationally defined not solely by their intrinsic developmental potential but by their interaction with the permissive or restrictive microenvironments in which they reside. Furthermore, the stem cell niche is a dynamic "temporal" niche with the capacity to modify stem cell behavior/readout in different contexts. Moreover, stem cell-associated markers are not uniquely expressed by stem cells and are unreliable predictors of the stem cell potential of isolated cells, requiring validation by functional assays and lineage-tracing studies, particularly when interrogating isolated cells in which histomorphometric spatial and positional cues are lost. Also included in this session was a presentation by Rick Wetsel (University of Texas) demonstrating that cells with phenotypic characteristics of type 2 alveolar epithelial cells could be derived in vitro from one of the approved human embryonic stem (ES) cell lines without the requirement for an embryoid body intermediate. Although the study of human ES cells has been restricted in the United States, only limited information exists from work in other countries on use of human ES cells for lung repair and regeneration.

The second and third sessions highlighted advances in cell therapy approaches for lung diseases and also presented data from clinical trials of cell therapies in other diseases. New and developing areas in bioengineering approaches for cell therapies of lung diseases were explored in the second session. Presentations by Dennis Discher (University of Pennsylvania) and Mingyao Liu (University of Toronto) explored the effects of physical environment and three-dimensional matrices on stem cells and lung regeneration. Dario Fauza (Boston Children's Hospital) demonstrated that amniotic fluid-derived MSCs could be used for tracheal repair. Bethany Moore (University of Michigan) and Kurt Stenmark (University of Colorado Health Sciences Center) reviewed current understanding of the role of fibrocytes in fibrotic lung disease and of EPCs in pulmonary vascular and fibrotic lung diseases, respectively. Finally, Johnny Huard (University of Pittsburgh) presented an update in stem cell trials for muscle diseases.

Immunomodulatory effects of stem cells were explored in the third session. Results of a phase 2 clinical trial of MSCs in Crohn's disease were presented by Jane Onken (Duke University School of Medicine) demonstrating both safety and efficacy in otherwise treatment-resistant patients. This was followed by exploration of MSC effects in inflammatory and immune-mediated lung diseases by Donald Phinney (Tulane University) and Daniel Weiss (University of Vermont). Ellen Burnham (University of Colorado Health Sciences Center) and Duncan Stewart (University of Toronto) presented an update on EPCs and initial results from the EPC trial in pulmonary hypertension being conducted at the
University of Toronto. Keith March (Indiana University) presented an update on cardiac trials and Donald Fink (U.S. Food and Drug Administration [FDA]) presented a perspective from the FDA. After extensive discussion, both immunomodulation and bioengineering approaches using MSCs and other stem cell populations were identified as areas of high priority for expanding study.

In the final session, Alan Michelson (National Institutes of Health $[\mathrm{NIH}]$ ) discussed a systems-based strategy to cell therapies, and Mike Rosenzweig and John Walsh, respective presidents of the Pulmonary Fibrosis and Alpha-1 Foundations, presented perspectives on stem cell research from the views of nonprofit respiratory disease foundations. The conference concluded with vigorous discussion on future research and funding priorities, led by Darwin Prockop (Tulane University). As in the 2005 conference, discussion was spirited as to how and when to proceed to further clinical investigation in addition to the trial occurring at the University of Toronto. It was agreed that strong emphasis must continue to be placed on animal models of human lung diseases, with a focus on studies that incorporate relevant functional outcome measures. Nonetheless, the safety and efficacy results obtained with MSCs in Crohn's disease and other inflammatory and immune-mediated diseases suggest a potential role in inflammatory and immune-mediated lung diseases even in the absence of a comprehensive understanding of the mechanisms by which the MSCs are acting. There was a growing consensus at the meeting to move toward early studies in humans to determine safety and dosing parameters, and to design carefully controlled clinical trials that offer patients benefits at relatively little risk.

It was acknowledged by all participants that the role of endogenous lung progenitor cells and of cell therapy approaches for lung diseases remains a timely and exciting area of study. Nonetheless, there are many areas in which our understanding of the processes and mechanisms remain poorly understood. Recommendations for areas of continued and future investigation are presented in Table 2. More extensive details on each session are presented below. The conference program, executive summaries for each speaker, and abstracts from the poster sessions are included in the online supplement.

\section{BACKGROUND AND REVIEW}

A comprehensive summary of relevant published literature since the 2005 workshop and through January 2008 is presented below. See the report from that workshop for a comprehensive review of the literature up to that point (1). Readers are also referred to a number of reviews of each of the below topics that have appeared over approximately the past 2 years (2-27).

\section{Structural Engraftment and Functional Effects of Circulating or Exogenously Administered Stem or Progenitor Cells}

Structural engraftment. A number of publications over approximately the past 10 years have suggested that a variety of bone marrow-derived cells, including hematopoietic stem cells, MSCs, multipotent adult progenitor cells, and other populations, could structurally engraft as mature differentiated airway and alveolar epithelial cells. This literature has been predominantly based on studies in mice using techniques that evaluated histologic demonstration of donor-derived marrow cells in recipient lungs after systemic administration of male marrow cells to female recipients, usually but not always after myeloablation of the recipient mouse bone marrow (reviewed in Reference 1). Prior lung injury was usually required to observe engraftment, although lung injury did not always result in increased apparent engraftment (28). 


\section{TABLE 1. GLOSSARY AND DEFINITION OF TERMINOLOGY}

Potency: Sum of developmental options available to cell.

Totipotent: Ability to (re)generate an organism in total. In mammals only the zygote and the first cleavage blastomeres are totipotent.

Pluripotent: Ability to form all lineages of body. Example: embryonic stem cells.

Multipotent: Ability of adult stem cells to form multiple cell types of one lineage. Example: hematopoietic stem cells.

Unipotent: Cells form one cell type. Example: spermatogonial stem cells (can only generate sperm).

Reprogramming: Change in epigenetics that can lead to an increase in potency, dedifferentiation. Can be induced by nuclear transfer, cell fusion, genetic manipulation.

Transdifferentiation: The capacity of a differentiated somatic cell to acquire the phenotype of a differentiated cell of the same or different lineage. An example is epithelial-mesenchymal transition (EMT), a process whereby fully differentiated epithelial cells undergo transition to a mesenchymal phenotype, giving rise to fibroblasts and myofibroblasts.

Plasticity: Hypothesis that somatic stem cells have broadened potency and can generate cells of other lineages, a concept that is controversial in mammals.

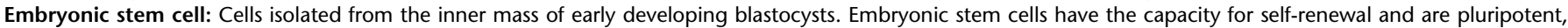
having the ability to differentiate into cells of all embryologic lineages and all adult cell types. However, embryonic stem cells cannot form extraembryonic tissue such as trophectoderm.

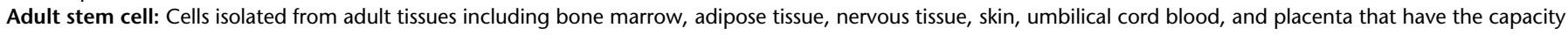
for self-renewal. In general, adult stem cells are multipotent, having the capacity to differentiate into mature cell types of the parent tissue. Some populations of adult stem cells, such as mesenchymal stem cells exhibit a range of lineage differentiation that is not limited to a single tissue type. Whether adult stem cells exhibit plasticity and can differentiate into a wider variety of differentiated cells and tissues remains controversial.

Adult tissue-specific stem cell: The same as adult stem cells but with defined tissue specificity. A relatively undifferentiated cell within a given tissue that has the capacity for self-renewal through stable maintenance within a stem cell niche. Adult tissue-specific (endogenous) stem cells have a differentiation potential equivalent to the cellular diversity of the tissue in which they reside. The hematopoietic stem cell is a prototypical adult tissue stem cell.

Induced pluripotent stem cell: Reprogrammed adult somatic cells that have undergone dedifferentiation, such as dermal fibroblasts, reprogrammed by retroviral transduction to express four transcription factors: Oct 3/4, Sox2, c-Myc, and Klf4. Induced pluripotent stem cells are similar to embryonic stem cells in morphology, proliferation, gene expression, and ability to form teratomas. In vivo implantation of induced pluripotent stem cells results in formation of tissues from all three embryonic germ layers. Induced pluripotent stem cells have been generated from both mouse and human cells.

Progenitor cell: A collective term used to describe any proliferative cell that has the capacity to differentiate into different cell lineages within a given tissue. Unlike stem cells, progenitor cells have limited or no self-renewal capacity. The term "progenitor cell" is commonly used to indicate a cell can expand rapidly, but that undergoes senescence after multiple cell doublings. Terminology that takes into account the functional distinctions among progenitor cells is suggested below.

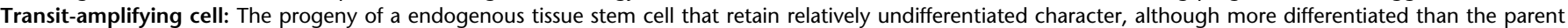
stem cell, and which have a finite capacity for proliferation. The sole function of transit-amplifying cells is generation of a sufficient number of specialized progeny for tissue maintenance.

Obligate progenitor cell: A cell that loses its ability to proliferate once it commits to a differentiation pathway. Intestinal transit-amplifying cells are obligate progenitor cells.

Facultative progenitor cell: A cell that exhibits differentiated features when in the quiescent state yet has the capacity to proliferate for normal tissue maintenance and in response to injury. Bronchiolar Clara cells are an example of this cell type.

Classical stem cell hierarchy: A stem cell hierarchy in which the adult tissue stem cell actively participates in normal tissue maintenance and gives rise to a transitamplifying cell. Within this type of hierarchy, renewal potential resides in cells at the top of the hierarchy (i.e., the stem and transit-amplifying cell), and cells at each successive stage of proliferation become progressively more differentiated.

Nonclassical stem cell hierarchy: A stem cell hierarchy in which the adult tissue stem cell does not typically participate in normal tissue maintenance but can be activated to participate in repair following progenitor cell depletion.

Rapidly renewing tissue: Tissue in which homeostasis is dependent on maintenance of an active mitotic compartment. Rapid turnover of differentiated cell types requires continuous proliferation of stem and/or transit-amplifying cells. A prototypical rapidly renewing tissue is the intestinal epithelium.

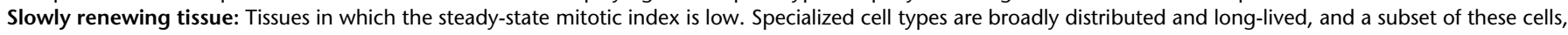
the facultative progenitor cell, retains the ability to enter the cell cycle. The relative stability of the differentiated cell pool is paralleled by infrequent proliferation of stem and/or transit-amplifying cells. The lung is an example of a slowly renewing tissue.

Hematopoietic stem cell: Cell that has the capacity for self-renewal and ability to differentiate into mature leukocytes, erythrocytes, and platelets. Whether hematopoitic stem cells exhibit plasticity and can differentiate into mature cells of other lineages remains controversial.

Endothelial progenitor cell: Circulating cells that have the potential to proliferate and differentiate into mature endothelial cells. Studies of endothelial progenitor cells have been complicated by the use of the same terminology to define at least two different cell populations that have different cell surface markers, different cell sources, and different abilities to differentiate into mature endothelial cells in vitro and in vivo. There is a critical need to develop a consensus definition of endothelial progenitor cells with particular emphasis on the functional capabilities of these cells.

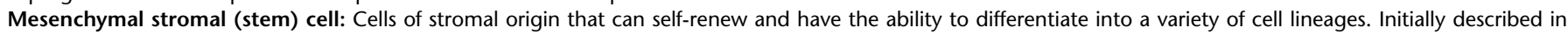
a population of bone marrow stromal cells, they were first described as fibroblastic colony-forming units, subsequently as marrow stromal cells, then as mesenchymal stem cells, and most recently as multipotent mesenchymal stromal cells or MSCs. MSCs have now been isolated from a wide variety of tissues, including umbilical cord blood, Wharton's jelly, placenta, adipose tissue, and lung. The Mesenchymal and Tissue Stem Cell Committee of the International Society for Cellular Therapy has recently updated the minimal criteria for defining (human) MSCs (see Table 3). MSCs have been described to differentiate into a variety of mature cell types and may also have immunomodulatory properties.

Fibrocyte: A cell in the subset of circulating leukocytes that produce collagen and home to sites of inflammation. The identity and phenotypic characterization of circulating fibrocytes is more firmly established than that for endothelial progenitor cells. These cells express the cell surface markers CD34, CD45, CD13, and major histocompatibility class II, and express type 1 collagen and fibronectin.

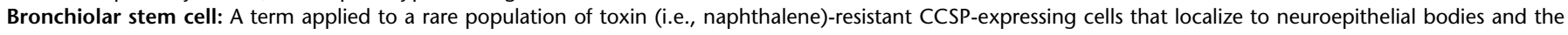
bronchoalveolar duct junction of the rodent lung. These cells proliferate infrequently in the steady state but increase their proliferative rate following depletion of transit-amplifying (Clara) cells. Lineage-tracing studies indicate that these cells have the differentiation potential to replenish specialized cell types of the bronchiolar epithelium. Human correlates have not yet been identified.

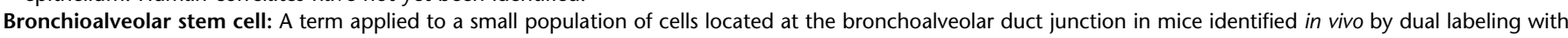
CCSP and SPC and by resistance to destruction with toxins (i.e., naphthalene). In culture, some of the dual-labeled cells also express Sca1 and CD34, self-renew, and give rise to progeny that express either CCSP, pro-SPC, or aquaporin 5, leading to speculation that a single cell type has the capacity to differentiate into both bronchiolar (Clara cells) and alveolar (type 1 and 2 pneumocytes) lineages. At present, the relationship of the cells studied in vitro to those observed by dual labeling in vivo is unclear. Human correlates have not yet been identified.

Definition of abbreviations: CCSP = Clara cell secretory protein; SPC = surfactant protein C.

Modified by permission from References 307 and 308. 


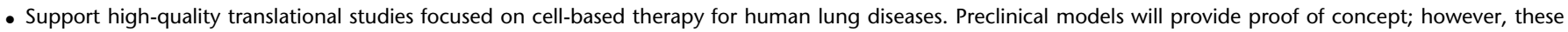
must be relevant to the corresponding human lung disease. Disease-specific models, particularly large-animal models, should be developed for lung diseases.

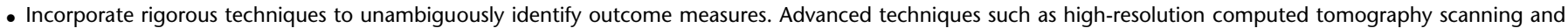
histomorphometry should be used where applicable. Preclinical models require clinically relevant functional outcome measures-for example, pulmonary physiology/mechanics, electrophysiology, and other techniques.

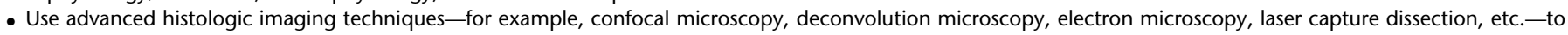
avoid being misled by inadequate photomicroscopy and immunohistochemical approaches. Imaging techniques must be used in combination with appropriate statistical and other analyses to maximize the utility of detecting rare events.

- Encourage new research to elucidate molecular programs for development of lung cell phenotypes, including mechanisms of epithelial/endothelial/mesenchymal interactions in development.

- Develop more sophisticated tools to mimic and study ex vivo the relevant microenvironments for study of endogenous lung progenitor cells.

- Elucidate how endogenous lung stem and progenitor cells are regulated in normal development and in diseases.

- Identify additional cell surface markers that characterize lung cell populations for use in visualization and sorting techniques.

- Identify and characterize putative lung cancer stem cells and regulatory mechanisms guiding their behavior.

- Continue to explore other potential sources of stem cells, such as adipose tissue and cord blood.

- Elucidate mechanisms by which embryonic stem cells develop into lung tissue.

- Elucidate potential deleterious effects with prolonged culture of stem and progenitor cells.

- Investigate immunomodulatory properties and paracrine effects of MSCs and other cell types in lung diseases.

- Uncover mechanisms of recruitment, mobilization, homing, and phenotypic conversion of circulating or therapeutically administered cells to lung epithelial, interstitial, and pulmonary vascular cells.

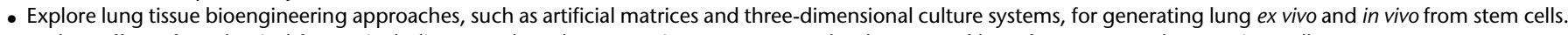

- Evalute effect of mechanical forces, including stretch and compression pressure, on development of lung from stem and progenitor cells.

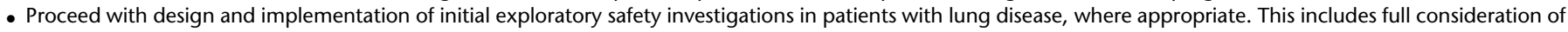
ethical issues involved, particularly which patients should be initially studied.

- Provide increased clinical support for cell therapy trials in lung diseases.

- Disseminate information about and encourage use of existing core services, facilities, and web links.

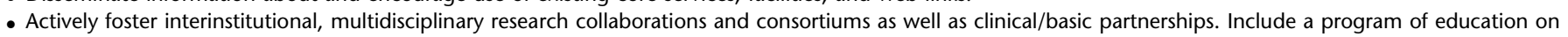
lung diseases and stem cell biology.

Furthermore, the myeloablative regimen used, usually total body irradiation, was also believed to contribute to lung injury and be required for evident engraftment $(29,30)$. A smaller body of literature in clinical bone marrow and lung transplantation also appeared to have demonstrated varying degrees of apparent chimerism in lungs of the transplant recipients (reviewed in Reference 1). However, more recent reports have called into question whether epithelial engraftment does in fact occur (31, 32). Several technical issues contributed to misinterpretation of results in the initial reports, including inadequate microscopic techniques in which donor-derived cells superimposed on resident airway or alveolar epithelial cells were not effectively discriminated. Exquisite care and sophisticated microscopic approaches, including confocal and deconvolution techniques, must be used to effectively demonstrate potential engraftment (1, 31,32). Furthermore, a variety of leukocytes, notably airway and alveolar macrophages, reside in the lung. Many of the early reports did not used antibodies directed against CD45 or other leukocyte markers to exclude the possibility that cells of donor origin detected in airway or alveolar epithelium were donorderived leukocytes rather than epithelial cells. Other tools, such as use of green fluorescence protein (GFP) as a marker of donorderived marrow cells obtained from transgenic GFP mice in recipient mouse lungs can be subject to error in the presence of autofluorescent cells (33).

Nonetheless, recent reports suggest that engraftment of donor-derived airway and/or alveolar epithelium can occur after perturbation of airway or alveolar epithelium in lung injury models. This has been observed with MSCs of bone marrow or cord blood origin (34), side population cells $(35,36)$, plastic adherent marrow stromal cells (36-40), or full marrow transplantation after a myeloablative regimen $(36,41-44)$ (Figure 1). These studies have tended to use more sophisticated microscopic and other analytical techniques. Nonetheless, epithelial engraftment in general is rare, except under conditions discussed below. In parallel, recent studies also continue to demonstrate rare apparent engraftment of pulmonary interstitium and vasculature after total marrow transplant in a variety of injury models $(43,44)$.
These reports suggest that engraftment of lung tissues with circulating or donor-derived cells can occur under certain conditions, usually after previous perturbation through induction of lung injury. However, there are many variables still left to be explored that may increase epithelial, interstitial, or pulmonary vascular engraftment with circulating or donor-derived cells. A wide range of lung injury models has been used in published studies. Interestingly, several recent reports suggest that chronic or progressive lung injury may result in more substantial engraftment of type 2 alveolar epithelial cells and of interstitial and pulmonary vascular cells with donor-derived cells in mouse or rat models $(38,43)$. However, not all chronic lung injury models resulted in more substantial engraftment (45). The effect of age of either donor cells or of recipients is also less well explored, although one report demonstrated that transplantation of whole marrow into 1-day-old mouse pups, using a variety of conditioning regimens, did not increase the number of bone marrow-derived cells over that observed following total marrow administration to adult mice (42). Route of administration of donor-derived cells is also less well characterized because most studies have investigated engraftment after systemic administration of donor cells. Direct intratracheal administration of MSCs also did not result in much apparent epithelial engraftment (46). Nonetheless, this area remains underexplored.

The types of marrow-derived, cord blood-derived, or fully differentiated nonpulmonary cells that might engraft as lung epithelium, interstitium, or pulmonary vasculature remain to be fully explored. In addition to existing studies of hemapoietic stem cells (HSCs), MSCs (of bone marrow and cord blood origin), EPCs, and fibrocytes, the possibility remains that there may be other cell populations that could be recruited to lung or localize to lung after a systemic or other route of administration $(47,48)$. A population of circulating bone marrow-derived $\mathrm{CD} 45^{+} / \mathrm{CXCR}^{+} /$ cytokeratin $^{+}$cells has been described to participate in reepitheliazation of denuded tracheal xenografts (49). A population of cord blood cells termed "multiplineage progenitor cells" isolated from human cord blood can be induced in vitro to express prosurfactant $\mathrm{C}$ and thus suggests derivation of type 2 alveolar 

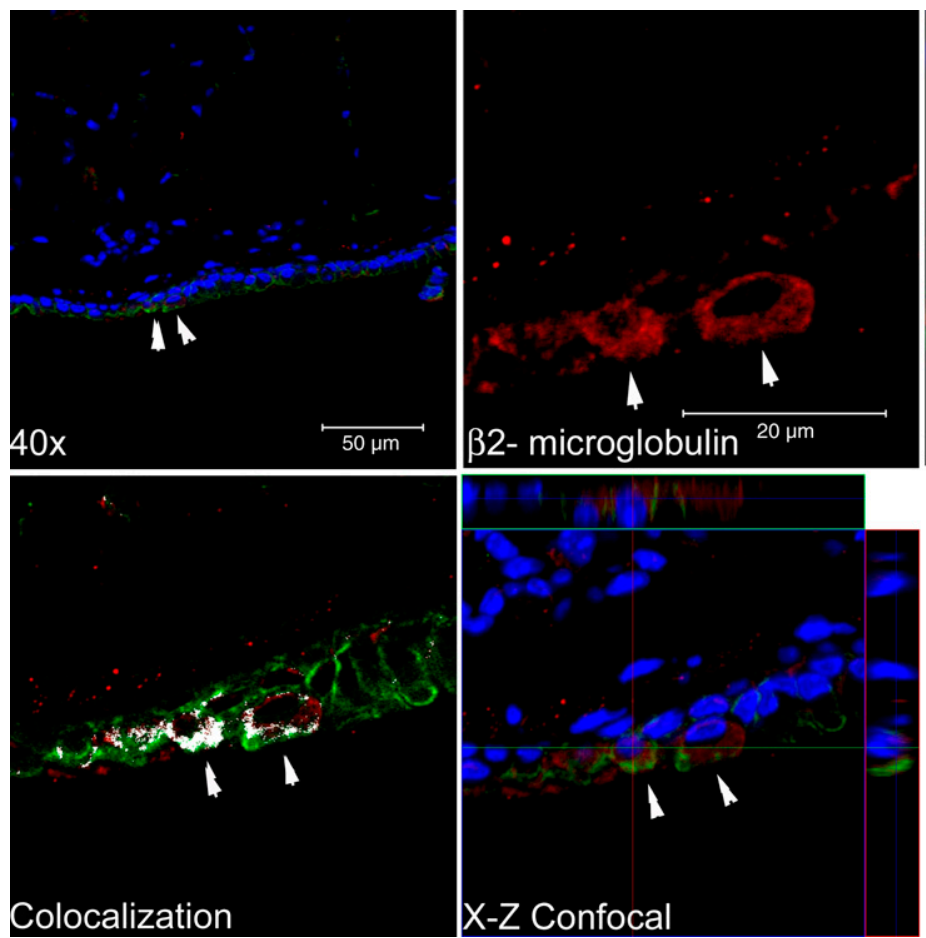

epithelial cells. However, these cells have not yet been extensively characterized or described to result in lung engraftment in vivo (50). Other sources of stem or progenitor cells, such as adipose tissues, also have not yet been extensively characterized for ability to engraft as lung tissue (51-53). However, the ability to structurally engraft in adult lung may not solely be a property of stem or progenitor cells. Intratracheal administration of neonatal mouse lung fibroblasts resulted in apparent alveolar and interstitial engraftment and engraftment was higher in areas of elastase-induced lung injury (54). More recently, it has been demonstrated that intratracheal administration of type 2 alveolar epithelial cells results in rare engraftment in areas of injured lung after bleomycin administration to rats (55). Notably, bleomycininjured rats that received the type 2 cells had less histologic injury and decreased hydroxyproline content. In another report, systemically administered skin fibroblasts, transduced ex vivo to express angiopoeitin-1, protected against subsequent lung injury produced by intratracheal endotoxin administration in rats (56). These results suggest that lung injuries might be amenable to a variety of cell therapy approaches.

For those reports in which more robust evidence of engraftment has been suggested, the potential role of fusion has not yet been fully elucidated. Bone marrow-derived cells can be induced to fuse with lung epithelial cells in vitro, but an initial in vivo investigation in a transgenic mouse model suggested that fusion did not occur $(57,58)$. A more recent report suggests that fusion of donor-derived marrow cells with type 2 alveolar epithelial cells can occur in mouse lungs, but that the Y chromosome may be lost from the resulting heterokaryon cells (59).

Mechanisms by which circulating or systemically administered stem or progenitor cells might be recruited to lung remain poorly understood. After systemic (i.e., venous) administration, many cells initially localize in lung, and recent studies continue to confirm that lung injury results in increased localization and/or retention of marrow-derived cells in lung (60-62). The timing of cell administration after lung injury can also influence recruitment and phenotypic conversion. Systemic administration of MSCs 4 hours after lung irradiation resulted in apparent engraft-

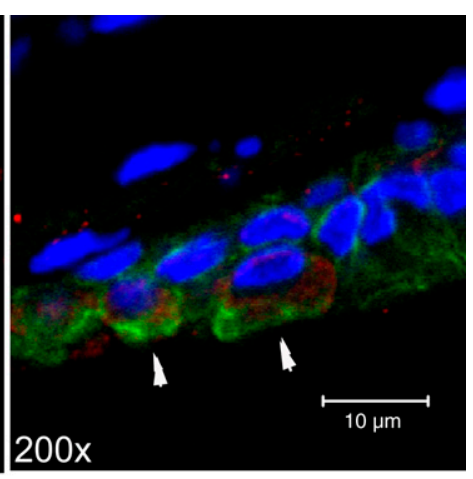

Figure 1. Human $\beta_{2}$-microglobulin-positive cells can be detected in NOD-SCID (nonobese diabetic/severe combined immunodeficient) mouse airways for up to 3 months after systemic administration of human cord blood-derived mesenchymal stem cells (CB-MSCs) (arrowheads). NOD-SCID lung sections 3 months following $C B$ MSC administration. Blue = DAPI (4'-6-diamidino-2-phenylindole) nuclear stain, green $=$ pancytokeratin, red $=\beta_{2^{-}}$ microglobulin, white $=$ colocalization of pancytokeratin and $\beta_{2}$-microglobulin. Original magnifications, $\times 40, \times 200$. Adapted by permission from Reference 34.

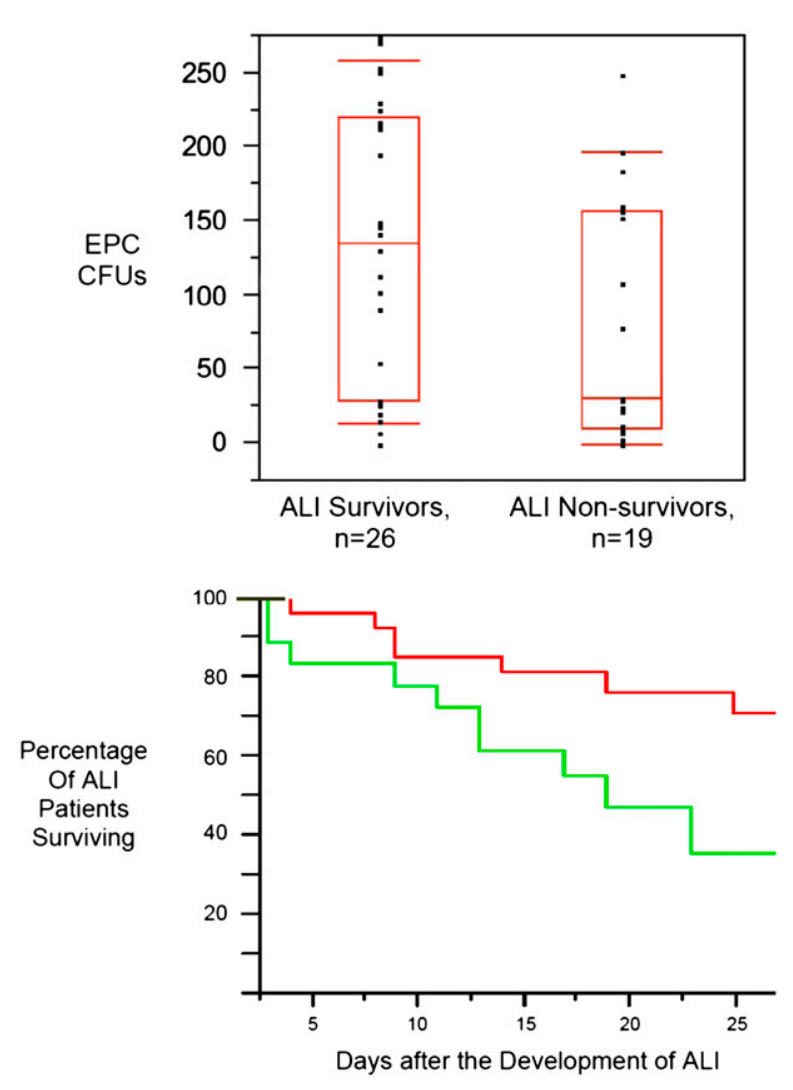

Figure 2. Patients with higher numbers of circulating endothelial progenitor cells (EPCs) during the first 72 hours of acute lung injury (ALI) had improved survival. (Top) Boxes represent the median, 25th, and 75th percentiles. Tenth and 90th percentiles are signified by floating red bars. (Bottom) Kaplan-Meier curve of patients with ALI stratified by EPC cfu counts of $\geqslant 35$ (red line) or $<35$ (green line). Patients with EPC CFU counts $\geqslant 35$ had survival benefit (70 vs. $35 \%$ survival at 28 d). Adapted by permission from Reference 76 . 
ment of cells as epithelial and vascular endothelial cells (60). However, MSCs administered at later time points appeared to engraft as interstitial cells and participate in development of fibrosis $(60,63)$. Recipient immune responses also play significant yet poorly characterized roles in retention of cells in lung (64). Commonly used approaches of sex-mismatched transplantation or cell administration may also result in clearance of cells (59). The range and identity of chemotactic soluble mediators released by injured lung cells and the role of up-regulation of adhesion molecules with which circulating cells might interact remain poorly understood (reviewed in Reference 1 and References 65-67). As with engraftment, a number of factors, including age of donor or recipient, type of cell administered, route of administration, and so forth, all might affect recruitment to lung.

Comparably, the mechanisms by which stem or progenitor cells might be induced to acquire the phenotype of lung epithelial, interstitial, or vascular endothelial cells remain poorly understood. In vitro studies continue to demonstrate that soluble factors released from lung epithelial cells or from injured lung homogenates can induce expression of lung epithelial markers in several types of marrow-derived cells, possibly through activation of $\beta$-catenin signaling pathways (68-70). One novel mechanism of inducing phenotypic change might involve release of membranederived microvesicles, a recently appreciated means of intercellular communication that involves horizontal transfer of mRNA and proteins between cells $(71,72)$.

Endothelial progenitor cells. In the past decade, circulating bone marrow-derived cells similar to embryonal angioblasts have been identified (73), termed "endothelial progenitor cells." These cells have the potential to proliferate and differentiate into mature endothelial cells $(73,74)$. Increasing evidence demonstrates that EPCs play a role in pathogenesis of a wide variety of lung diseases, including pulmonary hypertension, pulmonary fibrosis, airway diseases including both asthma and chronic obstructive pulmonary disease (COPD), acute lung injury, and lung cancer $(66,75-82)$. However, studies of EPCs in lung diseases have been hampered by lack of consensus regarding identification of these cells. Early investigations relied almost exclusively on the use of flow cytometry in conjunction with immunostaining to identify and enumerate these cells both in bone marrow as well as in the circulation. Furthermore, when similar techniques were used in different reports, a different group of markers was used. This has complicated comparative assessments for similar disease processes. As a result, the field is beginning to encourage the use of functional assays both in vitro and in vivo in conjunction with the use of flow cytometry and immunohistochemistry to not only enumerate EPCs but to better characterize their true ability to form functional endothelium. A critical area for future study is to develop a consensus-based approach to definition and use of EPCs with particular emphasis on functional capabilities of these cells.

A recent development in the characterization of EPCs has been the observation of two major types of these cells in human peripheral blood $(83,84)$. The first, termed "early EPCs," are characterized by early growth in vitro, CD34/CD31/CD14 positivity, the inability to form tubes in a matrigel tube-forming assay, and high levels of cytokine secretion. The other type of EPC, termed "late outgrowth EPCs" or "outgrowth endothelial cells," is characterized by CD31 positivity, a better ability to form tubes either with or without human umbilical vein endothelial cell coculture, and a low level of cytokine secretion. Each of these cell types may have a unique potential in lung microvascular repair, with early EPCs having a role as paracrine cells, and late EPCs functioning more specifically in restoring vascular structures of the lung. Intravenous infusion of each type of cell in an animal model has shown their ability to preferentially localize to lung
(85). In addition, preliminary evidence exists that the two EPC types when infused together may have a synergistic role in restoring vascular structure and function (84). Further characterization of these two EPC types, including methods to enhance their numbers ex vivo, could have implications for the development of therapy specific to the phenotypic abnormalities of a given lung disease.

The number of circulating EPCs has been correlated with a variety of clinical variables in several lung disease states, demonstrating the potential utility of EPCs as biomarkers. Although increased circulating EPC numbers correlate with survival in acute lung injury/acute respiratory distress syndrome (ARDS) (Figure 2) and are associated with less residual lung damage in patients with pneumonia $(76,77)$, increased numbers do not necessarily correlate with better outcomes or more normal physiology in all lung diseases. For example, an increase in the number of circulating EPCs in patients with COPD was associated with more abnormal spirometry (78), although a different study showed that levels of circulating EPCs were inversely correlated with COPD disease severity (79). Increased numbers of circulating EPCs also portended worse survival among those with non-small cell lung cancer $(81,82)$. In asthma, numbers of circulating EPCs were increased compared with nonasthmatic controls, but this did not correlate with clinical outcomes (75).

Several clinical factors have been implicated in the mobilization of EPCs, and mechanisms for their effects have begun to be elucidated. Hypoxia appears to be a stimulus for EPC mobilization and recruitment, whereas hyperoxia is correlated with decreased circulating EPCs. These features may play a role in bronchopulmonary dysplasia in premature infants and neonates exposed to high oxygen levels $(86,87)$. They also suggest that EPCs could contribute to lung repair after acute lung injury. Defective lung development or defective lung repair in the setting of protracted inflammation and injury may result in part from inadequate contribution of local or circulating EPCs. Age has been previously reported to be inversely correlated with EPC number (88). Newer data suggest that there are also differences in the ability of EPCs to home to ischemic tissues based on age, and that this may be mediated through the inability of aged tissues to normally activate the hypoxia-inducible factor- $1 \alpha$-mediated hypoxia response (89). Use of HMG-CoA (3-hydroxy-3-methylglutaryl coenzyme A) reductase inhibitors had been previously shown to have a beneficial effect on the mobilization of EPCs (90). Recent in vitro work demonstrates that this may be related to the effect of this class of drugs in the prevention of EPC apoptosis in response to noxious stimuli, including the effects of tumor necrosis factor (TNF)- $\alpha$ and IL-1 $\beta$, thereby enhancing EPC survival and differentiation (91). These factors and others may simultaneously exist in patients with lung disease, making it incumbent on investigators to perform larger clinical studies of EPCs in specific lung diseases, using well-defined patient populations to account for their effects on the number and function of EPCs.

Goals of increasing numbers of EPCs, or developing methods to enhance their mobilization, may not be appropriate for all diseases that affect the lung, particularly for lung cancers (12, 81, 82). EPCs may have an effect on the development of lung tumor vasculature and homing to sites of lung metastases as well as in other cancers (92-98). However, enumerating EPCs could be useful as a marker of lung cancer severity or to follow responsiveness to therapy. For example, increased levels of circulating EPCs were found to correlate with worsened outcomes in patients with non-small cell lung cancers (81). Because neovascularization involves the recruitment of EPCs from the bone marrow, these cells are a logical target for antiangiogenesis therapy. Recently, an investigational drug, TK 1-2 (the 
kringle domain of tissue-type plasminogen activator), was demonstrated to be useful in blocking adhesion, differentiation, and migration of ex vivo human EPCs (96). When EPCs were coimplanted with A549 cells into nude mice, tumor growth and vascular density were increased. TK 1-2 treatment of these animals resulted in a decrease in tumor growth and vascularity, and a decrease in the expression and secretion of vascular endothelial growth factor (VEGF) by EPCs. These findings suggest that blocking EPCs could be an important therapy in the prevention of cancer progression. In addition, after systemic injection, EPCs localize to lung and also appear to home to metastatic tumors in lung through as yet poorly understood mechanisms $(92,93)$. This suggests that modification of EPCs to express suicide genes or other therapeutic molecules could potentially be used in cell-based therapy approaches for lung cancer $(92,93)$. Mechanisms controlling mobilization and homing of EPCs to lung remain poorly understood and are the subject for more intense investigation (66).

Earlier studies in mice and dogs have also demonstrated a role for exogenously administered EPCs in vasculogenesis and vascular repair in experimental models of pulmonary hypertension (99-102). Furthermore, EPCs can be transduced to express proangiogenic factors, such as endothelial nitric oxide synthetase (eNOS), or inhibitors of smooth muscle cell proliferation, such as calcitonin gene-related peptide, and appear to home to sites of endothelial damage and lung injury $(61,101)$. EPCs also preferentially localize to areas of injured lung after systemic administration (61). As such, a pilot trial of autologous EPC administration for primary pulmonary hypertension conducted at Zhejiang University, Hangzhou, China, demonstrated increased six-minute-walk capacity and improved hemodynamic variables, including mean pulmonary artery pressure, pulmonary vascular resistance, and cardiac output, 12 weeks after systemic administration of autologous EPCs with conventional therapy $(n=15)$ compared with patients receiving conventional therapy alone $(n=16)(103)$. Importantly, no adverse effects of EPC administration were noted, although long-term follow-up is pending. A therapeutic trial of administration of autologous EPCs transduced to express eNOS for patients with pulmonary hypertension, the Pulmonary Hypertension and Cell Therapy (PHACeT) trial, has been initiated at the University of Toronto. As of January 2008, the PHACeT trial has completed enrollment of the first dose panel, with three patients receiving a total of 7 million early-growth EPCs transfected to overexpress human eNOS (information courtesy of Duncan Stewart, M.D., F.R.C.P.C., principal investigator of the PHACeT trial). The cell delivery procedure was well tolerated and there were no safety concerns. Notably, the first three patients all showed a remarkable (nearly $50 \%$ ) reduction in total pulmonary vascular resistance over the course of the 3-day delivery period, which might represent the effect of increase NO release by the engineered EPCs within the pulmonary microcirculation. The trial's Data Safety Monitoring Board has approved moving to panel 2, which calls for a total of 23 million cells, again in three divided doses over 3 days. The investigators expect that completion of the third dose panel (50 million cells) will provide sufficient support to move forward with the design of a randomized controlled trial that can assess potential efficacy of this cell therapy approach in pulmonary arterial hypertension (PAH).

Circulating fibrocytes. Circulating fibrocytes were first described as a subset of circulating leukocytes that produced collagen and homed to sites of inflammation $(104,105)$. The identity and phenotypic characterization of circulating fibrocytes are more firmly established, and these cells are described by the cell surface markers CD34, CD45, CD13, and major histocompatibility class (MHC) II, and also express type 1 collagen and fibronectin $(10,13,23)$. Circulating fibrocytes have been implicated in the pathogenesis of lung fibrosis in several mouse models including irradiation and bleomycin-induced lung injury (reviewed in References 10, 13, and 23). Circulating fibrocytes have also been implicated in the subepithelial fibrosis that can develop in severe asthma $(106,107)$ and in clinical bronchiolitis obliterans in lung transplant patients (108). Several chemokines, including stromal-derived factor (SDF)-1 and the CCR2 and CCR5 axes, have been implicated in recruitment of circulating fibrocytes to fibrotic lungs, but overall mechanisms of fibrocyte recruitment to lung are poorly understood (109-112). Similarly, the mechanisms by which fibrocytes are induced to undergo phenotypic transformation into fibroblasts and myofibroblasts and contribute to fibrogenesis in lung are poorly understood, although recently both haptoglobin and cysteinyl leukotrienes have been implicated $(113,114)$. A recent study suggests that levels of circulating fibrocytes are increased in patients with usual or nonspecific interstitial pneumonitis (Figure 3) (115). Although suggestive, this small study needs to be confirmed in larger cohorts. Dr. Bethany Moore presented unpublished data that fibrocytes isolated from peripheral blood of patients with idiopathic pulmonary fibrosis exhibit increased proliferative and collagen-producing capacities. Together, the available information strongly suggests a role of circulating fibrocytes in fibrotic lung diseases and offers potential pathways for therapeutic interventions.

Fibrocytes are also increasingly implicated in pathogenesis of vascular remodeling underlying development of pulmonary hypertension (116). Hypoxia is a potent stimulus for release by pulmonary vascular endothelium of a variety of factors that both serve to recruit fibrocytes as well as induce phenotypic conversion to fibroblasts or myofibroblasts (109-112). Fibrocytes make up a significant proportion of mononuclear cells that infiltrate the adventitia and media of pulmonary vessels in rat and calf models of hypoxic lung injury (Figure 4) (116). Notably, depletion of circulating fibrocytes abrogated hypoxia-induced perivascular remodeling in rats (116). These results suggest that specific inhibition of fibrocytes or their use as drug delivery vehicles may also be important therapeutic targets in pulmonary vascular disease. Circulating fibroblast precursors found in blood of patients with lung cancer contributed to tumor development when systemically administered to NOD SCID (nonobese diabetic/severe combined immunodeficient) mice engrafted with human lung cancer xenografts (117). Bone marrow-derived cells may also contribute to fibroblasts and myofibroblasts in tumor stromal tissue (118). These may be other poorly understood properties of fibrocytes or comparable circulating fibroblast precursors.

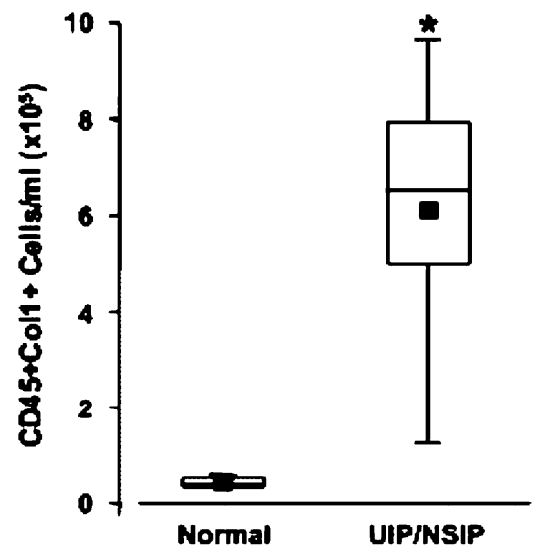

Figure 3. Levels of circulating $\mathrm{CD} 45^{+} \mathrm{Col} 1^{+}$cells are increased in blood from patients with usual interstitial pneumonitis (UIP) or fibrotic nonspecific interstitial pneumonitis (NSIP). ${ }^{*} P<0.05$ compared with normal volunteers $(n=5$ per group). Adapted by permission from Reference 115. 

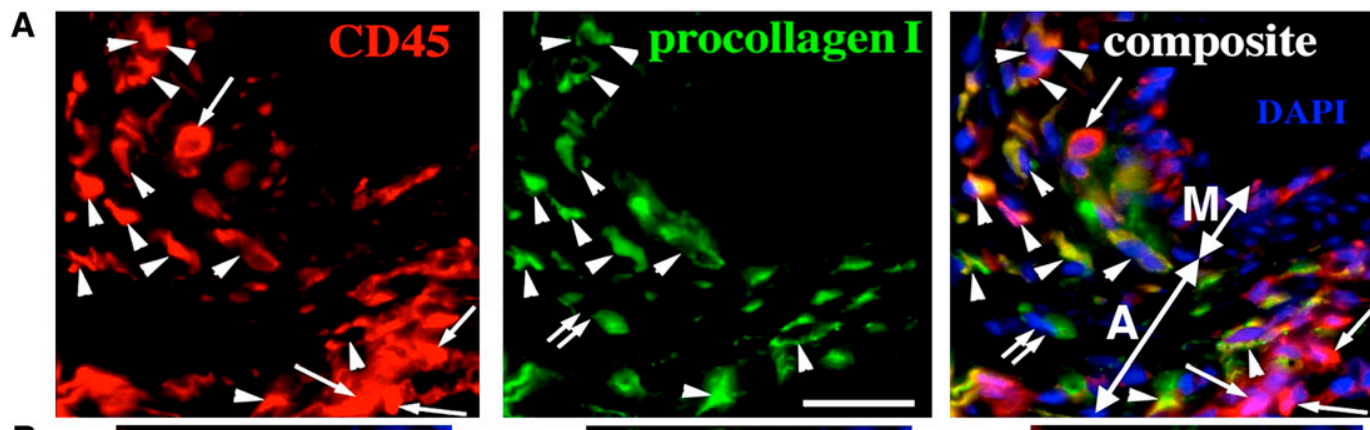

B
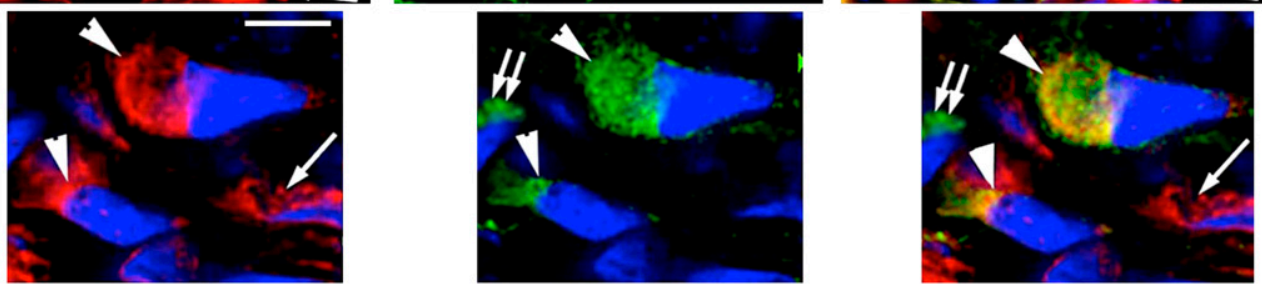

Figure 4. Fibrocytes $\left(\mathrm{CD} 45^{+} /\right.$ procollagen ${ }^{+}$) comprise almost $40 \%$ of leukocytes in the remodeled pulmonary artery adventitia of neonatal calves with severe hypoxic pulmonary hypertension. $(A, B)$ Triple-labeled immunofluorescent staining (CD45, red; procollagen, green; cell nuclei [DAPI], blue) demonstrates numerous fibrocytes $\left(\mathrm{CD} 45^{+} /\right.$ procollagen ${ }^{+}$; marked by arrowheads) in the remodeled adventitia. Leukocytes (CD45 ${ }^{+} /$ procollagen $^{-}$) are marked by single arrows, and fibroblasts $\left(\mathrm{CD}^{2} 5^{-} /\right.$procollagen $^{+}$) by double arrows. Pulmonary artery adventitia $(A)$ and media $(M)$ are marked by double-headed arrows in $(A)$. Scale bars, 20 $\mathrm{mm}(A) ; 5 \mathrm{~mm}(B)$. (B) Deconvolution confocal microscopy with a high magnification of a field as shown in (A). Adapted by permission from Reference 116.

Mesenchymal stem cells. MSCs are cells of stromal origin that can self-renew and have the ability to differentiate into a variety of cell lineages. Initially described in a population of bone marrow stromal cells, they were first described as fibroblastic colony-forming units (119), subsequently as marrow stromal cells, then as MSCs (120), and most recently as multipotent mesenchymal stromal cells or MSCs (121). MSCs have now been isolated from a wide variety of tissues, including umbilical cord blood, Wharton's jelly, placenta, and adipose tissue (34, 51-53, 122-129). Most recently, MSCs have been isolated from adult mouse lungs (130) and from lungs of both neonates and lung transplant recipients $(131,132)$. Human bronchial fibroblasts have also been described to be capable of exhibiting properties consistent with MSCs, as have adult mouse lung side population cells $(133,134)$. MSCs isolated from each of these sources generally express comparable cell surface markers and differentiate along recognized lineage pathways. However, differences in gene expression, lineage tendencies, and other properties have been described among MSCs isolated from the different sources (135-142). As with EPCs, many of the published studies have used different definitions and characterizations of MSCs. This has complicated comparative assessments of published studies. The Mesenchymal and Tissue Stem Cell Committee of the International Society for Cellular Therapy (ISCT) has recently updated the minimal criteria for defining (human) MSCs (121) (Table 3). It is hoped that rigorous adherence to these criteria will help to focus comparative investigations of there potential utility in lung diseases. Nonetheless, the field remains complex because MSC characteristics can change with culture conditions and microenvironment (143-148). Furthermore, there is growing evidence that MSCs are heterogeneous and that different MSC subtypes exist (149151).

MSCs can be induced in vitro to express phenotypic markers of airway and/or alveolar epithelial cells and can engraft as, or fuse with, airway and/or alveolar epithelium, interstitium, or vascular endothelium in vivo after systemic administration (reviewed in References 1 and 19). As discussed above, engraftment is gen- erally rare, although many variables remain to be explored. Nonetheless, there are an increasing number of studies demonstrating a functional role of MSCs in rodent models of acute lung inflammation and fibrosis in the absence of significant lung engraftment. Intratracheal administration or systemic administration of MSCs immediately after intratracheal bleomycin administration decreased subsequent lung collagen accumulation, fibrosis, and levels of matrix metalloproteinases (152). Secretion of IL-1 receptor antagonist by MSCs has been hypothesized to account for at least some of these effects (153). Intratracheal administration of MSCs 4 hours after intratracheal endotoxin administration decreased mortality, tissue inflammation, and concentration of proinflammatory mediators, such as $\mathrm{TNF}-\alpha$ and macrophage inflammatory protein (MIP)- $1 \beta$, in bronchoalveolar lavage fluid compared with endotoxin-only treated mice (46) (Figure 5). Systemic MSC administration also decreased lung inflammation after endotoxin administration in mice (70,153-155). Notably, transduction of the MSCs to express angiopoietin-1 further decreased endotoxin-mediated lung injury, presumably through abrogation of endotoxin-mediated endothelial injury $(154,155)$. However, systemic administration of skin fibroblasts transduced to express angiopoietin-1 also decreased acute endotoxin-induced lung injury, suggesting that a variety of cell types might be used for cell therapy approaches to acute lung injury (56). Coculture of MSCs with lung cells obtained from LPS-treated mice resulted in decreased proinflammatory cytokine release from the lung cells (70). In other lung injury

\section{TABLE 3. THE MESENCHYMAL AND TISSUE STEM CELL COMMITTEE OF THE INTERNATIONAL SOCIETY FOR CELLULAR THERAPY MINIMAL CRITERIA FOR DEFINING MESENCHYMAL STEM CELLS \\ 1. Plastic adherence in standard tissue culture conditions \\ 2. Expression of CD73, CD90, and CD105 \\ 3. No expression of CD11b, CD14, CD19, CD34, CD45, CD79 $\alpha$, or of HLA-DR \\ 4. Differentiation in vitro to osteoblasts, adipocytes, and chondroblasts}

Adapted from Reference 121. 
A
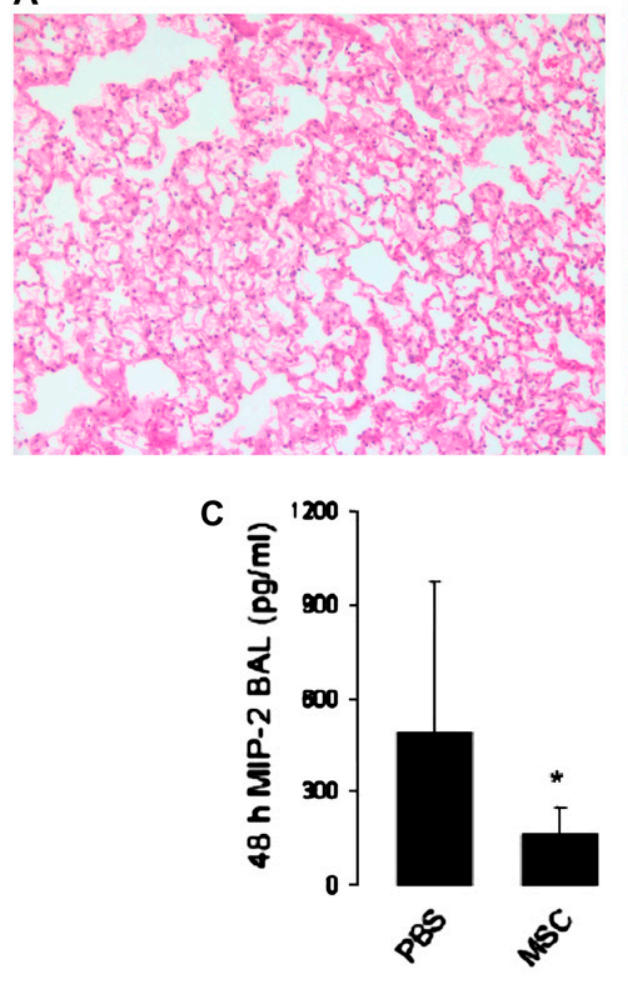

B
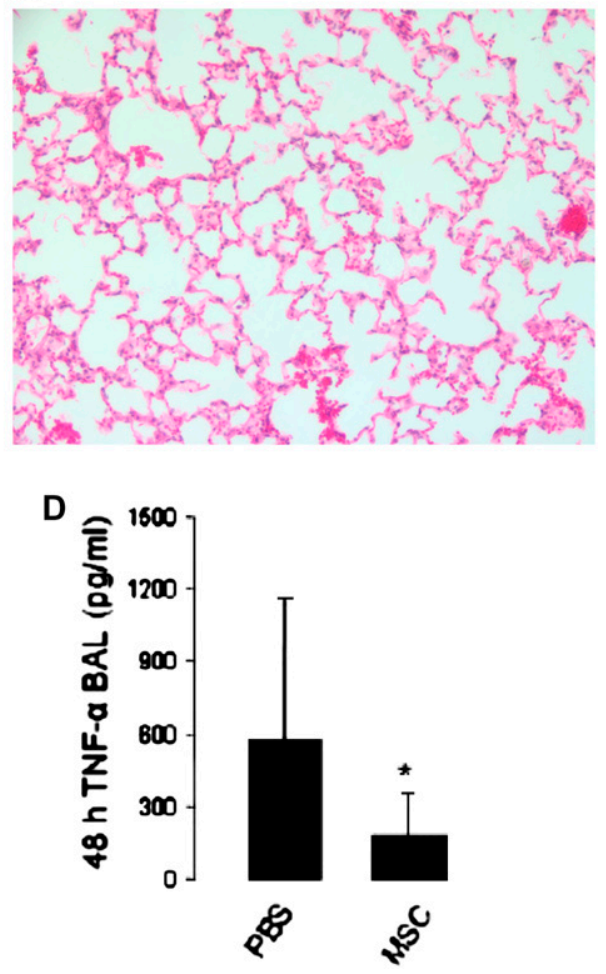

Figure 5. Mice receiving intratracheal administration of mesenchymal stem cells (MSCs) demonstrated decreased histologic injury and bronchoalveolar lavage (BAL) fluid levels of proinflammatory cytokines in response to endotoxin-induced lung injury. (A) Hematoxylin-and-eosin-stained lung sections 48 hours after instillation of endotoxin + phosphate-buffered saline (PBS) $(A)$ or endotoxin + MSCs $(B)$. Original magnification, $20 \times(B)$. BAL fluid levels of macrophage inflammatory protein (MIP)-2 (C) and tumor necrosis factor (TNF)- $\alpha(D)$ were decreased 48 hours after instillation of either PBS or MSCs in endotoxin-induced lung injury. Adapted by permission from Reference 46. models, intratracheal administration of bone marrow-derived MSCs decreased pulmonary hypertension and other manifestations of monocrotaline (MCT)-induced pulmonary vascular injury (156). Systemic administration of a heterogenous population of autologous adipose-derived stromal cells decreased manifestations of elastase-induced emphysema in rats (157). Hepatocyte growth factor secreted by the stromal cells was postulated as a potential mechanism of injury repair in this report.

These results suggest that MSCs can have significant immunomodulatory effects in the lung in the absence of significant engraftment, although the mechanisms by which this occurs are largely unknown. However, growing information suggests several possible actions of MSCs (Figure 6). MSCs produce a wide variety of soluble mediators and can be influenced by specific microenvironments to release different patterns of mediators $(143,146$, 158-160). For example, MSCs in bone marrow secrete cytokines and growth factors supportive of hematopoeitic cell proliferation and development, including G-CSF, SCF, LIF, M-CSF, IL-6, and IL-11 (143). Stimulation of MSCs with IL-1 $\alpha$, a proinflammatory cytokine that enhances bone marrow hematopoeisis, increases secretion of G-CSF, M-CSF, IL-6, and IL-11. The culture system in which MSCs are maintained ex vivo influences release of cytokines and other inflammatory molecules (145-148). For example, culturing MSCs in a three-dimensional hyaluronan scaffolding increased release of SDF-1, and matrix metalloproteinase-3 (146) compared with standard tissue culturing, whereas culturing under hypoxic conditions in a synthetic fibrous matrix increased fibronectin expression (144). Matrix stiffness can also affect the differentiation of MSCs (Figure 7) (147).

Also, it is probable that release of inflammatory mediators from MSCs is influenced by the type of inflammatory environment found in different conditions of lung injury (reviewed in References 19, 20, and 158-160). MSCs express a wide variety of chemokine and cytokine receptors, including those for TNF- $\alpha$, IL-4, IL-17, and IFN- $\gamma$, as well as several Toll-like receptors, including the endotoxin receptor TLR4 $(161,162)$. The IL-17 receptor in particular is expressed in high abundance $(161,163)$ and IL-17 has recently been described as a proliferative stimulus for MSCs (163). Stimulation with IFN- $\gamma$ can alter expression of MHC and costimulatory molecules by MSCs. Nonetheless, effects on MSC secretion of soluble mediators by other cytokines and chemokines by microenvironment conditions found during lung injury have been less well explored.

MSCs can also inhibit the proliferation and function of a broad range of immune cells, including $\mathrm{T}$ cells, B cells, natural killer (NK) cells, and dendritic cells (Figure 6) (20, 158-160, 160-184). Notably, MSCs inhibit T-lymphocyte proliferation, activation, and cytokine release in response to either alloantigens or to

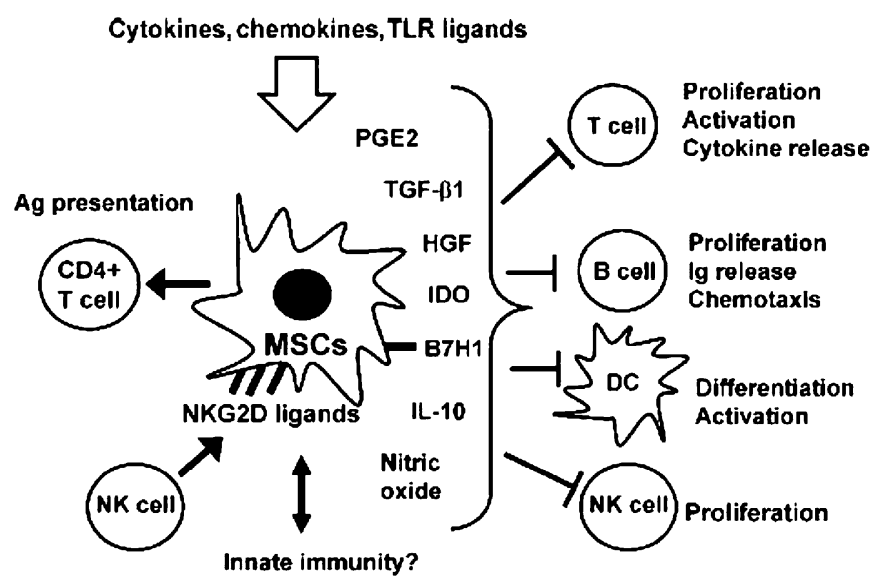

Figure 6. Schematic illustrating the range of in vitro immune-modulating effects described for mesenchymal stem cells (MSCs). Ag = antigen; $\mathrm{DC}=$ dendritic cell; $\mathrm{HGF}=$ hepatocyte growth factor; $\mathrm{NK}=$ natural killer; $\mathrm{PGE}=$ prostaglandin $\mathrm{E} ; \mathrm{TGF}=$ transforming growth factor; $\mathrm{TLR}=$ Toll-like receptor. Adapted by permission from Reference 158. 
mitogenic stimuli through a dose-dependent direct suppressive effect on proliferation. The mechanisms of MSC inhibition of Tcell proliferation and function in vitro are only partly understood and both direct cell-cell contact as well as release of soluble mediators have been proposed (158-160,164-180). Furthermore, MSCs constitutively express low levels of HLA class I molecules and do not express HLA class II molecules or the costimulatory molecules CD40, CD80, and CD86, which are essential for activation of T-lymphocyte-mediated immune responses (20, 158-160, 164, 180). As such, these properties render MSCs generally nonimmunogenic and have been the basis of several clinical reports and, more recently, clinical trials using both autologous and allogeneic MSCs for immune-mediated diseases, such as GVHD and Crohn's disease (181-188). As discussed by Jane Onken at this workshop, these trials have demonstrated both efficacy and safety of MSC administration in otherwise treatment-resistant patients with Crohn's disease and, importantly, no significant adverse effects have been observed. These results suggest that administration of MSCs may be a safe and feasible clinical approach for immune-mediated lung diseases.

MSCs are also increasingly described as vehicles for delivery of therapeutic genes and proteins (189-193). Notably, MSCs can home to tumors, through as yet unclear mechanisms, and serve as vehicles for delivery of chemotherapeutic and other antitumor agents (194-197). This has recently been described in mouse lung tumor models and may provide a viable therapy for lung cancers (198-201). In contrast, MSCs may also contribute to tumor stroma and influence behavior of cancer cells (194, 202-206). Whether marrow-derived cells contribute to development of epithelial cancers remains an active area of investigation $(205,206)$.

Some additional cautions with regard to systemic administration of MSCs have been raised. Most culture strategies use fetal or bovine calf serum. Despite washing of the cells before systemic administration, some bovine antigens may remain adherent to cell surfaces and trigger immune reactions as well as decrease potential engraftment in recipient mice or patients (207). Culture of MSCs in medium with lower calf serum content, use of heterologous species-specific serum or alternative serum substitutes such as platelet lysate, and removal of calf serum antigens before administration are proposed strategies to decrease these potential adverse effects (208-211). In addition, after intravenous administration, MSCs initially lodge in the lung vasculature before moving through the pulmonary capillary system and on to other organs. However, depending on the preparative regimens used, MSCs can clump and potentially lodge as emboli in lung capillaries $(212,214)$. Pretreatment of mice with the vasodilator sodium nitroprusside has been proposed as a mechanism of decreasing cell trapping of MSCs in pulmonary capillaries (213). Furthermore, development of lung sarcomas from systemically administered MSCs has been described $(212,214)$. Interestingly, this has been described with administration of mouse but not human MSCs and may reflect a greater propensity of mouse MSCs to acquire chromosomal abnormalities with serial passages in culture $(214,215)$. However, extensive culture of almost any mammalian cell in culture can lead to crisis, followed by immortalization, and then transformation to tumorigenic cells, as has been well documented for mouse fibroblasts (216). Murine MSCs that were extensively expanded in culture through many passages developed chromosomal instability and produced lung sarcomas in mice $(212,214)$. Human MSCs that were cultured for 4 to 7 months underwent similar changes $(217,218)$. It is anticipated that additional strategies to maximize therapeutic utility of MSCs while decreasing chance of any adverse effects will develop over the next several years.

Lung tissue bioengineering. One growing area of investigation is the utilization of three-dimensional matrices or other artificial scaffolding for growth of functional lung tissue from stem cells ex vivo and in vivo. These approaches have been increasingly successfully used in regeneration of other tissues, including skin, vasculature, cartilage, and bone. Given the complex three-dimensional architecture of the lung, this is a daunting task; nonetheless, there has been significant progress in several areas. Notably, MSCs isolated from amniotic fluid, umbilical cord blood, or bone marrow can be seeded on biodegradable polyglycolic acid or other biosynthetic scaffolds and generate tracheal cartilage for use in repair of congenital tracheal defects and also in tendon tissue for use in congenital diaphragmatic defects $(142,219-226)$. Notably, the extracellular matrix properties of the cartilage depend on the source of the MSCs (142). In data presented by Dr. Fauza at this conference, preclinical studies in large-animal models (sheep) suggest safety and efficacy, and clinical trials in neonates with congenital tracheal or diaphragmatic defects are being planned.

Three-dimensional culture systems have also been used as matrices for ex vivo lung parenchymal development and for study of growth factors and mechanical forces on lung remodeling (227233). Culture of fetal rat lung suspensions in a three-dimensional glycosaminoglycan (GAG) scaffold resulted in formation of alveolar-like structures in the scaffold (232). Fetal mouse cells cultured in three-dimensional hydrogels and in synthetic polymer scaffolds resulted in generation of alveolar-like units (228). Notably, stimulation of fetal mouse cells in polymer scaffolds with different isoforms of fibroblast growth factor stimulated different patterns of development, demonstrating the power of three-dimensional culture systems to evaluate lung development and repair (227). In vivo, a recent study demonstrated that fetal rat lung cells cultured in a biosynthetic gelatin matrix and subsequently injected into normal rat lungs induced formation of branching, sacculated epithelial structures reminiscent of lung parenchymal architecture (234) (Figure 8). However, there are few studies as yet evaluating whether stem or progenitor cells isolated from adult bone marrow, cord blood, or other sources can also comparably form airway or alveolar-like structures when cultivated in a three-dimensional matrix or other scaffolding material or, furthermore, whether stem or progenitor cells cultured in such fashion can be used for functional lung regeneration in vivo. A population of cells described as adult lung somatic progenitor cells isolated from adult sheep lungs cultured in synthetic polymer constructs resulted in expression of airway and alveolar epithelial markers by the cells (235). Structures resembling lung airways and parenchyma developed when impregnated constructs were implanted subcutaneously in nude mice or inserted into the wound cavity after wedge lung resection in sheep. Adipose-derived MSCs, cultured ex vivo in sheets of polyglycolic acid and then applied to wound edges after lung volume reduction surgery in rats, accelerated alveolar and vascular regeneration (157). Several abstracts presented at this workshop and also to be presented at the 2008 American Thoracic Society International Conference have begun to further explore these questions. Lung tissue bioengineering with stem cells is projected to be an area of intense investigation.

\section{Endogenous Lung Stem and Progenitor Cells}

Endogenous tissue stem cells are undifferentiated cells that have been identified in nearly all tissues and are believed to contribute to tissue maintenance and repair. These are rare, unspecialized cells that are often localized to specialized niches within each tissue and usually cycle infrequently. These cells exhibit selfrenewal capacity - they can produce more unspecialized cellsand can also give rise to daughter cells known as progenitor cells or transit-amplifying cells. Progenitor cells have a finite life span 


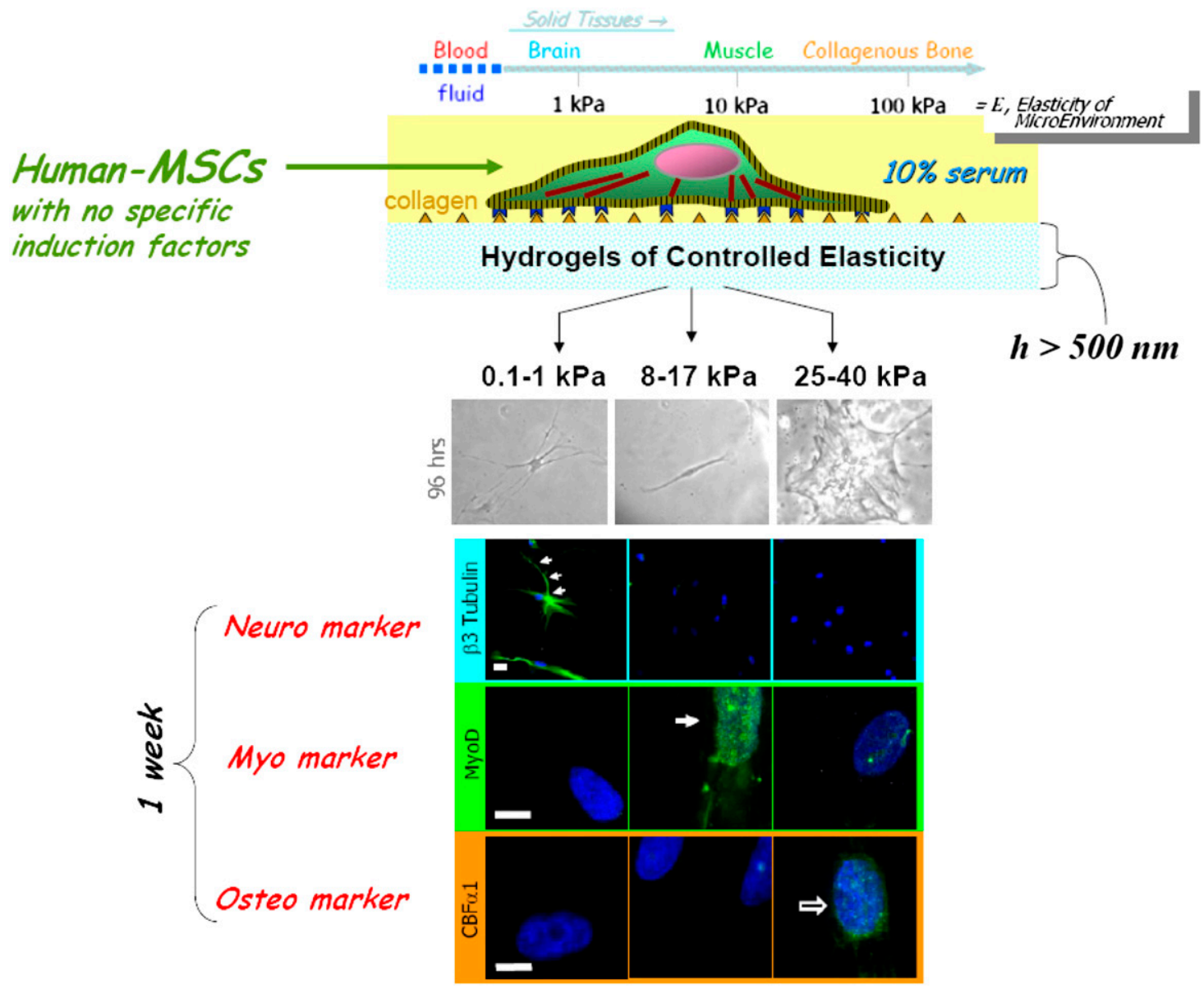

Figure 7. Schematic demonstrating inherent matrix stiffness of different tissues and that culture of human mesenchymal stem cells (MSCs) in hydrogels of increasing stiffness directs differentiation along different pathways. Adapted by permission from Reference 147.

and higher rates of proliferation compared with stem cells. Both stem and progenitor cells may give rise to the more specialized, or differentiated, cells of the organ $(7,14,15)$.
However, significant terminology problems exist as to how endogenous stem cells and other progenitor cell types (in this context, progenitor cell being used to describe any cell with
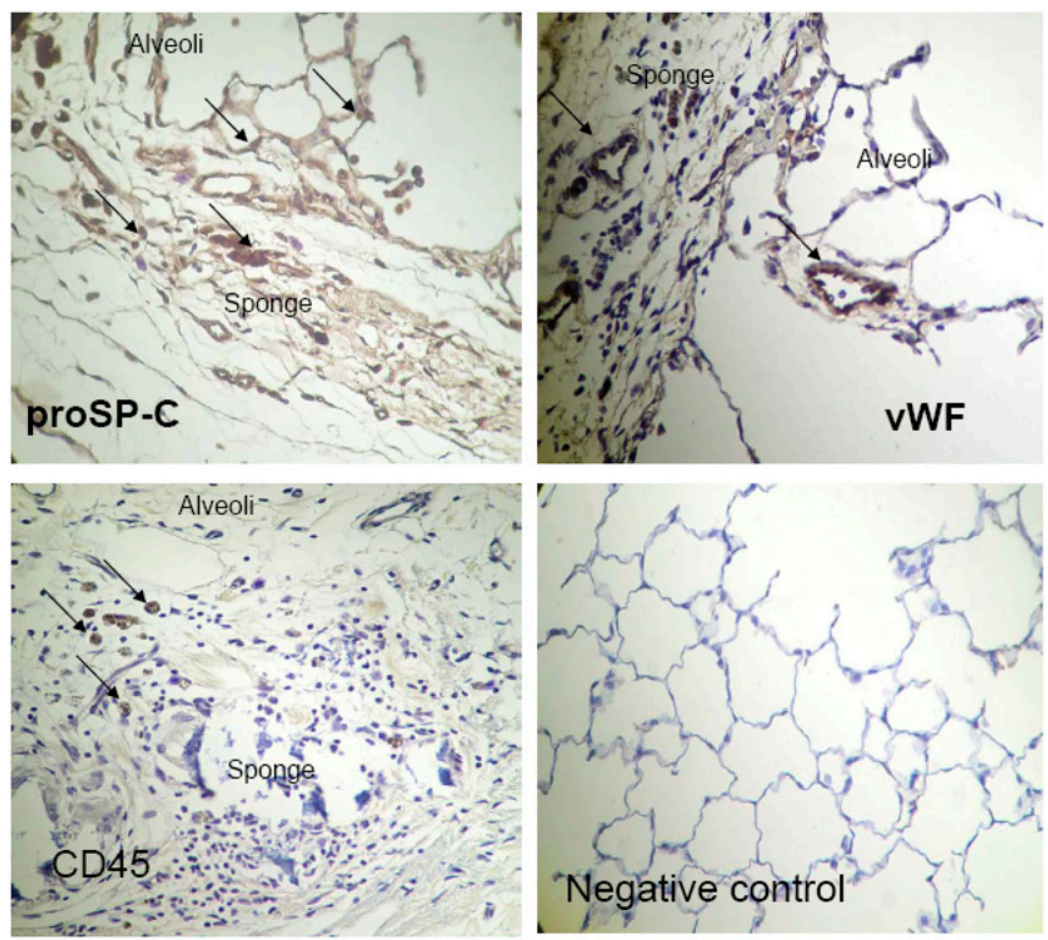

Figure 8. Expression of epithelial and endothelial markers in gelfoam sponges implanted into rat lung. Sixty days after injection of gelfoam sponges impregnated with fetal rat lungs cells into adult rat lungs, expression of various markers of mature lung cells was detected in the sponge. Original magnification, $\times 100$. pro-SPC $=$ pro-surfactant protein $\mathrm{C}$; $\mathrm{vWF}=$ von Willebrand factor. Adapted by permission from Reference 234 . 
more robust proliferative potential, such as toxin-resistant cells, Clara cells, basal cells, etc.). This is a problem that not restricted to the lung: for example, similar terminology issues occur in intestine, particularly as progenitor cell types in different organs differ in their properties and regulation. The glossary depicted in Table 1 does not necessarily reflect an overall consensus for the definition of each term and will undergo continuing revision as overall understanding of the cell types and mechanisms involved in lung repair continue to be elucidated. Nonetheless, it is a useful framework.

Evidence indicating the existence of cellular components of an airway epithelial stem cell hierarchy comes from studies in mouse models in which selective ablation of epithelial cells is achieved through exposure to toxic chemicals or through cell type-specific expression of toxic genes in transgenic mice. Using these approaches, several populations of progenitor cells with some properties of tissue stem cells have been identified along the tracheobronchial tree $(7,14,15)$ (Figure 9). In trachea and large airways, a subpopulation of basal epithelial cells that express cytokeratins 5 and 14 has been implicated (236-238). In mice, Clara cells exhibit characteristics of transit-amplifying cells after injury to ciliated airway epithelial cells. However, unlike transit-amplifying cells in tissues with higher rates of epithelial turnover, such as intestine, Clara cells exhibit a low proliferative frequency in the steady state, are broadly distributed throughout the bronchiolar epithelium, and contribute to the specialized tissue function. In more distal airways, toxin (i.e., naphthalene)-resistant variant Clara cells have been identified as having stem cell functions and have been termed as "bronchiolar stem cells" (239-241). Naphthalene-resistant cells are also located within discrete microenvironments within bronchioles that include the neuroepithelial body and bronchoalveolar duct junction (BADJ) $(239,240)$.

At the BADJ in mouse lungs, a population of naphthaleneresistant cells that stain both for CCSP and for pro-surfactant protein C (pro-SPC) have been described $(14,15,246)$. Although rare, these cells were found to proliferate in response to naphthalene injury. Furthermore, when pro-SPC/CCSP dual-

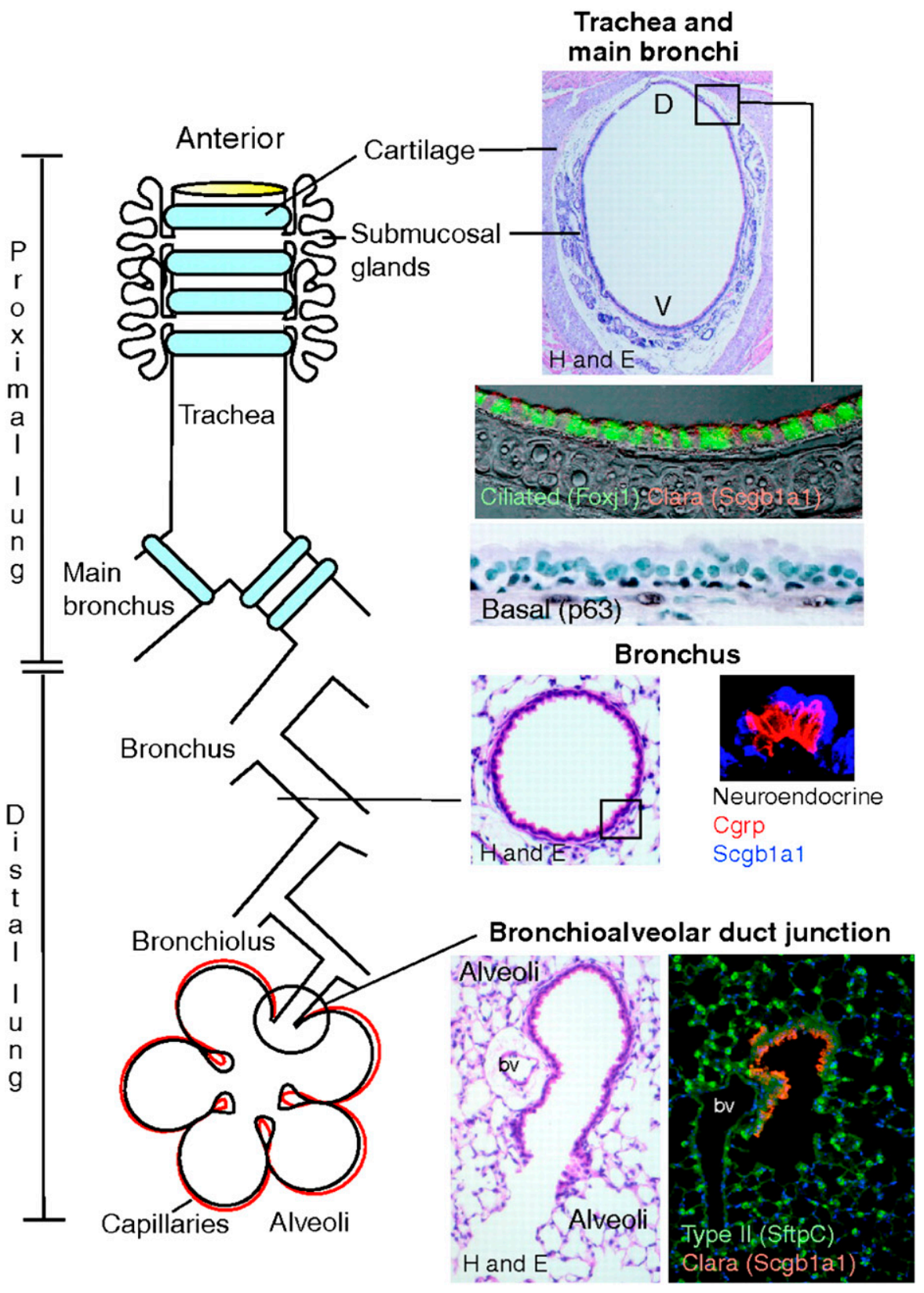

Figure 9. Schematic of endogenous progenitor cells. $\mathrm{D}=$ dorsal; $\mathrm{V}=$ ventral. Adapted by permission from Reference 7. 
positive cells were isolated using methods developed for enrichment of type 2 alveolar epithelial cells, some of the dual-labeled cells exhibited a unique cell surface phenotype, Sca $1^{\text {pos }} / \mathrm{CD} 34^{\mathrm{pos} /} \mathrm{CD} 45^{\text {neg/ }} \mathrm{CD} 31^{\text {neg }}$. These cells were found to self-renew in culture and give rise to progeny expressing CCSP, pro-SPC, or aquaporin 5. As such, these cells have been termed "bronchioalveolar stem cells" (BASCs). However, whether the properties of these cells in vitro also apply in vivo is unknown. It is possible that toxin-resistant Clara cells, BASCs, and other cells may represent different interpretations of the same cell population(s) and highlights the need both for rigorous methods of lineage tracing as well as further underscoring the importance of the in vivo microenvironment on cell behavior. Although several signaling pathways, including Wnt, Hedgehog, and Notch, are implicated in stem cell function in other tissues, there remains a paucity of understanding of the key elements that establish and maintain the adult lung tissue.

Recent investigations have begun clarifying cell signaling and other regulatory mechanisms regulating putative lung progenitor populations (7). For example, tumorigenic insults, including deletion of mitogen-activated protein kinase, p18 deletion, and p27 oncogenic mutation, have been shown to induce an expansion of CCSP/pro-SPC dual-labeled BADJ cell number and also enhance lung tumorigenesis. However, the precise role of these and other pathways in endogenous lung stem and progenitor cells remains to be determined (247-249). Most recently, another population of putative progenitor cells expressing CCSP, stem cell antigen (SCA)-1, stage-specific embryonic antigen (SSEA)-1, and the ES cell marker Oct-4 have been identified in neonatal mice $(250,251)$. These cells were able to form epithelial colonies and differentiate into both type 1 and type 2 alveolar epithelial cells. Interestingly, these cells were susceptible to infection with the SARS (severe acute respiratory syndrome) virus, raising the possibility that endogenous lung progenitor cells may be specific disease targets. Endogenous progenitor cells may also be attractive candidates for targeting with gene transfer vectors that provide sustained expression. The possibility remains that other endogenous stem or progenitor populations exist, and there is much room for additional information on regulatory mechanisms and pathways as have been elucidated in other epithelial progenitor cell populations (252).

Less information is available about differences in endogenous stem and progenitor cells in different clinical lung diseases. Airway epithelium in patients with cystic fibrosis (CF) contains primitive cuboidal cells that express primitive cell markers, including thyroid transcription factor and cytokeratin 7 (242). Neuroepithelial cells also express CF transmembrane conductance regulator (CFTR), which appears to play a role in neuropeptide secretion $(243,244)$. CFTR knockout mice also contain fewer pulmonary neuroendocrine cells during embryonic development but increased numbers of these cells postnatally (245). This suggests that endogenous progenitor cell pathways in CF lungs may be altered, but this has not been extensively investigated.

In addition to the role of endogenous lung stem and progenitor cells in repair from lung injury, increasing information suggests that mature differentiated lung cells may transdifferentiate and change phenotype. Best described for epithelial-mesenchymal transition, recent investigations describe a wider range of reversible phenotypes in epithelial and mucus cells (253-258). These mechanisms may also play significant roles in injury or repair from injury.

Overall, there remains much to be learned about endogenous stem and lung progenitor cells, including clarification of human counterparts to the cells identified in mouse models.
Furthermore, relatively little is known about the behavior of endogenous stem or progenitor cells in clinical lung disease models.

Lung cancer stem cells. There is intense current interest in the connections between endogenous stem or progenitor cells and cancer stem cells. Cancer stem cells have been defined in transplantation assays as the critical cells from tumors that are capable of propagating disease and are hypothesized to be the cells that maintain tumor progression and disease resistance (259, 260). Although cancer stem cells have been described in breast and other solid cancers, the existence of a lung cancer stem cell or cells is less well established (12). BASCs have been suggested to have a role in development of lung cancer in mice, but their role in tumor maintanance has not been established, nor has the human correlation been demonstrated. A recent study has shown that $\mathrm{CD}_{133^{+}}$cells from cultured lung cancer cells and primary lung tumors exhibit the ability to propagate lung cancer when injected subcutaneously in mice (261). Side population CD45- Hoechsteffluxing cells have also recently been identified in several human lung cancer cell lines and exhibit tumorigenic properties when subcutaneously implanted into NOD SCID mice (262). Side population cells have also been identified in clinical lung cancer specimens (262). However, despite suggestive data from these two reports, further work is needed to clarify the connections between endogenous lung stem cells, the cells of origin of cancer, and cancer stem cells, and to determine their potential role as therapeutic targets. Recent studies have begun elucidating cell signaling and gene expression pathways including Wnt, hedgehog, and others that may play roles in transformation of endogenous progenitor cells into cancer cells (263-267). In addition, bone marrow-derived or circulating MSCs, HSCs, EPCs, and fibrocytes may contribute to development of lung and other malignancies in mouse models, in part by providing a supportive stroma for the cancers and/or by participating in tumor vascularization (91, 94-98, 118, 194, 202-206). However, MSCs and EPCs have been demonstrated to home to areas of tumor development, and engineered EPCs and MSCs, as well as HSCs, have been used to suppress tumor growth in mouse tumor models $(92,93,194$ 200, 268). Cell-based therapies may thus be useful in lung cancer therapeutics.

\section{Embryonic Stem Cells}

Mouse ES cells can be induced in culture to express prosurfactant B, a marker of type 2 alveolar epithelial cells (269, 270). Furthermore, exposure of mouse ES cells to dissociated fetal lung cells induces pseudoglandular formation and pro-SPC expression (271). In one notable study, mouse ES cells cultured at air-liquid interface formed a pseudostratified epithelium resembling mouse tracheal epithelium (272). These studies demonstrate the capacity of ES cells to acquire airway epithelial phenotype in vitro. Comparable studies with human ES cells remain limited due to current restrictions on human ES cell use, particularly in the United States. Nonetheless, it has recently been demonstrated that cells of one of the approved human ES lines in the United States can be induced in vitro to express phenotypic characteristics of type 2 alveolar epithelial cells (273) (Figure 10). Comparable studies in England also have demonstrated induction of pro-SPC expression in cultured human ES cells (274). A recent study in Australia compared mouse and human ES cells exposed to dissociated fetal lung cells and found several differences in patterns of lung gene expression (275). The ATS issued a statement in 2006 calling for expanded human ES cell research and it is anticipated that human ES cell research will expand in the United States over the next several years (2). A human deltaF508 embryonic stem cell line has been established in England and another described in Belgium (276,277). These cells exhibit normal morphology and protein expression compared 

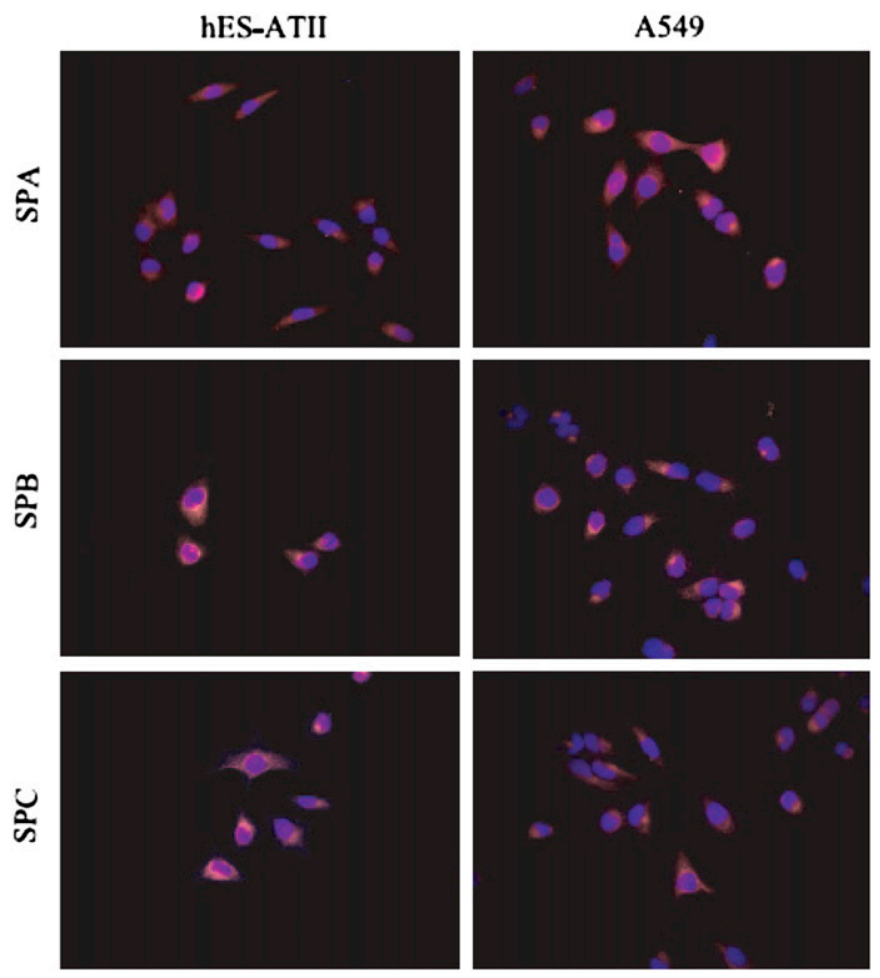

Figure 10. Human embryonic stem cells (hES E.9) transduced with a pro-surfactant protein $C$ (pro-SPC)/Neo.74 vector and selected in $\mathrm{G} 418$ express surfactant proteins A, B, and C (red stain). Nuclei are counterstained with DAPI (blue). ATII = type II alveolar epithelial cells. Original magnification, $\times 400$. Adapted by permission from Reference 273 .

with other ES cell lines but have not been studied in detail. Recent descriptions of induction of pluripotency in adult skin fibroblasts and other adult cell types offer another possibility of generating lung cells from autologous somatic cells (278-281). In particular, it might be possible to generate induced pluripotent cell lines from lung patients as models of disease.

\section{SCIENTIFIC PRESENTATIONS}

The workshop was organized into four oral presentation sessions and one poster presentation session. The goal of the presentations was to provide a state-of-the-art summary of existing information and to highlight questions to be addressed by future research directions. A summary of the oral presentations is provided below. The executive summaries of each speaker's presentation and the poster abstracts are presented in the accompanying online supplement.

\section{Session 1: Endogenous Lung Stem and Progenitor Cells}

The goal of this session was to review the current state of knowledge of endogenous stem cell populations in the lung, their role in lung development, and the role of the niche and microenvironment on lung progenitor cells. The session began with Diane Krause (Yale University School of Medicine) who provided a general overview of "stem" cells, highlighting that although many cells that are referred to as stem cells can differentiate into multiple cell types, true stem cells are capable of extensive selfrenewal, whereas progenitors, found in different specialized regions of the lung, are limited in this capacity. The control of differentiation is determined in part by the cell's response to its microenvironmental niche that contains cues such as $\mathrm{O}_{2}$ tension and extracellular matrix components. Dr. Krause discussed the different endogenous lung progenitors, including $\mathrm{CK} 5^{+} \mathrm{CK} 14^{+}$ basal cells of the submucosal glands in the proximal airway, Clara cells and Clara cell variants $\left(\mathrm{CCSP}^{+} \mathrm{SPC}^{+}\right)$found in bronchoalveolar duct junctions of conducting airways, and type II pneumocytes as alveolar progenitors. The capacity of extrapulmonary precursors, such as those derived from bone marrow, to become pulmonary epithelial cells was described using the established male into female bone marrow transplant mouse model system together with the histochemical analyses required to demonstrate engraftment and pulmonary differentiation of the donor cells. There are several multipotent bone marrow subpopulations that can engraft and become epithelial cells, probably by different mechanisms, but an abundance of evidence demonstrates that tissue damage, such as that induced by irradiation, is required for bone marrow-derived epithelial engraftment, and such cells appear to be functional as shown in $\mathrm{CFTR}^{-1-}$ and $\mathrm{SPC}^{-/-}$mouse experiments in which deficient gene expression was partially restored in the lungs. Many mechanisms for the plasticity of adult stem cells were proposed, including differentiation, direct and indirect transdifferentiation, fusion, and combinations thereof. Discrepancies in the literature are, in part, due to different types and severity of lung injury induced to provide homing signals, different assays that are used to determine "stemness" (e.g., label retention, retroviruses, transgenic reporter systems, cell ablation techniques), and the fact that different laboratories use different markers to identify and isolate the precursor cells. These areas certainly need to be addressed in the future. Other issues that need to be addressed include definition of the proliferative and differentiative activity of stem/precursor cells in different regions of the adult lung, development of improved methods to transplant and track cells in vivo, improved isolation and validation of such cells, identification of critical niche components, which should lead to better engraftment and differentiation, determination of risks of exogenous cell administration, and development of safe, effective treatments that promote lung progenitor function.

Wellington Cardoso (Boston University School of Medicine) discussed the role of specific pathways in the developmental programs of lung progenitor cells as these early programs may be relevant to adult lung regeneration/repair. Identification of critical factors in these programs may be used to design and develop treatments for lung disease. The key will be to understand the signals provided by the niche and the context in which they need to be delivered. Mouse studies describing the identification of the early pulmonary progenitors in the embryo were reviewed. The transcription factor TitF1 (Nkx2.1) labels lung progenitors in the foregut endoderm before formation of the lung buds. The importance of TitF1 and other transcription factors (e.g., Foxa2) in lung epithelial development and lung homeostasis was discussed. Dr. Cardoso underscored the critical role of fibroblast growth factor receptor $2 b$ (FGFR2b) signaling via FGF10 in expansion of early lung progenitors during formation of the lung primordium and presented data on targets of FGF10 (BmpR1A, Tacstd2 [tumor-associated calcium signal transducer 2], cathepsin $\mathrm{H}$ ) during branching morphogenesis (282-285). He discussed the control of the bone morphogenetic protein (BMP) pathway by FGF10, which maintains epithelial survival, and also presented evidence that FGF10 can act as a proto-oncogene. Transgenic mice expressing FGF10 in the lung epithelium develop multiple pulmonary tumors $(286,287)$. FGF10 is a potent inducer of Tacstd2, which is expressed by epithelial progenitors in FGF10-dependent structures, including the lung, as well as in many epithelial cancers. Tacstd 2 may play a role in injury repair processes because it is induced in bronchial epithelial cells exposed to Pseudomonas and during renal regeneration and repair $(288,290)$. The importance of retinoic acid (RA) in lung progenitor cell expansion, through inhibition of the 
transforming growth factor (TGF)- $\beta$ pathway and induction of FGF10, and the potential role of RA in alveolarization and lung injury repair were reviewed (289-293). Lessons from lung development need to be integrated into regeneration strategies. The inductive signals that trigger specific differentiation programs need to be identified, as does the context (timing and positional cues). Further investigation is also needed to identify the physical properties of the cells and of the local microenvironment vis-à-vis mechanical forces and bioelectricity (i.e., the correct microenvironment needs to be re-created) (294). Strategies and technologies to characterize the molecular signature of developing and adult lung components need to be developed, and studies that integrate genetic, developmental, and bioengineering aspects of the lung need to be designed using biologically relevant model systems.

Dr. Rick Wetsel (University of Texas-Houston) described the derivation of type II alveolar epithelial cells from one of the human ES cell lines, H9. Embryonic body formation was not required in contrast to what has been previously documented by Ann Bishop's lab using mouse ES cells. Dr. Wetsel's protocol (273) entailed the use of matrigel plates, and G418 selection, after which $99.6 \%$ of cells were $\mathrm{SPC}^{+}$and had lamellar bodies. Molecular analysis showed that these cells expressed CFTR, surfactant proteins $\mathrm{A}, \mathrm{B}$, and $\mathrm{C}, \alpha_{1}$-antitrypsin and complement components C3 and C5. After further incubation, these cells expressed alveolar type I cell markers. Preliminary data were also shown demonstrating that human ES-derived alveolar type II cells could ameliorate bleomycin-induced lung injury in mice, indicating the potential therapeutic use of these cells.

Barry Stripp (Duke University Medical Center) reviewed the current state of knowledge of the hierarchy of stem cells and their progeny in adult tissues. Comparisons were made between bronchiolar stem cells and other more classical stem cell hierarchies, such as those of the hematopoietic system and the intestine (295). The classical hierarchy consists of infrequently cycling cells and their more rapidly dividing transit-amplifying (TA) progeny. TA cells vary between organs in their abundance, have differentiation potential equivalent to a stem cell, but cycle frequently and have finite proliferative capacity. In contrast, the lung exhibits a nonclassical hierarchy where TA cells (e.g., Clara cells) cycle infrequently and have a differentiated phenotype, and their proliferative capacity is unknown. The anatomic sites of niches for different stem/progenitor cells in the lungs were discussed (296). Comparisons were also made to stem cell niches of other tissues and the role of asymmetric cell division and adherens junction complexes in the maintenance of the stem cell pool (e.g., intestinal crypts, hair follicles, bone marrow, subventricular zone of the brain) (297). Dr. Stripp reviewed data demonstrating the existence of latent bronchiolar tissue-specific stem cells and their role in airway repair after ablation of Clara cells by administration of naphthalene. This allowed the identification of distal airway stem cells that were resistant to naphthalene that localized to two discrete microenvironments, the neuroepithelial body and the BADJ. Other experiments showed that $\beta$-catenin stabilization (by truncating the $\mathrm{N}$-terminus of $\beta$-catenin) altered the phenotype of Clara cells and increased the proliferation potential of the airways for 2 to 3 days after naphthalene injury (B. Stripp, unpublished data). Many fundamental issues and ideas remain to be addressed, including the relationship between a developmental progenitor cell and an adult tissue stem cell, whether lung tissue stem cells are required postnatally, what the constituents of a stem cell niche are, and how the niche changes in the setting of chronic or acute lung disease. Strategies to replicate or replace the stem cell niche need to be developed as do cell-based therapeutic approaches. Another challenge will be to define the relationship between normal repair versus tissue remodeling.
Ivan Bertoncello (Australian Stem Cell Center) described how local microenvironments in the lung interact with endogenous lung stem cells to specify their fate and modulate their cell surface phenotype. Stem cells exist in a state of dynamic reciprocity with their microenvironment, such that reciprocal signaling between stem cells, the extracellular matrix, supporting stromal cells, and accessory cells mediated by soluble and insoluble factors regulates their regenerative potential in the steady state and in response to injury (298). Dr. Bertoncello emphasized that stem cells are defined operationally by what they do rather than by how they are decorated. The evidence so far shows that stem cells are multiply marked, and that common stem cell-associated markers, including Sca-1, CD34, and membrane transport proteins, which confer the Hoechst 33342 side population phenotype, are not restricted to a single cell lineage and are typically shared and variably expressed by cells of differing developmental potential, activation state, and maturational age. Whether these markers define putative bronchioalveolar stem/progenitor cells is not clear and needs to be validated by robust in vitro and in vivo functional assays. The literature so far suggests the existence of discrete stem/progenitor cells along the proximal-distal axis of the lung: stem/progenitor cells located in submucosal glands giving rise to upper airway epithelium and expressing CK14/15; those located in the neuroepithelial body niche expressing CCSP giving rise to secretory airway epithelium; and $\mathrm{CCSP}^{+}$pro-SPC ${ }^{+}$ cells in the BADJ giving rise to alveolar type II and type I pneumocytes (7). Advances in understanding the organization of lung stem/progenitor cell hierarchies and their microenvironmental regulation is contingent on the prospective isolation of candidate stem cell(s) for further study. However, in the absence of unique stem cell markers, this objective is confounded by the loss of spatial information and histomorphometric cues on dissagregation of the lung, and the lack of functional surrogate assays that accurately measure their developmental potential and regenerative capacity.

Data were presented demonstrating that the emergence and exponential expansion of Sca-1-positive cells in the neonatal murine lung coincides with the transition from the saccular to the alveolar stage of lung development. Nonhematopoietic $\left(\mathrm{CD} 45^{-}\right)$, nonendothelial $\left(\mathrm{CD} 31^{-}\right) \mathrm{Sca}-1^{+} \mathrm{CD} 34^{+}$cells comprise heterogeneous, predominantly mesenchymal cells containing precursors of both respiratory epithelium and their stromal microenvironment that do not coexpress $\mathrm{CC} 10$ or pro-SPC and that give rise to both fibroblastoid and epithelial cells in culture.

Dr. Bertoncello concluded that lessons learned from delineation of the hematopoietic stem cell hierarchy should be applied to the identification and characterization of lung stem/progenitor cells. Gold-standard in vivo assays are required to validate in vitro surrogate assay readouts and lung stem cell phenotypic marker repertoires, and to confirm the ability of surrogate assays to predict the regenerative potential of lung stem/progenitor cells in perturbation and mutant mouse models. The recent demonstration of the generation of a functional mammary gland from a single orthotopically transplanted mammary stem cell isolated on the basis of the differential expression of CD24 and CD29 was presented as an example of a gold-standard in vivo assay to which the field should aspire (299).

Douglas Ball (Johns Hopkins University School of Medicine) discussed the role of progenitor cells in lung cancer. There is much overlap in the fields of lung cancer and developmental biology. In fact, normal progenitor cell subtypes define the scope of differentiation phenotypes in lung cancer. Treatment resistance is an overriding issue in clinical lung cancer and understanding lung stem cell biology is a key to attacking resistant niches. The "stem cell repertoire" of cancer-initiating cells may be altered by initiating genetic or epigenetic changes in genes that encode for proteins such as retinoblastoma protein $(\mathrm{Rb}), \mathrm{p} 53$, p16, ras, and 
epidermal growth factor receptor (EGFR). Activating mutations in EGFR can result in rapid emergence of treatment-resistant forms of non-small cell lung cancer. There is evidence showing that the cells with tumor-initiating potential express markers of lung progenitors such as BASCs. BASCs $\left(\mathrm{CCSP}^{+} \mathrm{SP}_{-} \mathrm{C}^{+} \mathrm{Sca}-\right.$ $\left.1^{+} \mathrm{CD} 34^{+}\right)$may be a cancer-prone progenitor population. Data were presented showing that they respond to K-ras ${ }^{\mathrm{G} 12 \mathrm{D}}$ (unlike ATII cells). Naphthalene airway injury and mutations in p53 augment proliferation and transformation of BASCs (246). In mouse models of lung cancer, Rb-p53 loss in airways (300), targeting of p18 and Men1 in Clara cells and BASCs (270), and inducing the basic helix-loop-helix transcription factor ASCL1 using the CC10 promoter (301) all show how progenitor cells potentiate lung carcinoma and can give rise to mixed neuroendocrine phenotype. It is also interesting that 1 to $8 \%$ of cultured human non-small cell lung cancer cells exhibit the side population-ABCG2 dye efflux phenotype (261). Such cells have a 1-log increase in tumor-forming efficiency, are more invasive in matrigel, express higher levels of human telomerase reverse transcriptase (hTert), and exhibit marked resistance to a spectrum of drugs including cisplatin, etoposide, gemcitabine, and doxorubicin (261). In the normal lung, SP cells are $0.03-0.07 \%$ of total lung cells and are evenly distributed in proximal and distal lung regions (302). They are Sca- 1 positive, CD34 positive, HNF3 $\beta$ positive, and TTF-1 negative. Furthermore, SP cells from adult mouse lungs are highly clonogenic (22). Putative markers for lung cancer stem cells include CD133, aldehyde dehydrogenase (Aldh1A1), and ASCL1. In ASCL1 shRNA-mediated knockdown experiments, CD133 and Aldh1A1 are decreased in small cell lung cancer cells, and this is associated with increased radiosensitivity of these cells post-5-Gy irradiation. Data were shown demonstrating that $\mathrm{G}_{2}-\mathrm{M}$ arrest is reduced as is the ATMdependent DNA damage response (pChk2 and pRad17). Future research for clinical translation of these findings will require a robust panel of markers for characterizing different stages in stem and progenitor development in the lung, understanding how differentiation potential is progressively restricted and how this process is preserved and altered in lung cancer, understanding how to recognize early progenitor and transit-amplifying or differentiated phenotypes within a complex tumor and how the survival of such cells can be monitored during primary treatment, and finally, understanding how to distinguish lung cancer progenitor targets from essential pathways in normal renewing tissues.

\section{Session 1 Discussion Summary}

The discussion section was led by Drs. Carla Kim (Children's Hospital Boston), Sue Reynolds (University of Pittsburgh), and Jeff Spees (University of Vermont). The discussion began with the basic question "Is there a lung stem cell?" and how should the term be defined for the lung. Suggestions included the following: (1) a cell that reconstitutes the entire organ, (2) a cell that supplies progenitors in the repair of injury, and (3) a cell that supplies progenitors in the steady state. There is still a major need for new methods and markers with which to identify and track stem cells (both during development and in the context of injury), a need to identify the microenvironmental niche factors required for maintaining "stemness," and, critically, a reproducible model analogous to what is used in the hematopoietic field, so that consistency between labs can be established. Using lung cancer stem cells to identify markers, and working backward from there, may be a useful approach. It was suggested that the use of serial injury instead of serial transplant be used to evaluate regenerative capacity of lung stem/progenitor cells. The stratification and hierarchical ordering of hematopoietic stem and progenitor cell compartments by temporal analysis of hematopoietic regeneration after 5-fluorouracil myeloablation was suggested as an example of the power of this approach $(303,304)$. The need to establish consistency between methods used in different labs was again emphasized because the phenotypes of cells isolated differ with respect to which digestion protocol is used (e.g., collagenase, dispase, pronase). There was discussion concerning the Sca-1 marker, because this is expressed postnatally in the mouse and the human correlate is not known. It is also unclear whether aquaporin 3 is a marker in humans. The session ended with expression of the need for further investigation into the effects of epigenetics and compilation of methylation maps relevant to the lung stem cell field.

\section{Session 2: Microenvironment, Tissue Engineering, Fibrocytes}

The second session was eclectic and, rather than being dominated by a single concept, was composed of three loosely related topics. The first of these was a collection of reviews addressing the mechanisms by which stem cells mechanically sense their environment to determine what constitutes an appropriate niche that fosters their proliferation and differentiation. After initial discussion of these basic events, two talks concentrated on potential preclinical approaches to facilitate the translation of these observations to maximize the therapeutic use (delivery and differentiation) of endogenous or exogenous progenitors to repair injured or degenerated lung.

Dennis E. Discher (University of Pennsylvania) demonstrated that, like most normal tissue cells, stem cells are anchorage dependent and therefore not able to survive if exclusively suspended in fluid media. How stem cells determine the stiffness of their matrix has been an elusive question and only recently, with the development of atomic force microscopy and the availability of culture conditions that allow for close regulation of elasticity to resemble physiologic conditions, has it been possible to determine that stem cells experience significant biological alterations involving the formation of adhesion complexes and induction of signal transductions, leading to alterations of the actin myosin cytoskeleton with contractile changes transferred throughout transcellular structures. Dr. Discher illustrated the importance of the nonmuscle myosin to the differentiation biology of the stem cells by pointing out that ES cells deficient in nonmuscle myosin II expression generate embryoid bodies that are flaccid and do not exhibit functional differentiation. Similarly, this deficiency is embryonically lethal at day E7.5) due to the lack of development of cardiovascular structures, such as blood vessels or heart. Citing previous literature, Dr. Discher indicated that, under normal conditions, surface flexibility was the predominant determinant of cell locomotion and therefore cells grown on stiffer substrates assemble focal adhesions and demonstrate larger spread than those cultured on softer and more flexible substrates. Matrix stiffness also determines stem cell lineage differentiation. Thus, naive MSCs cultured in soft matrices predominantly exhibit neurogenic differentiation, whereas stiffer matrices induce myogenic or osteogenic differentiation. Because tissues vary in their intrinsic flexibility (blood has the elasticity of fluids, whereas brain tissues have an average of $1 \mathrm{kPa}$, and those found in muscle and bone are 10- and 100-fold higher), it should be possible to anticipate the differentiation potential of stem cells for therapeutic purposes. This postulate is clearly demonstrated by findings showing that culture of human MSCs (currently undergoing clinical trials) under substrates that closely resemble specific organ stiffness induced expression of differential markers (Figure 7 ), even when these cells were cultured in the absence of specific induction factors. These principles will be fundamental to the use of stem cells to treat lung diseases because the elasticity of the lung is clearly altered during injury (i.e., increased in lung fibrosis) and degeneration. 
Dr. Mingyao Liu (University of Toronto) shared his experience with different matrixes as an effective mechanism to deliver stem cells into the injured lung to promote regeneration. Dr. Liu identified the three-dimensional complexities, inherent to the lung, as a formidable challenge to tissue regeneration in lung in which newly generated lung epithelia need to be in close proximity to vascular structures to assure appropriate gas exchange. Dr. Liu further discussed that current approaches to cellbased therapies in lung have focused in targeting progenitors to areas of injury where they are needed. These strategies have been based on the use of tissue-specific progenitors, expanded and sometimes modified in culture, administered as cell suspensions either systemically or intratracheally. A viable alternative is the introduction of engineered tissue into the lung with hopes for survival of the graft and subsequent expansion with invasion of the graft by native cells. These approaches logically require the use of scaffolding material to provide a three-dimensional matrix for implantation of the stem cells and to provide an opportunity for the surrounding tissue cells to migrate, proliferate, and foment the production of alveolar-like structures.

Subsequently, Dr. Liu detailed the physical properties of several of sponge-based scaffoldings to demonstrate "organotypic culture" or the ability of cells to form alveolar-like structures. This included an initial review of previous demonstrations of lung alveolar structure formation from fetal mouse or rat lung cells when cultured in synthetic collagen glycosaminoglycan or poly-lactic-co-glycolic-acid (PLGA) and poly-L-lactic acid (PLLA) scaffolds (227-233). Dr. Liu then reported on his group's experience at the University of Toronto where they demonstrated that gelfoam sponge with fetal lung cells surgically implanted in the chest cavity of rats survived for extended periods of time (up to $35 \mathrm{~d}$ ). Subsequently, surrounding native tissue cells migrated into the sponge structures and formed alveolar-like structures that connected to the pulmonary circulation. This was followed by degradation of the sponge scaffolds several months after the original implantation (Figure 8) (234).

The third speaker, Dr. Dario O. Fauza (Children's Hospital at Harvard), discussed his group's experience investigating engineered airway reconstruction with cartilage constructs based on MSCs. In detailed studies of the ability of MSCs from amniotic fluid (AF), bone marrow, or umbilical cord blood, his group has shown that AF MSCs have a rate of proliferation that is twice the one observed in bone marrow or cord blood MSCs. Of these three sets of MSCs, AF-derived MSCs have the highest concentration of sulfated glycosaminoglycans and elastin. In fact, the AF elastin concentration is as high as that of the native elastic cartilage. Because the proteoglycan concentration determines mechanical compressive strength, and elastin the flexibility of the native elastic cartilage, AF-derived MSCs appear to be optimal for the development of engineered cartilage to be used for airway reconstruction.

Dr. Fauza pointed out that AF-based MSCs are easily obtained with low volumes of fluid obtained at amniocentesis: 5 to $10 \mathrm{ml}$ will produce sufficient amounts of MSCs to successfully engineer a cartilage preparation. Although these artificially engineered cartilages are depleted of epithelial coverage, after implantation they would be lined by ciliated, pseudostratified columnar epithelium derived from the host in vivo.

The second topic in this session pertained to the biology of circulating fibrocytes and their contribution to lung injury and remodeling. Initially identified by Bucala and coworkers, fibrocytes were described as a subset of circulating cells that simultaneously exhibit leukocyte (CD45, CD34, CD11b, CD13, CD14, CXCR4, CCR7) and mesenchymal (collagens I and III, as well as vimentin) markers (104). Dr. Bethany B. Moore (University of Michigan) reviewed the role that these cells play in the pathogen- esis of lung fibrosis. Dr. Moore pointed out that upon recruitment into the injured lung, fibrocytes lose their expression of leukocyte markers, enhance their production of extracellular matrix, and express inflammatory mediators such as IL-1, TNF, CCL2, plateletderived growth factor (PDGF), TGF- $\beta$, and cysteinyl leukotrienes. Dr. Moore's work indicates that leukotrienes contribute to the fibroblasts' and myofibroblasts' differentiation of these cells in several animal models of lung fibrosis, such as bleomycin, fluorescein isothiocyanate, and herpesvirus infection (99-114). Furthermore, Dr. Moore's data indicate that adoptive transfer of fibrocytes worsens the severity of experimental pulmonary fibrosis (110).

A role for circulating fibrocytes has also been implicated in the pathogenesis of human lung injury. Citing work by Schmidt and Nihlberg and colleagues, Dr. Moore indicated that these cells contribute to the subepithelial fibrosis observed in the airways of patients afflicted by severe allergic asthma $(106,107)$. Similarly, the number of circulating fibrocytes is increased (Figure 4) in patients with usual or nonspecific interstitial pneumonitis and may contribute to the acute exacerbations observed in these patients (115). Taken together, this available information strongly supports a role for circulating fibrocytes in the pathogenesis of fibrotic lung diseases and offers new potential pathways for therapeutic interventions.

Dr. Kurt R. Stenmark (University of Colorado Health Sciences Center) discussed data showing an important role for fibrocytes in the pathogenesis of the vascular remodeling observed during the development of pulmonary hypertension in response to hypoxia. After exposure of neonatal calves to chronic hypoxia, Dr. Stenmark's laboratory observed robust accumulation of monocytes and fibrocytes in the adventitia and media of pulmonary, but not systemic, vessels. To further study the biology of fibrocytes in hypoxic pulmonary hypertension, Dr. Stenmark's laboratory is taking advantage of the freemartin calf, a female animal that has a chimeric (XX-YY) bone marrow. Exposure of these freemartins to hypoxia is followed by the appearance of vimentin expressing Y-chromosome cells in the adventitia of small vessels, thus suggesting a bone marrow origin for these cells. Laser capture microdisection studies showed time-dependent increases in VEGF, SDF1, 5-lipoxygenase, endothelin-1, intercellular adhesion molecule (ICAM)-1, and vascular cell ahesion molecule (VCAM)-1 mediators with chemoattractant and proliferative activity properties. Dr. Stenmark also presented data indicating that depletion of circulating fibrocytes nearly abrogated hypoxia-induced vascular remodeling in rats (116). Therefore, as in the case of fibrotic lung diseases, these results also identify the fibrocyte as an important player in vascular pathology and suggest that physical or pharmacologic inhibition of these cells may constitute important therapeutic options in the treatment of pulmonary vascular disease.

During the final lecture of this second section, Dr. Johnny Huard (University of Pittsburgh) discussed the role of musclederived stem cells as potential sources for regenerative medicine. Similar to what has been achieved in bone marrow, Dr. Huard indicated that his laboratory has identified based on adhesion, proliferation, and stem cell marker expression, several populations of myogenic cells from the skeletal muscle of adult mice. One population of cells in particular exhibits self-renewal and differentiation potential and these cells are termed "muscle-derived stem cells." Transplantation of muscle-derived stem cells, but not myogenic cells, improved the regeneration of dystrophic muscle and efficiently delivered dystrophin, a protein deficient in these muscle cells. These effects were more significant when femalerather than male-derived cells were used. Dr. Huard indicated that the mechanism responsible for the differences in gender efficiency among muscle-derived stem cells is not completely understood but may involve better inhibition of the TGF- $\beta$ signal transduction. 
Finally, Dr. Huard reviewed data suggesting that muscle-derived stem cells could be engineered to express osteogenic (BMP2, BMP4) proteins and VEGF properties that his laboratory has used successfully to promote cartilage and bone healing.

\section{Session 2 Discussion Summary}

The discussion section was led by Drs. Zea Borok (University of Southern California), Ed Ingenito (Harvard Medical School), and Darrell Kotton (Boston University). Because of the eclectic nature of the talks in this section, the discussion was broad, sensing the audience's opinion as to what constitutes an ideal stem cell type to be used in clinical trials. Although no definitive conclusions were achieved, the overwhelming consensus was that MSCs and endothelial progenitors offered the best prospects for use in human trials of lung injury and regeneration. Finally, representatives from participating patient advocate groups reminded the audience of the immediacy of their needs and encouraged the immediate launch of exploratory clinical trials with these cells as a desperate measure that could improve the lives of many terminally ill individuals.

\section{Session 3: Preclinical and Clinical Uses of Stem Cells}

The goal of this session was to review the current state of knowledge of the preclinical and clinical applications of stem cells in human disease. The session began with Jane Onken (Duke University School of Medicine), who provided an overview of ongoing clinical trials of standardized preparations of MSCs in acute myocardial infection (Provacel; Osiris Pharmaceuticals, Inc., Columbia, MD), acute GVHD and steroid-resistant GVHD (Prochymal; Osiris Pharmaceuticals, Inc., Columbia, MD) and an update on an ongoing clinical trial of adult MSCs in Crohn's disease with Prochymal. The MSC preparations under study have shown very low immunogenicity and thus do not require HLA matching. A phase 1 trial of Prochymal has been completed in steroid-resistant GVHD in 46 patients. There were no drugrelated serious adverse events, and over the 2-year study there was a reduction in observed mortality from 45 to $22 \%$. On the basis of this trial, a phase 2 trial was initiated in 32 patients with acute GVHD, which has shown a $90 \%$ response rate (partial and complete responses). The trial in Crohn's disease is a phase 2 open-label study in 10 subjects. The trial will investigate a low dose $\left(2 \times 10^{6}\right.$ cells $\left./ \mathrm{kg}\right)$ and a high dose $\left(8 \times 10^{6}\right.$ cells $\left./ \mathrm{kg}\right)$ given at study entry and 7 days later. The primary outcome measure is the Crohn's Disease Activity Index (CDAI), with a clinical response being defined as a reduction in CDAI by at least 100 on Day 28. Secondary endpoints are clinical remission (a drop in CDAI of at least 150) and improved quality of life, as determined by a disease-specific questionnaire. Dr. Onken presented data on nine evaluable patients and mean decrease of CDAI of 105 in these individuals as well as three of nine patients showing clinical responses. Of note, these three had no longer shown responses to anti-TNF therapy. Again, in this study, there were no infusionrelated serious adverse events. Future studies are being designed to determine optimal dose (number of cells, frequency), durability of response, and suitability of biomarkers as surrogate outcome measures, and to examine mucosal healing, as well as longterm safety.

Donald Phinney (Tulane Center for Gene Therapy School of Medicine) discussed using cell-based therapy to alter the lung microenvironment using a mouse model of pulmonary fibrosis and reviewed the current literature on MSCs in acute lung injury. The Phinney lab has characterized a population of immunodepleted murine MSCs (IDmMSCs), which are cultured and expanded from mouse bone marrow for 8 to 10 days and enriched by plastic adherence followed by immunodepletion with anti-
CD11b, anti-CD34, and anti-CD45 (305). IDmMSC administration immediately after bleomycin challenge significantly reduced both lung inflammation and increases in collagen content (as measured by lung hydroxyproline levels) at 14 days post-challenge (152). Using serial analysis of gene expression, the investigators observed significant increases in the expression of IL-1 receptor antagonist in isolated IDmMSCs as well as increased expression in the lungs of bleomycin-injured mice after transfer of the cells in vivo (153). Other investigators have similarly demonstrated that either systemic or intratracheal MSC administration also reduced endotoxin-induced lung injury and that MSC administration was associated with decreased neutrophil influx as well as local TNF- $\alpha$ levels and CXC chemokine expression (46, 70, 154, 155). Again, using Serial Analysis of Gene Expression (SAGE), the Phinney lab has observed many immune genes expressed in IDmMSCs such as IL-15, VEGF B, pleiotrophin, and macrophage migration inhibitor protein; however, the expression of these genes is not homogeneous and therefore there may be subpopulations of MSCs that could be exploited for specific immunotherapy.

Daniel Weiss (University of Vermont) showed data that one can achieve CFTR expression in lung tissue of $\mathrm{CFTR}^{-1-}$ mice after irradiation and bone marrow transplant, but the level of engraftment of CFTR-expressing cells was below 1\%. Despite this, the investigators could measure functional chloride conductance and also reported engraftment of human cord blood cells in the epithelium of NOD SCID mice. These data suggest that to exploit this, both homing and recruitment would need to be better understood and improved. Based on the fact that MSCs have regulatory properties and can reduce acute lung inflammation, the Weiss laboratory investigated whether adult mouse bone marrow-derived MSCs (provided by the MSC Core facility at the Tulane Center for Gene Therapy) could attenuate Th2mediated inflammation and airway hyperresponsiveness in a mouse model of asthma induced by ovalbumin. Administration of MSCs significantly attenuated ovalbumin-induced increases in airway hyperresponsiveness as well as the number of eosinophils in bronchoalveolar lavage fluid after ovalbumin challenge. Moreover, there was a substantial reduction of Th2 cytokines in the lungs of MSC-treated mice. Notably, this effect occurred with both syngeneic and allogeneic MSC administration, consistent with the concept of MSC immunoprivilege that has underscored use of MSCs in current clinical trials. Ongoing work is investigating if MSCs are affecting dendritic cell activation, antigen presentation, T-cell lineage commitment or T-cell effector function.

Ellen Burnham (University of Colorado Health Sciences Center) spoke on the role of EPCs in lung diseases with the idea that many lung diseases such as ARDS, pulmonary hypertension, emphysema, asthma, bronchopulmonary dysplasia, and lung cancer have significant vascular components to their pathogenesis. Burnham and colleagues have previously shown that, in patients with ARDS, EPC frequency by flow cytometry or by colony formation is associated with improved survival (76). However, data in other diseases have been conflicting, possibly due to the different protocols used to immunophenotype these cells. Yoon has suggested that early EPCs could be identified as $\mathrm{CD} 34^{+}, \mathrm{CDC}_{3}{ }^{+}$, and $\mathrm{CD} 14^{+}$, and although these cells express VEGF they are weak producers of nitric oxide and poor at tube formation (84). In contrast, late-outgrowth EPCs lose CD34 and CD14 expression but retain CD31 and have much higher NO production and show excellent angiogenic potential. Moreover age, sex, smoking, and diabetes have each been shown to affect EPC frequencies, which may complicate their use in clinical trials. Several studies have shown that progenitor cell infusion in the coronary circulation is safe, and in one study by Assmus and 
colleagues, the administration of bone marrow progenitor cells was associated with greater increase in left ventricular function compared with circulating progenitor cells (306). Dr. Burnham suggested it would be prudent to also examine current drug trials for lung diseases-for example, the ARDS granulocytemacrophage colony-stimulating factor trial-to determine any effects on EPC frequency in the blood. Last, there was discussion of subpopulations of patients in whom EPC therapy may be more beneficial.

Keith L. March (Indiana Center for Vascular Biology and Medicine) provided an update on cardiac trials as models for potential stem cell trials in lung disease. Clinicaltrials.gov currently lists 198 trials for stem cells in cardiovascular diseases but only two clinical trials (pulmonary hypertension) and two clinical investigations (pulmonary hypertension and lung cancer) in lung disease. The major focus of cell-based therapy has focused on ischemic heart disease and acute myocardial infarction. Despite this focus, the approach to mobilize cells and the types of cells studied have varied widely from mobilizing endogenous stem cells with growth factors to ex vivo expansion of defined populations of cells to administration of whole bone marrow. The March laboratory has recently described a population of multipotent CD34+ ${ }^{+}$adipose stromal cells that share pericyte and mesenchymal surface markers (53). These cells reside in a periendothelial location and contribute to endothelial networks when grown on matrigel substrates. A challenge of these newer stem cell populations will be to develop in vitro and in vivo assays in which to screen their multipotency and success in clinical trials.

Duncan J. Stewart (University of Ottawa) gave an update on an ongoing clinical trial of EPCs in pulmonary hypertension. The trial involves a population of EPCs transfected with eNOS. Preclinical studies using the MCT model of PAH have shown that EPCs delivered 3 days after administration of MCT can prevent PAH and cell therapy as late as 3 weeks later was also effective in blocking progression of disease. These data led to the development of the PHACeT trial, a dose-ranging study to assess tolerability of eNOS-transfected EPCs in idiopathic PAH. The trial is designed to enroll up to 18 patients with five dosing cohorts with a low end of $7 \times 10^{6}$ cells, up to $150 \times 10^{6}$ cells. Three patients have been enrolled and have tolerated the therapy to date.

Donald W. Fink (U.S. Food and Drug Administration [FDA]) closed the didactic portion of session 3 with an overview of the agency's perspective on initiating early-phase clinical safety studies. Regardless of the source of cells (adult, fetal, embryonic, allogeneic, or autologous), cell-based therapy is regulated by the FDA Center for Biological Evaluation and Research (CBER). Dr. Fink reviewed several key aspects regarding the evaluation of an Investigation New Drug (IND) application pertaining to first-in-human clinical studies using stem cells. The application must include information on cell source/donors and describe the methods to isolate and expand and/or differentiate the stem cell preparations. To this end, the investigators should provide data on the reproducible nature of the cell expansion/differentiation assays and the stability of the stem cell phenotypes. The application should also describe unique characteristics of the stem cell-based cellular product that permits specific analytical testing on the product to assess identity and cellular profile. An assessment of immunologic potential is recommended as well as assays for viability and untoward differentiation, such as tumorgenicity. Due to the complexity of the field, investigators are highly encouraged to engage the agency in a pre-IND submission conference with the FDA-CBER. For more information, see http://www.fda.gov/ CBER/genetherapy/stemcell031406df.htm.

\section{Session 3 Discussion Summary}

The discussion section was led by Drs. Kenneth Brigham (Emory), Alan Fine (Boston University), Michael Matthay (University of California, San Francisco), Marc Moss (University of Colorado), and Ben Suratt (University of Vermont). The discussion began with the question "What diseases are prime candidates for stem cell therapy?" There was much excitement about the fact that the pulmonary community is now poised to capture critical safety and tolerability data from the EPC trial in PAH. From a regulatory perspective, however, this trial has two hurdles to clear: one is the characterization of the EPCs themselves and second is the transfection procedure. Trials using MSCs for acute lung injury would require cell characterization, but on the basis of preclinical data to date it is unclear whether otherwise non-genetically engineered cells would be effective. Due to the low engraftment of these cells in the lung, there was a tendency to further develop cell therapy for acute lung injury as potential therapy as opposed to diseases that may require engraftment.

\section{Session 4: Recommendations, Summation, and Future Directions}

This session included a presentation from Alan Michelson, Chief, Laboratory of Developmental Systems Biology at the NHLBI, on integrative systems-level approaches in biology and medicine. These are novel and potentially powerful means of approaching the complex multidimensional aspects of cell therapy approaches for lung diseases. Following this, Dorothy Gail, Chief of the Lung Biology and Disease Branch of the NHLBI, and John Thomas, Program Director of Transfusion Medicine and Cellular Therapeutics at the NHLBI, presented the NHLBI perspective on stem cell and cell therapy approaches for lung diseases. Available resources from the NHLBI and the NIH were described, including the NIH Production Assistance for Cellular Therapies (PACT) program (http://www.pactgroup.net/). Further resources are listed in the conference recommendations. Also included in this session were presentations from Mike Rosenzweig and John Walsh, CEOs, respectively, of the Pulmonary Fibrosis and Alpha-1 Foundations, on the importance of stem cell research to these particular patient populations and the role of nonprofit research organizations in supporting this and other novel areas of research. After these presentations, a vigorous pro-con discussion was held on whether to move ahead toward clinical trials. There are currently two clinical investigations of stem/progenitor cells in lung diseases, one each for lung cancer and for pulmonary hypertension, and two trials of cell therapy approaches for pulmonary hypertension listed in clinicaltrials.gov (Table 4). Salient points from the pro-con discussion are summarized in Table 5. Overall, there was a consensus that lung diseases still present major challenges, but it is probably time to cautiously move ahead with carefully designed trials. The major considerations are that many lung diseases are devastating and current therapies offer little hope for patients, encouraging results are being reported with cell therapies for many other diseases, and there are very few examples of effective therapies in medicine that were fully understood at the time they were introduced or even after they became common medical practice. At the same time, there was a consensus that far too little is known to narrow the scope of basic research on lung that is very likely to open new avenues for therapies.

As reflected in the sessions and the abstracts, the conference covered a broad scope of topics, ranging from the basic biology of the lung to approaches for new therapies for lung diseases. Remarkable progress had been made since the last conference 2 years ago in areas such as the following: the developmental biology of the lung; new systems for analyzing complex biological 
TABLE 4. CLINICAL INVESTIGATIONS AND TRIALS OF STEM/PROGENITOR CELLS IN LUNG DISEASES LISTED IN clinicaltrials.gov

1. Microarray Analysis of Gene Expression and Identification of Progenitor Cells in Lung Carcinoma NCT00568906

Stanford

Principal investigator: Glenn D. Rosen, M.D.

This study will investigate gene expression profiles in normal human lung tissue, lung carcinoma, and metastatic tumor to the lung. The expression of up to 20,000 genes in a given lung tissue sample will be examined by cDNA microarray analysis and compared with normal lung tissue. In addition, we hope to identify a particular subset of lung cancer cells with an enhanced capacity for proliferation and self-renewal, analogous to the stem cells recently identified for certain types of leukemia, breast cancer, and brain tumors.

2. Endothelial Progenitor Cells and Pulmonary Idiopathic Arterial Hypertension NCT00551408

Unidad de Investigacion Clinica en Medicina SC, Monterrey, Mexico

Principal investigator: Carlos J. Sanchez Diaz, M.D.

Current evidence established that endothelial progenitor cells (EPCs) participate in several models of vascular disease as acute coronary syndromes, stroke, diabetes, peripheral artery disease, etc. However, EPCs in the setting of pulmonary arterial hypertension is less well established. The target of this study is to demonstrate if the number of EPCS is increased in a Mexican population of patients with pulmonary arterial hypertension.

3. Pulmonary Hypertension: Assessment of Cell Therapy (PHACeT) NCT00469027

Principal investigators: Michael Ward, M.D., St. Michael's Hospital, Toronto; David Langleben, M.D., Sir Mortimer B. Davis-Jewish General Hospital, Montreal The primary objective is to establish the safety of autologous progenitor cell-based gene therapy of heNOS in patients with severe pulmonary arterial hypertension refractory to conventional treatment. Northern Therapeutics.

As of January 2008, the PHACeT trial has completed enrollment of the first-dose panel, with three patients receiving a total of 7 million early-growth EPCs transfected to overexpress human nitric oxide synthetase (eNOS). The cell delivery procedure was well tolerated and there were no safety concerns. Notably, the first three patients all showed a remarkable (nearly 50\%) reduction in total peripheral vascular resistance (PVR) over the course of the 3 -day delivery period, which might represent the effect of increase NO release by the engineered EPCs within the pulmonary microcirculation.

4. Safety and Efficacy Study of Transplantation of EPCs to Treat Idiopathic Pulmonary Arterial Hypertension (completed, see Reference 103) NCT00257413

The First Affiliated Hospital, College of Medicine, Zhejiang University, China

Principal investigator: Junzhu Chen, M.D.

Objectives: The goal of this study was to investigate the feasibility, safety, and initial clinical outcome of intravenous infusion of autologous endothelial progenitor cells (EPCs) in patients with idiopathic pulmonary arterial hypertension (IPAH).

Background: Experimental data suggest that transplantation of EPCs attenuates monocrotaline-induced pulmonary hypertension in rats and dogs. In addition, clinical studies suggest that autologous progenitor cell transplantation is feasible and safe in patients with ischemic diseases.

Methods: We conducted a prospective, randomized trial comparing the effects of EPC transplantation plus conventional therapy with those of conventional therapy alone in patients with IPAH. The primary endpoint was change in the six-minute-walk distance using a standardized protocol. The secondary endpoints were changes in hemodynamic variables as assessed by right heart catheterization.

Results: After 12 weeks of follow-up, the mean distance walked in 6 minutes increased by $48.2 \mathrm{~m}$ in the cell infusion group (from $263 \pm 42 \mathrm{~m}$ to $312 \pm 34 \mathrm{~m}$ ), and an increase of $5.7 \mathrm{~m}$ occurred in the conventional therapy group (from $264 \pm 42 \mathrm{~m}$ to $270 \pm 44 \mathrm{~m}$ ). The mean difference between the two groups was $42.5 \mathrm{~m}$ ( $95 \%$ confidence interval, 28.7 to $56.3 \mathrm{~m} ; P<0.001)$. The patients in the cell infusion group also had significant improvement in mean pulmonary artery pressure, pulmonary vascular resistance, and cardiac output. There were no severe adverse events with cell infusion.

Conclusions: This preliminary study showed that intravenous infusion of autologous EPCs seemed to be feasible and safe, and might have beneficial effects on exercise capacity and pulmonary hemodynamics in patients with IPAH.

system; defining new subpopulations of cells in the lung, including resident stem/progenitor cells; defining which circulating or bone marrow cells can contribute to repair of the lung; and new mechanisms for cellular differentiation. Among the many new themes explored was that exogenous cells from bone marrow or other sources may hasten repair of the lung by modulating inflammatory and immune reactions without the cells engrafting long term or differentiating into pulmonary cells. A number of new approaches to cell therapies were explored, including cell-impregnated scaffolds for lung repair, use of cells transduced to express therapeutic genes, and isolation of new subpopulations of cells for repair of lung from embryos, the lung, the circulation, and bone marrow.

It is hoped that the workshop recommendations will spark new research that will provide further understanding of the role of stem and reparative cells in lung biology and further provide a sound scientific basis for therapeutic use of adult reparative cells in lung diseases. As such, the following recommendations are suggested. Many of these are similar to those outlined in the 2005 workshop (1). Overall conference recommendations are found in Table 2.

\section{GENERAL RECOMMENDATIONS}

\section{Terminology}

The terms "stem" and "progenitor" cell continue to be used with varying degrees of rigor in published studies. This results in confusion and misconceptions about research findings and methodology. This may further be problematic given continuing public debate about the use of stem cells in biologic research. Furthermore, there is a lack of consensus among experts about what constitutes certain stem and progenitor populations, notably MSCs and EPCs. Investigators are urged to use the most recent ISCT Mesenchymal and Tissue Stem Cell Committee criteria for defining (human) MSCs (121). It is also possible that there may be different subtypes of MSCs and it is expected that the criteria will be updated as the field continues to develop. Discussion and interaction between investigators using EPCs and MSCs, as well as other stem and progenitor cell types, are encouraged to help guide use of similar cell populations in comparative studies. A guide to terminology is shown in Table 1. This glossary does not necessarily reflect an overall consensus for the definition of each term and will undergo continuing revision as overall understanding of the cell types and mechanisms involved in lung repair continue to be elucidated. Nonetheless, it is a useful framework.

\section{BASIC SCIENCE INVESTIGATIONS}

In addition to clarifying and understanding the mechanisms and role of exogenous cells and of endogenous lung stem and progenitor cells in lung biology, an important goal is to develop 
Pro

- There is a considerable safety record with clinical use of stem cells (i.e., bone marrow transplantation).

- Recent studies with MSCs in a variety of nonpulmonary diseases have demonstrated safety and in some cases efficacy.

- Available information from two clinical trials of EPCs in primary pulmonary hypertension suggests both safety and efficacy.

- Initial exploratory trials, phase 1 or otherwise, can be safely designed and implemented with appropriately measurable outcome assessments.

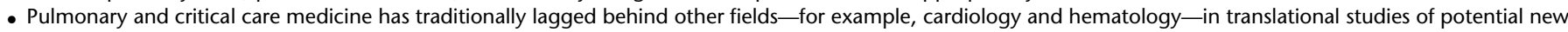
therapies, including use of reparative cells.

- Initial exploratory clinical trials are important in hypothesis generation for future basic and translational studies.

- The FDA will support carefully designed initial investigatory trials. These will be reviewed on an individual basis.

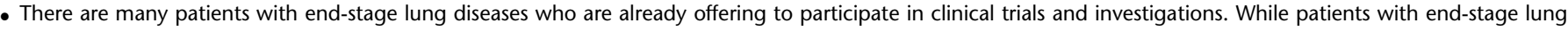
diseases may not be the optimal population to study, initial investigations will provide important data about safety and will generate future hypotheses for study.

Con

- There is not enough evidence for a function of exogenous cells in lung repair to venture into clinical trials.

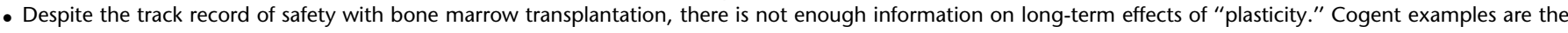
recent publications demonstrating development of gastric cancer from transplanted stem cells in a mouse model of chronic Heliobacter pylori infection and the potential role of adult stem cells in development of lung cancer.

- There are unresolved ethical issues.

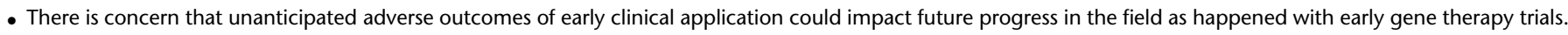

Definition of abbreviations: EPCs = endothelial progenitor cells; FDA = U.S. Food and Drug Administration; MSCs = mesenchymal stem cells.

a firm scientific basis for translational approaches to the repair and regeneration of the diseased lung using these cells. To fully explore and promote understanding of the role of these cells in lung development, repair, and remodeling, a number of specific recommendations were developed, as follows, many of which are similar to those recommended after the 2005 conference.

\section{Techniques}

Rigorous techniques must be used to assess potential in situ engraftment of exogenous cells in lung and to delineate populations of endogenous stem and progenitor cells. Results obtained from routine photomicroscopy of lung sections to detect markers delineated by fluorescent in situ hybridization, immunohistochemical, as well as other techniques can be misleading.

\section{Recommendations:}

- Photomicroscopy should incorporate advanced imaging techniques, including confocal microscopy, deconvolution microscopy, electron microscopy, laser capture, and other techniques as applicable.

- Techniques including flow cytometry, DNA and/or RNA analyses, and other comparable approaches should be done in parallel where feasible.

\section{Functional Outcome Measures}

The functional role of endogenous stem and progenitor cells and of exogenously administered cells is largely unknown in different lung disease states. Furthermore, in the growing number of studies in which a functional role has been suggested, the mechanism or mechanisms by which functional alterations occur are poorly understood. In addition, analysis of functional outcome may be different for different diseases. These questions are crucial to potential cell therapeutic applications.

\section{Recommendations:}

- Functional outcomes should be included to the extent feasible in all preclinical studies.

- Functional outcomes should be tailored to each specific disease model investigated.

- Functional outcomes must be sensitive (high throughput) and easily and reproducibly quantitated. Examples include the following:

Expression of a missing gene or gene product and/or measurement of a gene product function (i.e., chloride current following CFTR expression).
Restored pulmonary function (high-resolution computed tomography scans, histomorphometry, small-animal pulmonary mechanics).

\section{Standardized Preclinical Models of Human Lung Disorders}

The relevance is to promote greater understanding of cellular and molecular pathophysiology of human disorders. Many available mouse models do not fully recapitulate the human disease, limiting extrapolation of therapeutic interventions. Considerable effort should be directed toward developing better models of human disease, including large-animal models.

\section{Recommendations:}

- Several models are currently available, primarily in mice. Development of additional models that mimic features of important human lung diseases remains a desired goal.

- A suggested, but not inclusive, list of available (mouse) and/ or desired models includes the following:

Bronchopulmonary dysplasia or surfactant deficiency

Idiopathic pulmonary fibrosis

Adult-onset emphysema/COPD

$\mathrm{CF}$

Acute lung injury due to environmental factors

ARDS

Primary pulmonary hypertension

Post-transplant bronchiolitis obliterans

Asthma

Lung cancer

- Development of larger animal models of clinical lung diseases. Acknowledging the high costs and other practical considerations for larger animal work, particularly in nonhuman primates, developing cores for appropriate largeanimal models of specific lung diseases is a desired goal.

\section{Development of Novel Tools}

Continued development of more robust tools for identification and characterization of potential cell populations is a high priority area. Of particular mention is the need to develop these tools in parallel in both rodent and human cells and disease models.

\section{Recommendations:}

- Characterization of cell-specific markers for isolation and prospective characterization of different endogenous stem and progenitor cell populations. 
- Development of additional cell-specific promoters that track endogenous stem and progenitor cell expression with good fidelity.

- Development of more robust markers for histology, suitable for laser capture microscopy, confocal microscopy, and so forth.

- Development of more robust markers specific for flow cytometry, for example, fluorescent, protease-resistant surface markers.

- Development of lung-specific (monoclonal) antibody libraries.

- Development of genetic mouse models for investigation of functional pathways in lung development and repair. Examples include the following:

Conditional gene activation/deletion based on the use of CreERt2 or rtTA (doxycycline regulated).

Modified genes bred onto different genetic backgrounds, including mutants lacking specific immune cells.

Conditional deletion of specific cell populations (e.g., neuroendocrine, ciliated, type II).

\section{Fundamental Understanding of Lung Repair Mechanisms}

The cells that mediate lung repair and the mechanisms by which they do so remain incompletely understood. Both endogenous stem and progenitor cells and possibly circulating or marrowderived cells likely participate. Understanding the roles of each and their interactions is a crucial area of investigation. Recommendations focus largely but not exclusively on utilization of different models.

\section{Recommendations:}

- Use of different proof-of-concept models. Although some experimental injury/repair systems (e.g., using naphthalene, bleomycin, etc.) do not necessarily mimic human lung disorders, they are useful for testing specific hypotheses.

- Increased focus on clinically relevant disease models.

- Increased use and investigation of lung regeneration models. Some suggested models include post-pneumonectomy regeneration, septal proliferation after retinoic acid treatment, nutrition after neonatal deprivation, etc.

- Investigations of different plasticity/dedifferentiation models, including label-retaining tissue stem cell models for endogenous stem and progenitor cells.

- Investigations of basic development and repair mechanisms including the following:

Mechanisms for normal lineage specification of epithelial, interstitial, and endothelial cells

Mechanisms of epithelial/endothelial/interstitial interactions Cell-matrix interactions

Identification of stem/progenitor cell niches; how are they formed and maintained?

Impact of lung remodeling on niches

Impact of aging, disease, and the immune system on regenerative capacity

\section{Improved Understanding of the Microenvironmental Niches in Which Endogenous Stem and Progenitor Cells Reside}

The micrenvironmental niche in which endogenous stem and progenitor cells reside critically affects their behavior. More sophisticated tools to mimic ex vivo the relevant microenvironments for study of endogenous stem and progenitor cells are required.

\section{Recommendations:}

- Development of methods for culture systems that mimic in vivo niches:

a. Air-liquid interface.

b. Three-dimensional scaffolding/artificial matrices.

c. Use of multiple cell types.

d. Mechanical forces (stretch, strain, etc.)

\section{Mechanisms of Recruitment and Phenotypic Conversion of Circulating, Marrow-derived, or Exogenously Administered Cells}

Structural engraftment is now believed to be a rarer occurrence than first postulated. Nonetheless, structural engraftment as epithelial, interstitial, or pulmonary vascular cells can occur. The mechanisms by which cells are recruited to lung and/or induced to undergo conversion to functional lung cells remain poorly understood. Furthermore, there are many variables, such as chronic lung disease models, aging, route of cell administration, and so forth, that remain less well explored.

\section{Recommendations:}

- Development of appropriate in vivo model systems, including transgenic mice and use of gene transfer techniques, for conditional or targeted overexpression of candidate recruitment mediators.

- Demonstration of functional relevance of identified potential recruitment mechanisms.

- Exploration of factors that might influence recruitment and phenotypic conversion, such as the following:

a. Disease model (i.e., acute vs. chronic lung injury).

b. Age of cells or recipient lungs.

c. Route, dose, and frequency of cell administration.

d. Timing of administration related to lung injury.

e. Other, as yet unidentified, cell populations.

\section{Development of In Vitro Methods}

In addition to the in vivo studies delineated above, development of robust in vitro model systems is crucial to understanding the role of endogenous stem or progenitor cells and of circulating or exogenously administered cells in lung biology and disease.

\section{Recommendations:}

- Development of methods for in vitro expansion of lung progenitor and stem cells.

- Expansion and improvement of methods for testing cell therapies, including, but not limited to, the following:

1. Culture with and without feeder cells.

2. Culture with and without growth factors/serum/retinoids.

3. Culture using different substrata.

4. Combined culture with mesenchyme and grafting into permissive tissues such as under the kidney capsule.

5. Expansion of air-liquid interface culture studies.

6. Use of tracheal heterotopic transplantation modelseither denuded and inoculated with cells from different sources or repopulation by endogenous cells.

\section{Expansion of Bioengineering Approaches to Lung Regeneration}

In parallel with improved in vitro culture methods, development of novel approaches using artifical matrices and three-dimensional scaffolding for ex vivo and subsequent in vivo lung regeneration is 
desired. Effects of mechanical forces on lung development and repair should be incorporated into in vitro studies.

\section{Recommendations:}

- Development of methods for culture of stem and progenitor cells in artificial and cadaveric matrices and threedimensional scaffolding in vitro.

- Development of methods for in vivo assessment of cells grown in artificial matrices and three-dimensional scaffolding.

- Assessment of mechanical force effects on development of lung tissues from stem and progenitor cell populations.

\section{Consideration and Use of Core Centers and Resources}

The pros and cons of whether to establish core centers for training, cell culture, and generation and provision of specific cell types, functional outcome assessments, histologic assessments, and other methodologic techniques were discussed, and the following recommendations were made.

\section{Recommendations:}

- Active fostering of interinstitutional multidisciplinary collaborations and consortiums

- Widespread dissemination about already existing core services and facilities. A partial list includes the following:

ISSCR (International Society for Stem Cell Research) glossary: http://www.isscr.org/glossary/

NIH stem cell information: http://stemcells.nih.gov/index.asp What are stem cells? http://stemcells.nih.gov/info/basics/ defaultpage.asp

Link to 2001 report and 2006 update on regenerative medicine: http://stemcells.nih.gov/info/scireport/

NIH Production Assistance for Cellular Therapies (PACT) program: http://www.pactgroup.net/. The NIH PACT program is charged with providing scientific, manufacturing, and regulatory support, and educational opportunities in the field of novel cell therapies and has provided human clinical grade stem cells for therapy to the cardiovascular community (status post-myocardial infarction clinical trials).

NCRR Cell Core: http://www.ncrr.nih.gov/comparative_ medicine/resource_directory/biological_materials.asp

Tulane Mesenchymal Stem Cell Core (standardized preparations of human and rodent MSCs): http://www.som.tulane. edu/gene_therapy/distribute.shtml

NIH Lung Tissue Repository Center: http://www.ltrcpublic. $\mathrm{com} /$

\section{Educational Programs}

A highly desirable goal is to inform and educate the stem cell community about the potential role of stem and reparative cells in lung biology and disease. Conversely, the lung community needs to be educated about stem and reparative cell biology. This will lead to fruitful interactions and collaborations and, importantly, will result in less overlapping and duplicative research efforts.

\section{Recommendations:}

- Educational programs at national meetings.

- Stem cell training courses with both didactic and practical components from different disciplines.

- Arranging sabbaticals/training for both fellows and faculty in laboratories of established stem cell investigators not necessarily in the lung field.

\section{CLINICAL/TRANSLATIONAL RECOMMENDATIONS}

There is a growing impetus on moving toward initial safety and efficacy clinical investigations. This is based in part on the initial results from the PHACeT trial at the University of Toronto and in part on recent demonstration of safety and efficacy in phase 1 and 2 trials using MSCs for Crohn's disease and GVHD. It is acknowledged by participants that the mechanisms and both short- and long-term effects of cell-based therapies for lung diseases remain unknown. Furthermore, there remains concern as to whether cells such as EPCs or MSCs may contribute to development of lung or other cancers or may increase fibrotic reactions. Nonetheless, after vigorous discussion, the following recommendations for clinical and translational studies were made (see also Table 5).

\section{Recommendations: Clinical Studies}

- Proceed with design and implementation of initial exploratory and safety investigations.

- All appropriate ethical issues should be considered.

- Clinical and translational investigations should include consideration of mechanisms of cell actions and not be limited to simple outcome measurements.

- Careful consideration should be given to sample collections (i.e. blood, bronchoalveolar lavage fluid, biopsies, etc.) from already existing clinical trials wherein analyses of these samples might provide insight into potential roles and mechanisms of lung remodeling by adult reparative cells.

- A central coordinating center should be considered to take advantage of and appropriately distribute clinical samples to ensure maximal usefulness.

- The NIH, FDA, and other relevant agencies should work closely together to define parameters for adequate cell product characterization as well as preclinical proof-of-concept and toxicological testing to support the design and supervision of phase 1 and 2 clinical trials.

\section{CONCLUSIONS}

A continuing accumulation of data in both animal models and in clinical trials suggests that cell-based therapies may be potential therapeutic strategies for lung repair and remodeling after injury. In parallel, further understanding of the role of endogenous lung progenitor cells will provide further insight into mechanisms of lung development and repair after injury and may also provide novel therapeutic strategies. It is hoped that the workshop recommendations will spark new research that will provide further understanding of mechanisms of repair of lung injury and further provide a sound scientific basis for therapeutic use of stem and cell therapies in lung diseases.

Conflict of Interest Statement: D.J.W. does not have a financial relationship with a commercial entity that has an interest in the subject of this manuscript. J.K.K. does not have a financial relationship with a commercial entity that has an interest in the subject of this manuscript. L.A.O. does not have a financial relationship with a commercial entity that has an interest in the subject of this manuscript. A.P.-M. does not have a financial relationship with a commercial entity that has an interest in the subject of this manuscript. D.J.P has several patent applications submitted and two U. S. patents issued on mesenchymal stem cells; he has received royalties of less than $\$ 40,000$ a year on several of these through Thomas Jefferson University and Drexel University.

Organizing committee participants are as follows: Zea Borok, M.D., University of Southern California; Diane Krause, M.D., Ph.D., Yale University; Luis Ortiz, M.D., University of Pittsburgh; Darwin J. Prockop, M.D., Ph.D., Tulane University; Jeffrey Spees, Ph.D., University of Vermont; Benjamin T. Suratt, M.D., University of Vermont; Daniel J. Weiss, M.D., Ph.D., University of Vermont.

A list of conference participants, executive summaries of speaker presentations, and poster abstracts are included in the online supplement. 
Acknowledgment: The organizers thank the staffs of the University of Vermont Continuing Medical Education and University of Vermont College of Medicine Communications Offices, notably Terry Caron, Natalie Remillard, Jennifer Nachbur, and Carole Whitaker for organizational support, and Ivan Bertoncello, Carol Blaisdell, Ellen Burnham, Dorothy Gail, Carla Kim, Diane Krause, Bethany Moore, Barry Stripp, and John Thomas for editing and conceptual support for the final conference report.

\section{References}

1. Weiss DJ, Berberich MA, Borok Z, Gail DB, Kolls JK, Penland C, Prockop DJ. Adult stem cells, lung biology, and lung disease. NHLBI/ Cystic Fibrosis Foundation Workshop. Proc Am Thorac Soc 2006;3: 193-207.

2. Brown JK, Hogan BLM, Randell SH, Stripp B, Weiss DJ. Human embryonic stem cell research: an official ATS research policy statement. Am J Respir Crit Care Med 2006;173:1-3.

3. Fisher KA, Summer RS. 4. Stem and progenitor cells in the formation of the pulmonary vasculature. Curr Top Dev Biol 2006;74:117-131.

4. Herzog EL, Krause DS. Engraftment of marrow-derived epithelial cells: the role of fusion. Proc Am Thorac Soc 2006;3:691-695.

5. Liu X, Driskell RR, Engelhardt JF. Stem cells in the lung. Methods Enzymol 2006;419:285-321.

6. Neuringer IP, Randell SH. Lung stem cell update: promise and controversy. Monaldi Arch Chest Dis 2006;65:47-51.

7. Rawlins EL, Hogan BL. Epithelial stem cells of the lung: privileged few or opportunities for many? Development 2006;133:2455-2465.

8. van Haaften T, Thebaud B. Adult bone marrow-derived stem cells for the lung: implications for pediatric lung diseases. Pediatr Res 2006;59: 94R-99R.

9. Yen CC, Yang SH, Lin CY, Chen CM. Stem cells in the lung parenchyma and prospects for lung injury therapy. Eur J Clin Invest 2006;36:310-319.

10. Bellini A, Mattoli S. The role of the fibrocyte, a bone marrow-derived mesenchymal progenitor, in reactive and reparative fibroses. Lab Invest 2007;87:858-870.

11. Flotte TR, Ng P, Dylla DE, McCray PB Jr, Wang G, Kolls JK, Hu J. Viral vector-mediated and cell-based therapies for treatment of cystic fibrosis. Mol Ther 2007;15:229-241.

12. Giangreco A, Groot KR, Janes SM. Lung cancer and lung stem cells: strange bedfellows? Am J Respir Crit Care Med 2007;175:547-553.

13. Gomperts BN, Strieter RM. Fibrocytes in lung disease. J Leukoc Biol 2007;82:449-456.

14. Kim CB. Advancing the field of lung stem cell biology. Front Biosci 2007;12:3117-3124.

15. Kim CF. Paving the road for lung stem cell biology: bronchioalveolar stem cells and other putative distal lung stem cells. Am J Physiol Lung Cell Mol Physiol 2007;293:L1092-L1098.

16. Kotton DN, Fine A. Lung stem cells. Cell Tissue Res 2008:331:145-156.

17. Loebinger MR, Janes SM. Stem cells for lung disease. Chest 2007;132: 279-285.

18. Gharaee-Kermani M, Gyetko MR, Hu B, Phan SH. New insights into the pathogenesis and treatment of idiopathic pulmonary fibrosis: a potential role for stem cells in the lung parenchyma and implications for therapy. Pharm Res 2007;24:819-841.

19. Phinney DG, Prockop DJ. Concise review: mesenchymal stem/multipotent stromal cells: the state of transdifferentiation and modes of tissue repair-current views. Stem Cells 2007;25:2896-2902.

20. Prockop DJ. "Stemness" does not explain the repair of many tissues by mesenchymal stem/multipotent stromal cells (MSCs). Clin Pharmacol Ther 2007;82:241-243.

21. Sueblinvong V, Suratt BT, Weiss DJ. Novel therapies for the treatment of cystic fibrosis: new developments in gene and stem cell therapy. Clin Chest Med 2007;28:361-379.

22. Reynolds SD, Shen H, Reynolds PR, Betsuyaku T, Pilewski JM, Gambelli F, Di Giuseppe M, Ortiz LA, Stripp BR. Molecular and functional properties of lung SP cells. Am J Physiol Lung Cell Mol Physiol 2007;292:L972-L983.

23. Lama VN, Phan SH. The extrapulmonary origin of fibroblasts: stem/ progenitor cells and beyond. Proc Am Thorac Soc 2006;3:373-376.

24. Olsson F, Denham M, Cole TJ, Hooper SB, Mollard R. Deriving respiratory cell types from stem cells. Curr Stem Cell Res Ther 2007;2: 197-208.

25. Kannan S, Wu M. Respiratory stem cells and progenitors: overview, derivation, differentiation, carcinogenesis, regeneration and therapeutic application. Curr Stem Cell Res Ther 2006;1:37-46.

26. Murphy J, Summer R, Fine A. Stem cells in airway smooth muscle: state of the art. Proc Am Thorac Soc 2008;5:11-14.
27. Weiss DJ. Stem cells and cell therapies for cystic fibrosis and other lung diseases. Pulm Pharmacol Ther (In press)

28. Beckett T, Loi R, Prenovitz R, Poynter M, Goncz KK, Suratt BT, Weiss DJ. Acute lung injury with endotoxin or $\mathrm{NO} 2$ does not enhance development of airway epithelium from bone marrow. Mol Ther 2005; 12:680-686.

29. Theise ND, Henegariu O, Grove J, Jagirdar J, Kao PN, Crawford JM, Badve S, Saxena R, Krause DS. Radiation pneumonitis in mice: a severe injury model for pneumocyte engraftment from bone marrow. Exp Hematol 2002;30:1333-1338.

30. Herzog EL, Van Arnam J, Hu B, Krause DS. Threshold of lung injury required for the appearance of marrow-derived lung epithelia. Stem Cells 2006;24:1986-1992.

31. Kotton DN, Fabian AJ, Mulligan RC. Failure of bone marrow to reconstitute lung epithelium. Am J Respir Cell Mol Biol 2005;33:328-334.

32. Chang JC, Summer R, Sun X, Fitzsimmons K, Fine A. Evidence that bone marrow cells do not contribute to the alveolar epithelium. Am J Respir Cell Mol Biol 2005;33:335-342.

33. Swenson ES, Price JG, Brazelton T, Krause DS. Limitations of green fluorescent protein as a cell lineage marker. Stem Cells 2007;25:25932600.

34. Sueblinvong V, Loi R, Eisenhauer PL, Bernstein IM, Suratt BT, Spees JL, Weiss DJ. Derivation of lung epithelium from human cord bloodderived mesenchymal stem cells. Am J Respir Crit Care Med 2008;177: 701-711.

35. Macpherson H, Keir P, Webb S, Samuel K, Boyle S, Bickmore W, Forrester L, Dorin J. Bone marrow-derived SP cells can contribute to the respiratory tract of mice in vivo. J Cell Sci 2005;118:2441-2450.

36. MacPherson H, Keir PA, Edwards CJ, Webb S, Dorin JR. Following damage, the majority of bone marrow-derived airway cells express an epithelial marker. Respir Res 2006;7:145.

37. Loi R, Beckett T, Goncz KK, Suratt BT, Weiss DJ. Limited restoration of cystic fibrosis lung epithelium in vivo with adult bone marrowderived cells. Am J Respir Crit Care Med 2006;173:171-179.

38. Yan C, Lian X, Dai Y, Wang X, Qu P, White A, Qin Y, Du H. Gene delivery by the hSP-B promoter to lung alveolar type II epithelial cells in LAL-knockout mice through bone marrow mesenchymal stem cells. Gene Ther 2007;14:1461-1470.

39. Serikov VB, Popov B, Mikhailov VM, Gupta N, Matthay MA. Evidence of temporary airway epithelial repopulation and rare clonal formation by BM-derived cells following naphthalene injury in mice. Anat Rec (Hoboken) 2007:290:1033-1045.

40. Wong AP, Dutly AE, Sacher A, Lee H, Hwang DM, Liu M, Keshavjee $\mathrm{S}$, Hu J, Waddell TK. Targeted cell replacement with bone marrow cells for airway epithelial regeneration. Am J Physiol Lung Cell Mol Physiol 2007;293:L740-L752.

41. Bruscia EM, Price JE, Cheng EC, Weiner S, Caputo C, Ferreira EC, Egan ME, Krause DS. Assessment of cystic fibrosis transmembrane conductance regulator (CFTR) activity in CFTR-null mice after bone marrow transplantation. Proc Natl Acad Sci USA 2006;103:2965-2970.

42. Bruscia EM, Ziegler EC, Price JE, Weiner S, Egan ME, Krause DS. Engraftment of donor-derived epithelial cells in multiple organs following bone marrow transplantation into newborn mice. Stem Cells 2006;24:2299-2308.

43. Spees JL, Pociask DA, Sullivan DE, Whitney MJ, Lasky JA, Prockop DJ, Brody AR. Engraftment of bone marrow progenitor cells in a rat model of asbestos-induced pulmonary fibrosis. Am J Respir Crit Care Med 2007;176:385-394.

44. Raoul W, Wagner-Ballon O, Saber G, Hulin A, Marcos E, Giraudier S, Vainchenker W, Adnot S, Eddahibi S, Maitre B. Effects of bone marrow-derived cells on monocrotaline- and hypoxia-induced pulmonary hypertension in mice. Respir Res 2007;8:8.

45. Levis J, Loi R, Butnor KJ, Vacek P, Steele C, Mossman BT, Weiss DJ. Decreased asbestos-induced lung inflammation and fibrosis after radiation and bone marrow transplant. Am J Respir Cell Mol Biol 2008;38:16-25.

46. Gupta N, Su X, Popov B, Lee JW, Serikov V, Matthay MA. Intrapulmonary delivery of bone marrow-derived mesenchymal stem cells improves survival and attenuates endotoxin-induced acute lung injury in mice. J Immunol 2007;179:1855-1863.

47. Kucia M, Wysoczynski M, Ratajczak J, Ratajczak MZ. Identification of very small embryonic like (VSEL) stem cells in bone marrow. Cell Tissue Res 2008;331:125-134.

48. Kucia M, Zuba-Surma EK, Wysoczynski M, Wu W, Ratajczak J, Machalinski B, Ratajczak MZ. Adult marrow-derived very small embryonic-like stem cells and tissue engineering. Expert Opin Biol Ther 2007;7:1499-1514. 
49. Gomperts BN, Belperio JA, Rao PN, Randell SH, Fishbein MC, Burdick MD, Strieter RM. Circulating progenitor epithelial cells traffic via CXCR4/CXCL12 in response to airway injury. J Immunol 2006;176:1916-1927.

50. Berger MJ, Adams SD, Tigges BM, Sprague SL, Wang XJ, Collins DP, McKenna DH. Differentiation of umbilical cord blood-derived multilineage progenitor cells into respiratory epithelial cells. Cytotherapy 2006;8:480-487.

51. Meng X, Ichim TE, Zhong J, Rogers A, Yin Z, Jackson J, Wang H, Ge W, Bogin V, Chan KW, et al. Endometrial regenerative cells: a novel stem cell population. J Transl Med 2007;5:57.

52. Miao Z, Jin J, Chen L, Zhu J, Huang W, Zhao J, Qian H, Zhang X. Isolation of mesenchymal stem cells from human placenta: comparison with human bone marrow mesenchymal stem cells. Cell Biol Int 2006;30:681-687.

53. Traktuev DO, Merfeld-Clauss S, Li J, Kolonin M, Arap W, Pasqualini R, Johnstone BH, March KL. A population of multipotent CD34positive adipose stromal cells share pericyte and mesenchymal surface markers, reside in a periendothelial location, and stabilize endothelial networks. Circ Res 2008;102:77-85.

54. Kuang PP, Lucey E, Rishikof DC, Humphries DE, Bronsnick D, Goldstein RH. Engraftment of neonatal lung fibroblasts into the normal and elastase-injured lung. Am J Respir Cell Mol Biol 2005;33: 371-377.

55. Serrano-Mollar A, Nacher M, Gay-Jordi G, Closa D, Xaubet A, Bulbena O. Intratracheal transplantation of alveolar type II cells reverses bleomycin-induced lung fibrosis. Am J Respir Crit Care Med 2007;176:1261-1268.

56. McCarter SD, Mei SH, Lai PF, Zhang QW, Parker CH, Suen RS, Hood RD, Zhao YD, Deng Y, Han RN, et al. Cell-based angiopoietin-1 gene therapy for acute lung injury. Am J Respir Crit Care Med 2007; 175:1014-1026.

57. Spees JL, Olson SD, Ylostalo J, Lynch PJ, Smith J, Perry A, Peister A, Wang MY, Prockop DJ. Differentiation, cell fusion, and nuclear fusion during ex vivo repair of epithelium by human adult stem cells from bone marrow stroma. Proc Natl Acad Sci USA 2003;100:23972402.

58. Harris RG, Herzog EL, Bruscia EM, Grove JE, Van Arnam JS, Krause DS. Lack of a fusion requirement for development of bone marrowderived epithelia. Science 2004;305:90-93.

59. Herzog EL, Van Arnam J, Hu B, Zhang J, Chen Q, Haberman AM, Krause DS. Lung-specific nuclear reprogramming is accompanied by heterokaryon formation and $\mathrm{Y}$ chromosome loss following bone marrow transplantation and secondary inflammation. FASEB J 2007; 21:2592-2601.

60. Yan X, Liu Y, Han Q, Jia M, Liao L, Qi M, Zhao RC. Injured microenvironment directly guides the differentiation of engrafted Flk-1(+) mesenchymal stem cell in lung. Exp Hematol 2007;35:14661475.

61. Kahler CM, Wechselberger J, Hilbe W, Gschwendtner A, Colleselli D, Niederegger H, Boneberg EM, Spizzo G, Wendel A, Gunsilius E, et al. Peripheral infusion of rat bone marrow derived endothelial progenitor cells leads to homing in acute lung injury. Respir Res 2007;8:50.

62. Suzuki H, Hogg JC, van Eeden SF. Sequestration and homing of bone marrow-derived lineage negative progenitor cells in the lung during pneumococcal pneumonia. Respir Res 2008;9:25.

63. Epperly MW, Guo H, Gretton JE, Greenberger JS. Bone marrow origin of myofibroblasts in irradiation pulmonary fibrosis. Am J Respir Cell Mol Biol 2003;29:213-224.

64. Tolar J, O'Shaughnessy MJ, Panoskaltsis-Mortari A, McElmurry RT, Bell S, Riddle M, McIvor RS, Yant SR, Kay MA, Krause D, et al. Host factors that impact the biodistribution and persistence of multipotent adult progenitor cells. Blood 2006;107:4182-4188.

65. Viswanathan A, Painter RG, Lanson NA Jr, Wang G. Functional expression of $\mathrm{N}$-formyl peptide receptors in human bone marrowderived mesenchymal stem cells. Stem Cells 2007;25:1263-1269.

66. Satoh K, Kagaya Y, Nakano M, Ito Y, Ohta J, Tada H, Karibe A, Minegishi N, Suzuki N, Yamamoto M, et al. Important role of endogenous erythropoietin system in recruitment of endothelial progenitor cells in hypoxia-induced pulmonary hypertension in mice. Circulation 2006;113:1442-1450.

67. Son BR, Marquez-Curtis LA, Kucia M, Wysoczynski M, Turner AR, Ratajczak J, Ratajczak MZ, Janowska-Wieczorek A. Migration of bone marrow and cord blood mesenchymal stem cells in vitro is regulated by stromal-derived factor-1-CXCR4 and hepatocyte growth factor-c-met axes and involves matrix metalloproteinases. Stem Cells 2006;24:1254-1264.

68. Popov BV, Serikov VB, Petrov NS, Izusova TV, Gupta N, Matthay MA. Lung epithelial cells induce endodermal differentiation in mouse mesenchymal bone marrow stem cells by paracrine mechanism. Tissue Eng 2007;13:2441-2450.

69. Field-Corbett C, O'Dea S. Soluble signals from mechanically disrupted lung tissue induce lung-related gene expression in bone marrowderived cells in vitro. Stem Cells Dev 2007;16:231-242.

70. Xu J, Woods CR, Mora AL, Joodi R, Brigham KL, Iyer S, Rojas M. Prevention of endotoxin-induced systemic response by bone marrowderived mesenchymal stem cells in mice. Am J Physiol Lung Cell Mol Physiol 2007;293:L131-L141.

71. Ratajczak J, Miekus K, Kucia M, Zhang J, Reca R, Dvorak P, Ratajczak MZ. Embryonic stem cell-derived microvesicles reprogram hematopoietic progenitors: evidence for horizontal transfer of mRNA and protein delivery. Leukemia 2006;20:847-856.

72. Aliotta JM, Sanchez-Guijo FM, Dooner GJ, Johnson KW, Dooner MS, Greer KA, Greer D, Pimentel J, Kolankiewicz LM, Puente N, et al. Alteration of marrow cell gene expression, protein production, and engraftment into lung by lung-derived microvesicles: a novel mechanism for phenotype modulation. Stem Cells 2007;25:2245-2256.

73. Asahara T, Murohara T, Sullivan A, Silver M, van der Zee R, Li T, Witzenbichler B, Schatteman G, Isner JM. Isolation of putative progenitor endothelial cells for angiogenesis. Science 1997;275:964-967.

74. Hristov M, Erl W, Weber PC. Endothelial progenitor cells: mobilization, differentiation, and homing. Arterioscler Thromb Vasc Biol 2003; 23:1185-1189.

75. Asosingh K, Swaidani S, Aronica M, Erzurum SC. Th1- and Th2dependent endothelial progenitor cell recruitment and angiogenic switch in asthma. J Immunol 2007;178:6482-6494.

76. Burnham EL, Taylor WR, Quyyumi AA, Rojas M, Brigham KL, Moss M. Increased circulating endothelial progenitor cells are associated with survival in acute lung injury. Am J Respir Crit Care Med 2005; 172:854-860

77. Yamada M, Kubo H, Ishizawa K, Kobayashi S, Shinkawa M, Sasaki H. Increased circulating endothelial progenitor cells in patients with bacterial pneumonia: evidence that bone marrow derived cells contribute to lung repair. Thorax 2005;60:410-413.

78. Fadini GP, Schiavon M, Cantini M, Baesso I, Facco M, Miorin M, Tassinato M, de Kreutzenberg SV, Avogaro A, Agostini C. Circulating progenitor cells are reduced in patients with severe lung disease. Stem Cells 2006;24:1806-1813.

79. Palange P, Testa U, Huertas A, Calabro L, Antonucci R, Petrucci E, Pelosi E, Pasquini L, Satta A, Morici G, et al. Circulating haemopoietic and endothelial progenitor cells are decreased in COPD. Eur Respir J 2006;27:529-541.

80. Fadini GP, Schiavon M, Rea F, Avogaro A, Agostini C. Depletion of endothelial progenitor cells may link pulmonary fibrosis and pulmonary hypertension. Am J Respir Crit Care Med 2007;176:724-725. [Author reply, p. 725.]

81. Dome B, Timar J, Dobos J, Meszaros L, Raso E, Paku S, Kenessey I, Ostoros G, Magyar M, Ladanyi A, et al. Identification and clinical significance of circulating endothelial progenitor cells in human nonsmall cell lung cancer. Cancer Res 2006;66:7341-7347.

82. Pircher A, Kahler CM, Skvortsov S, Dlaska M, Kawaguchi G, Schmid T, Gunsilius E, Hilbe W. Increased numbers of endothelial progenitor cells in peripheral blood and tumor specimens in non-small cell lung cancer: a methodological challenge and an ongoing debate on the clinical relevance. Oncol Rep 2008;19:345-352.

83. Yoder MC, Mead LE, Prater D, Krier TR, Mroueh KN, Li F, Krasich R, Temm CJ, Prchal JT, Ingram DA. Redefining endothelial progenitor cells via clonal analysis and hematopoietic stem/progenitor cell principals. Blood 2007;109:1801-1809.

84. Yoon CH, Hur J, Park KW, Kim JH, Lee CS, Oh IY, Kim TY, Cho HJ, Kang HJ, Chae IH, et al. Synergistic neovascularization by mixed transplantation of early endothelial progenitor cells and late outgrowth endothelial cells: the role of angiogenic cytokines and matrix metalloproteinases. Circulation 2005;112:1618-1627.

85. Smits PA, Kleppe LS, Witt TA, Mueske CS, Vile RG, Simari RD. Distribution of circulation-derived endothelial progenitors following systemic delivery. Endothelium 2007;14:1-5.

86. Balasubramaniam V, Mervis CF, Maxey AM, Markham NE, Abman $\mathrm{SH}$. Hyperoxia reduces bone marrow, circulating, and lung endothelial progenitor cells in the developing lung: implications for the 
pathogenesis of bronchopulmonary dysplasia. Am J Physiol Lung Cell Mol Physiol 2007;292:L1073-L1084.

87. Scheubel RJ, Zorn H, Silber RE, Kuss O, Morawietz H, Holtz J, Simm A. Age-dependent depression in circulating endothelial progenitor cells in patients undergoing coronary artery bypass grafting. $J$ Am Coll Cardiol 2003;42:2073-2080.

88. Chang EI, Loh SA, Ceradini DJ, Chang EI, Lin SE, Bastidas N, Aarabi S, Chan DA, Freedman ML, Giaccia AJ, et al. Age decreases endothelial progenitor cell recruitment through decreases in hypoxiainducible factor 1alpha stabilization during ischemia. Circulation 2007:116:2818-2829.

89. Llevadot J, Murasawa S, Kureishi Y, Uchida S, Masuda H, Kawamoto A, Walsh K, Isner JM, Asahara T. HMG-CoA reductase inhibitor mobilizes bone marrow-derived endothelial progenitor cells. J Clin Invest 2001;108:399-405.

90. Henrich D, Seebach C, Wilhelm K, Marzi I. High dosage of simvastatin reduces TNF-alpha-induced apoptosis of endothelial progenitor cells but fails to prevent apoptosis induced by IL-1beta in vitro. J Surg Res 2007;142:13-19.

91. Hilbe W, Dirnhofer S, Oberwasserlechner F, Schmid T, Gunsilius E, Hilbe G, Woll E, Kahler CM. CD133 positive endothelial progenitor cells contribute to the tumour vasculature in non-small cell lung cancer. J Clin Pathol 2004;57:965-969.

92. Arap W, Pasqualini R. Engineered embryonic endothelial progenitor cells as therapeutic Trojan horses. Cancer Cell 2004;5: 406-408.

93. Wei J, Blum S, Unger M, Jarmy G, Lamparter M, Geishauser A, Vlastos GA, Chan G, Fischer KD, Rattat D, et al. Embryonic endothelial progenitor cells armed with a suicide gene target hypoxic lung metastases after intravenous delivery. Cancer Cell 2004;5:477-488.

94. Aghi M, Chiocca EA. Contribution of bone marrow-derived cells to blood vessels in ischemic tissues and tumors. Mol Ther 2005;12:994-1005.

95. Aghi M, Cohen KS, Klein RJ, Scadden DT, Chiocca EA. Tumor stromal-derived factor-1 recruits vascular progenitors to mitotic neovasculature, where microenvironment influences their differentiated phenotypes. Cancer Res 2006;66:9054-9064.

96. Oh HK, Ha JM, Enju O, Lee BH, Lee SK, Shim BS, Hong YK, Joe YA. Tumor angiogenesis promoted by ex vivo differentiated endothelial progenitor cells is effectively inhibited by an angiogenesis inhibitor, TK1-2. Cancer Res 2007;67:4851-4859.

97. Nolan DJ, Ciarrocchi A, Mellick AS, Jaggi JS, Bambino K, Gupta S, Heikamp E, McDevitt MR, Scheinberg DA, Benezra R, et al. Bone marrow-derived endothelial progenitor cells are a major determinant of nascent tumor neovascularization. Genes Dev 2007;21:1546-1558.

98. Gao D, Nolan DJ, Mellick AS, Bambino K, McDonnell K, Mittal V. Endothelial progenitor cells control the angiogenic switch in mouse lung metastasis. Science 2008;319:195-198.

99. Nagaya N, Kangawa K, Kanda M, Uematsu M, Horio T, Fukuyama N, Hino J, Harada-Shiba M, Okumura H, Tabata Y, et al. Hybrid cellgene therapy for pulmonary hypertension based on phagocytosing action of endothelial progenitor cells. Circulation 2003;108:889-895.

100. Takahashi M, Nakamura T, Toba T, Kajiwara N, Kato H, Shimizu Y. Transplantation of endothelial progenitor cells into the lung to alleviate pulmonary hypertension in dogs. Tissue Eng 2004;10:771-779.

101. Zhao Q, Liu Z, Wang Z, Yang C, Liu J, Lu J. Effect of preprocalcitonin gene-related peptide-expressing endothelial progenitor cells on pulmonary hypertension. Ann Thorac Surg 2007;84:544-552.

102. Zhao YD, Courtman DW, Deng Y, Kugathasan L, Zhang Q, Stewart DJ. Rescue of monocrotaline-induced pulmonary arterial hypertension using bone marrow-derived endothelial-like progenitor cells: efficacy of combined cell and eNOS gene therapy in established disease. Circ Res 2005;96:442-450.

103. Wang XX, Zhang FR, Shang YP, Zhu JH, Xie XD, Tao QM, Zhu JH, Chen JZ. Transplantation of autologous endothelial progenitor cells may be beneficial in patients with idiopathic pulmonary arterial hypertension: a pilot randomized controlled trial. J Am Coll Cardiol 2007;49:1566-1571.

104. Bucala R, Spiegel LA, Chesney J, Hogan M, Cerami A. Circulating fibrocytes define a new leukocyte subpopulation that mediates tissue repair. Mol Med 1994;1:71-81.

105. Chesney J, Bucala R. Peripheral blood fibrocytes: mesenchymal precursor cells and the pathogenesis of fibrosis. Curr Rheumatol Rep 2000;2:501-505

106. Schmidt M, Sun G, Stacey MA, Mori L, Mattoli S. Identification of circulating fibrocytes as precursors of bronchial myofibroblasts in asthma. J Immunol 2003;171:380-389.
107. Nihlberg K, Larsen K, Hultgardh-Nilsson A, Malmstrom A, Bjermer L, Westergren-Thorsson G. Tissue fibrocytes in patients with mild asthma: a possible link to thickness of reticular basement membrane? Respir Res 2006;7:50.

108. Brocker V, Langer F, Fellous TG, Mengel M, Brittan M, Bredt M, Milde S, Welte T, Eder M, Haverich A, et al. Fibroblasts of recipient origin contribute to bronchiolitis obliterans in human lung transplants. Am J Respir Crit Care Med 2006;173:1276-1282.

109. Phillips RJ, Burdick MD, Hong K, Lutz MA, Murray LA, Xue YY, Belperio JA, Keane MP, Strieter RM. Circulating fibrocytes traffic to the lungs in response to CXCL12 and mediate fibrosis. $J$ Clin Invest 2004; $114: 438-446$.

110. Moore BB, Murray L, Das A, Wilke CA, Herrygers AB, Toews GB. The role of CCL12 in the recruitment of fibrocytes and lung fibrosis. Am J Respir Cell Mol Biol 2006;35:175-181.

111. Moore BB, Kolodsick JE, Thannickal VJ, Cooke K, Moore TA, Hogaboam C, Wilke CA, Toews GB. CCR2-mediated recruitment of fibrocytes to the alveolar space after fibrotic injury. Am J Pathol 2005; $166: 675-684$

112. Ishida $\mathrm{Y}$, Kimura A, Kondo T, Hayashi T, Ueno M, Takakura N, Matsushima K, Mukaida N. Essential roles of the CC chemokine ligand 3-CC chemokine receptor 5 axis in bleomycin-induced pulmonary fibrosis through regulation of macrophage and fibrocyte infiltration. Am J Pathol 2007;170:843-854.

113. Larsen K, Macleod D, Nihlberg K, Gurcan E, Bjermer L, Marko-Varga G, Westergren-Thorsson G. Specific haptoglobin expression in bronchoalveolar lavage during differentiation of circulating fibroblast progenitor cells in mild asthma. $J$ Proteome Res 2006;5:1479-1483.

114. Vannella KM, McMillan TR, Charbeneau RP, Wilke CA, Thomas PE, Toews GB, Peters-Golden M, Moore BB. Cysteinyl leukotrienes are autocrine and paracrine regulators of fibrocyte function. $J$ Immunol 2007;179:7883-7890.

115. Mehrad B, Burdick MD, Zisman DA, Keane MP, Belperio JA, Strieter RM. Circulating peripheral blood fibrocytes in human fibrotic interstitial lung disease. Biochem Biophys Res Commun 2007;353:104-108.

116. Frid MG, Brunetti JA, Burke DL, Carpenter TC, Davie NJ, Reeves JT, Roedersheimer MT, van Rooijen N, Stenmark KR. Hypoxia-induced pulmonary vascular remodeling requires recruitment of circulating mesenchymal precursors of a monocyte/macrophage lineage. Am J Pathol 2006;168:659-669.

117. Ishii G, Ito TK, Aoyagi K, Fujimoto H, Chiba H, Hasebe T, Fujii S, Nagai K, Sasaki H, Ochiai A. Presence of human circulating progenitor cells for cancer stromal fibroblasts in the blood of lung cancer patients. Stem Cells 2007;25:1469-1477.

118. Direkze NC, Hodivala-Dilke K, Jeffery R, Hunt T, Poulsom R, Oukrif $\mathrm{D}$, Alison MR, Wright NA. Bone marrow contribution to tumorassociated myofibroblasts and fibroblasts. Cancer Res 2004;64:84928495.

119. Friedenstein AJ, Gorskaja JF, Kulagina NN. Fibroblast precursors in normal and irradiated mouse hematopoietic organs. Exp Hematol 1976;4:267-274.

120. Caplan AI. Osteogenesis imperfecta, rehabilitation medicine, fundamental research and mesenchymal stem cells. Connect Tissue Res 1995;31:S9-S14

121. Dominici M, Le Blanc K, Mueller I, Slaper-Cortenbach I, Marini F, Krause D, Deans R, Keating A, Prockop D, Horwitz E. Minimal criteria for defining multipotent mesenchymal stromal cells: the International Society for Cellular Therapy position statement. Cytotherapy 2006:8:315-317.

122. Lee OK, Kuo TK, Chen WM, Lee KD, Hsieh SL, Chen TH. Isolation of multipotent mesenchymal stem cells from umbilical cord blood. Blood 2004;103:1669-1675.

123. Lee MW, Choi J, Yang MS, Moon YJ, Park JS, Kim HC, Kim YJ. Mesenchymal stem cells from cryopreserved human umbilical cord blood. Biochem Biophys Res Commun 2004;320:273-278.

124. Bieback K, Kern S, Kluter H, Eichler H. Critical parameters for the isolation of mesenchymal stem cells from umbilical cord blood. Stem Cells 2004;22:625-634.

125. Wang HS, Hung SC, Peng ST, Huang CC, Wei HM, Guo YJ, Fu YS, Lai MC, Chen CC. Mesenchymal stem cells in the Wharton's jelly of the human umbilical cord. Stem Cells 2004;22:1330-1337.

126. Fukuchi Y, Nakajima H, Sugiyama D, Hirose I, Kitamura T, Tsuji K. Human placenta-derived cells have mesenchymal stem/progenitor cell potential. Stem Cells 2004;22:649-658.

127. Li D, Wang GY, Dong BH, Zhang YC, Wang YX, Sun BC. Biological characteristics of human placental mesenchymal stem cells and their 
proliferative response to various cytokines. Cells Tissues Organs 2007; 186:169-179.

128. Puissant B, Barreau C, Bourin P, Clavel C, Corre J, Bousquet C, Taureau C, Cousin B, Abbal M, Laharrague P, et al. Immunomodulatory effect of human adipose tissue-derived adult stem cells: comparison with bone marrow mesenchymal stem cells. Br J Haematol 2005;129:118-129.

129. Yanez R, Lamana ML, Garcia-Castro J, Colmenero I, Ramirez M, Bueren JA. Adipose tissue-derived mesenchymal stem cells have in vivo immunosuppressive properties applicable for the control of the graft-versus-host disease. Stem Cells 2006;24:2582-2591.

130. Summer R, Fitzsimmons K, Dwyer D, Murphy J, Fine A. Isolation of an adult mouse lung mesenchymal progenitor cell population. Am J Respir Cell Mol Biol 2007;37:152-159.

131. Hennrick KT, Keeton AG, Nanua S, Kijek TG, Goldsmith AM, Sajjan US, Bentley JK, Lama VN, Moore BB, Schumacher RE, et al. Lung cells from neonates show a mesenchymal stem cell phenotype. Am J Respir Crit Care Med 2007;175:1158-1164.

132. Lama VN, Smith L, Badri L, Flint A, Andrei AC, Murray S, Wang Z, Liao H, Toews GB, Krebsbach PH, et al. Evidence for tissue-resident mesenchymal stem cells in human adult lung from studies of transplanted allografts. J Clin Invest 2007;117:989-996.

133. Sabatini F, Petecchia L, Tavian M, Jodon de Villeroche V, Rossi GA, Brouty-Boye D. Human bronchial fibroblasts exhibit a mesenchymal stem cell phenotype and multilineage differentiating potentialities. Lab Invest 2005;85:962-971.

134. Martin JHK, Ruegg P, Varella-Garcia M, Burnham E, Majka S. Adult lung side population cells have mesenchymal stem cell potential. Cytotherapy 2008;10:140-151.

135. Kern S, Eichler H, Stoeve J, Kluter H, Bieback K. Comparative analysis of mesenchymal stem cells from bone marrow, umbilical cord blood, or adipose tissue. Stem Cells 2006;24:1294-1301.

136. Chang YJ, Shih DT, Tseng CP, Hsieh TB, Lee DC, Hwang SM. Disparate mesenchyme-lineage tendencies in mesenchymal stem cells from human bone marrow and umbilical cord blood. Stem Cells 2006; 24:679-685.

137. Tsai MS, Hwang SM, Chen KD, Lee YS, Hsu LW, Chang YJ, Wang CN, Peng HH, Chang YL, Chao AS, et al. Functional network analysis of the transcriptomes of mesenchymal stem cells derived from amniotic fluid, amniotic membrane, cord blood, and bone marrow. Stem Cells 2007;25:2511-2523.

138. Bernardo ME, Emons JA, Karperien M, Nauta AJ, Willemze R, Roelofs H, Romeo S, Marchini A, Rappold GA, Vukicevic S, et al. Human mesenchymal stem cells derived from bone marrow display a better chondrogenic differentiation compared with other sources. Connect Tissue Res 2007;48:132-140.

139. Panepucci RA, Siufi JL, Silva WA Jr, Proto-Siquiera R, Neder L, Orellana M, Rocha V, Covas DT, Zago MA. Comparison of gene expression of umbilical cord vein and bone marrow-derived mesenchymal stem cells. Stem Cells 2004;22:1263-1278.

140. De Ugarte DA, Morizono K, Elbarbary A, Alfonso Z, Zuk PA, Zhu M, Dragoo JL, Ashjian P, Thomas B, Benhaim P, et al. Comparison of multi-lineage cells from human adipose tissue and bone marrow. Cells Tissues Organs 2003;174:101-109.

141. Keyser KA, Beagles KE, Kiem HP. Comparison of mesenchymal stem cells from different tissues to suppress T-cell activation. Cell Transplant 2007;16:555-562.

142. Kunisaki SM, Fuchs JR, Steigman SA, Fauza DO. A comparative analysis of cartilage engineered from different perinatal mesenchymal progenitor cells. Tissue Eng 2007;13:2633-2644.

143. Haynesworth SE, Baber MA, Caplan AI. Cytokine expression by human marrow-derived mesenchymal progenitor cells in vitro: effects of dexamethasone and IL-1 alpha. J Cell Physiol 1996;166:585-592.

144. Grayson WL, Zhao F, Izadpanah R, Bunnell B, Ma T. Effects of hypoxia on human mesenchymal stem cell expansion and plasticity in 3D constructs. J Cell Physiol 2006;207:331-339.

145. Stolzing A, Scutt A. Effect of reduced culture temperature on antioxidant defences of mesenchymal stem cells. Free Radic Biol Med 2006; $41: 326-338$.

146. Lisignoli G, Cristino S, Piacentini A, Cavallo C, Caplan AI, Facchini A. Hyaluronan-based polymer scaffold modulates the expression of inflammatory and degradative factors in mesenchymal stem cells: Involvement of CD44 and CD54. J Cell Physiol 2006;207:364-373.

147. Engler AJ, Sen S, Sweeney HL, Discher DE. Matrix elasticity directs stem cell lineage specification. Cell 2006;126:677-689.
148. Gregory CA, Ylostalo J, Prockop DJ. Adult bone marrow stem/ progenitor cells (MSCs) are preconditioned by microenvironmental "niches" in culture: a two-stage hypothesis for regulation of MSC fate. Sci STKE 2005;2005:pe37.

149. Lee RH, Hsu SC, Munoz J, Jung JS, Lee NR, Pochampally R, Prockop DJ. A subset of human rapidly self-renewing marrow stromal cells preferentially engraft in mice. Blood 2006;107:2153-2161.

150. Crigler L, Robey RC, Asawachaicharn A, Gaupp D, Phinney DG. Human mesenchymal stem cell subpopulations express a variety of neuro-regulatory molecules and promote neuronal cell survival and neuritogenesis. Exp Neurol 2006;198:54-64.

151. Phinney DG. Biochemical heterogeneity of mesenchymal stem cell populations: clues to their therapeutic efficacy. Cell Cycle 2007;6:28842889.

152. Ortiz LA, Gambelli F, McBride C, Gaupp D, Baddoo M, Kaminski N, Phinney DG. Mesenchymal stem cell engraftment in lung is enhanced in response to bleomycin exposure and ameliorates its fibrotic effects. Proc Natl Acad Sci USA 2003;100:8407-8411.

153. Ortiz LA, Dutreil M, Fattman C, Pandey AC, Torres G, Go K, Phinney DG. Interleukin 1 receptor antagonist mediates the antiinflammatory and antifibrotic effect of mesenchymal stem cells during lung injury. Proc Natl Acad Sci USA 2007;104:11002-11007.

154. Mei SH, McCarter SD, Deng Y, Parker CH, Liles WC, Stewart DJ. Prevention of LPS-induced acute lung injury in mice by mesenchymal stem cells overexpressing angiopoietin 1. PLoS Med 2007;4:e269.

155. Xu J, Qu J, Cao L, Sai Y, Chen C, He L, Yu L. Mesenchymal stem cellbased angiopoietin-1 gene therapy for acute lung injury induced by lipopolysaccharide in mice. $J$ Pathol 2008;214:472-481.

156. Baber SR, Deng W, Master RG, Bunnell BA, Taylor BK, Murthy SN, Hyman AL, Kadowitz PJ. Intratracheal mesenchymal stem cell administration attenuates monocrotaline-induced pulmonary hypertension and endothelial dysfunction. Am J Physiol Heart Circ Physiol 2007;292: H1120-H1128.

157. Shigemura N, Okumura M, Mizuno S, Imanishi Y, Matsuyama A, Shiono H, Nakamura T, Sawa Y. Lung tissue engineering technique with adipose stromal cells improves surgical outcome for pulmonary emphysema. Am J Respir Crit Care Med 2006;174:1199-1205.

158. Stagg J. Immune regulation by mesenchymal stem cells: two sides to the coin. Tissue Antigens 2007;69:1-9.

159. Keating A. Mesenchymal stromal cells. Curr Opin Hematol 2006;13: 419-425.

160. Rasmusson I. Immune modulation by mesenchymal stem cells. Exp Cell Res 2006;312:2169-2179.

161. Phinney DG, Hill K, Michelson C, DuTreil M, Hughes C, Humphries S, Wilkinson R, Baddoo M, Bayly E. Biological activities encoded by the murine mesenchymal stem cell transcriptome provide a basis for their developmental potential and broad therapeutic efficacy. Stem Cells 2006;24:186-198.

162. Pevsner-Fischer M, Morad V, Cohen-Sfady M, Rousso-Noori L, ZaninZhorov A, Cohen S, Cohen IR, Zipori D. Toll-like receptors and their ligands control mesenchymal stem cell functions. Blood 2007;109: 1422-1432.

163. Huang W, La Russa V, Alzoubi A, Schwarzenberger P. Interleukin17A: a T-cell-derived growth factor for murine and human mesenchymal stem cells. Stem Cells 2006;24:1512-1518.

164. Nauta AJ, Fibbe WE. Immunomodulatory properties of mesenchymal stromal cells. Blood 2007;110:3499-3506.

165. Di Nicola M, Carlo-Stella C, Magni M, Milanesi M, Longoni PD, Matteucci P, Grisanti S, Gianni AM. Human bone marrow stromal cells suppress T-lymphocyte proliferation induced by cellular or nonspecific mitogenic stimuli. Blood 2002;99:3838-3843.

166. Bartholomew A, Sturgeon C, Siatskas M, Ferrer K, McIntosh K, Patil S, Hardy W, Devine S, Ucker D, Deans R, et al. Mesenchymal stem cells suppress lymphocyte proliferation in vitro and prolong skin graft survival in vivo. Exp Hematol 2002;30:42-48.

167. Krampera M, Glennie S, Dyson J, Scott D, Laylor R, Simpson E, Dazzi F. Bone marrow mesenchymal stem cells inhibit the response of naive and memory antigen-specific T cells to their cognate peptide. Blood 2003;101:3722-3729.

168. Klyushnenkova E, Mosca JD, Zernetkina V, Majumdar MK, Beggs KJ, Simonetti DW, Deans RJ, McIntosh KR. T cell responses to allogeneic human mesenchymal stem cells: immunogenicity, tolerance, and suppression. J Biomed Sci 2005;12:47-57.

169. Aggarwal S, Pittenger MF. Human mesenchymal stem cells modulate allogeneic immune cell responses. Blood 2005;105:1815-1822. 
170. Le Blanc K, Rasmusson I, Gotherstrom C, Seidel C, Sundberg B, Sundin M, Rosendahl K, Tammik C, Ringden O. Mesenchymal stem cells inhibit the expression of CD25 (interleukin-2 receptor) and CD38 on phytohaemagglutinin-activated lymphocytes. Scand J Immunol 2004;60:307-315.

171. Rasmusson I, Ringden O, Sundberg B, Le Blanc K. Mesenchymal stem cells inhibit lymphocyte proliferation by mitogens and alloantigens by different mechanisms. Exp Cell Res 2005;305:33-41.

172. Rasmusson I, Ringden O, Sundberg B, Le Blanc K. Mesenchymal stem cells inhibit the formation of cytotoxic $\mathrm{T}$ lymphocytes, but not activated cytotoxic $\mathrm{T}$ lymphocytes or natural killer cells. Transplantation 2003;76:1208-1213.

173. Beyth S, Borovsky Z, Mevorach D, Liebergall M, Gazit Z, Aslan H, Galun E, Rachmilewitz J. Human mesenchymal stem cells alter antigen-presenting cell maturation and induce T-cell unresponsiveness. Blood 2005;105:2214-2219.

174. Meisel R, Zibert A, Laryea M, Gobel U, Daubener W, Dilloo D. Human bone marrow stromal cells inhibit allogeneic T-cell responses by indoleamine 2,3-dioxygenase-mediated tryptophan degradation. Blood 2004;103:4619-4621.

175. Deng W, Han Q, Liao L, You S, Deng H, Zhao RC. Effects of allogeneic bone marrow-derived mesenchymal stem cells on $\mathrm{T}$ and $\mathrm{B}$ lymphocytes from BXSB mice. DNA Cell Biol 2005;24:458-463.

176. Spaggiari GM, Capobianco A, Abdelrazik H, Becchetti F, Mingari MC, Moretta L. Mesenchymal stem cells inhibit natural killer-cell proliferation, cytotoxicity, and cytokine production: role of indoleamine 2,3-dioxygenase and prostaglandin E2. Blood 2008;111:13271333.

177. Chabannes D, Hill M, Merieau E, Rossignol J, Brion R, Soulillou JP, Anegon I, Cuturi MC. A role for heme oxygenase-1 in the immunosuppressive effect of adult rat and human mesenchymal stem cells. Blood 2007;110:3691-3694.

178. Nauta AJ, Kruisselbrink AB, Lurvink E, Willemze R, Fibbe WE. Mesenchymal stem cells inhibit generation and function of both CD34+-derived and monocyte-derived dendritic cells. J Immunol 2006; 177:2080-2087.

179. Nasef A, Mathieu N, Chapel A, Frick J, Francois S, Mazurier C, Boutarfa A, Bouchet S, Gorin NC, Thierry D, et al. Immunosuppressive effects of mesenchymal stem cells: involvement of HLA-G. Transplantation 2007;84:231-237.

180. Nauta AJ, Westerhuis G, Kruisselbrink AB, Lurvink EG, Willemze R, Fibbe WE. Donor-derived mesenchymal stem cells are immunogenic in an allogeneic host and stimulate donor graft rejection in a nonmyeloablative setting. Blood 2006;108:2114-2120.

181. Le Blanc K, Rasmusson I, Sundberg B, Gotherstrom C, Hassan M, Uzunel M, Ringden O. Treatment of severe acute graft-versus-host disease with third party haploidentical mesenchymal stem cells. Lancet 2004:363:1439-1441.

182. Ringden O, Uzunel M, Rasmusson I, Remberger M, Sundberg B, Lonnies H, Marschall HU, Dlugosz A, Szakos A, Hassan Z, et al. Mesenchymal stem cells for treatment of therapy-resistant graftversus-host disease. Transplantation 2006;81:1390-1397.

183. Lazarus HM, Koc ON, Devine SM, Curtin P, Maziarz RT, Holland HK, Shpall EJ, McCarthy P, Atkinson K, Cooper BW, et al. Cotransplantation of HLA-identical sibling culture-expanded mesenchymal stem cells and hematopoietic stem cells in hematologic malignancy patients. Biol Blood Marrow Transplant 2005;11:389-398.

184. Fang B, Song YP, Liao LM, Han Q, Zhao RC. Treatment of severe therapy-resistant acute graft-versus-host disease with human adipose tissue-derived mesenchymal stem cells. Bone Marrow Transplant 2006:38:389-390.

185. Le Blanc K, Samuelsson H, Gustafsson B, Remberger M, Sundberg B, Arvidson J, Ljungman P, Lonnies H, Nava S, Ringden O. Transplantation of mesenchymal stem cells to enhance engraftment of hematopoietic stem cells. Leukemia 2007;21:1733-1738.

186. Ball LM, Bernardo ME, Roelofs H, Lankester A, Cometa A, Egeler RM, Locatelli F, Fibbe WE. Cotransplantation of ex vivo expanded mesenchymal stem cells accelerates lymphocyte recovery and may reduce the risk of graft failure in haploidentical hematopoietic stemcell transplantation. Blood 2007;110:2764-2767.

187. Osiris Therapeutics, Inc. Prochymal clinical trial information for the treatment of acute GVHD [Internet]. Available from: http://www. osiris.com/clinical_trials_prochymal_phaseII.php

188. Giordano A, Galderisi U, Marino IR. From the laboratory bench to the patient's bedside: an update on clinical trials with mesenchymal stem cells. J Cell Physiol 2007;211:27-35.
189. Pereboeva L, Komarova S, Mikheeva G, Krasnykh V, Curiel DT. Approaches to utilize mesenchymal progenitor cells as cellular vehicles. Stem Cells 2003;21:389-404.

190. Komarova S, Kawakami Y, Stoff-Khalili MA, Curiel DT, Pereboeva L. Mesenchymal progenitor cells as cellular vehicles for delivery of oncolytic adenoviruses. Mol Cancer Ther 2006;5:755-766.

191. Kurozumi K, Nakamura K, Tamiya T, Kawano Y, Ishii K, Kobune M, Hirai S, Uchida H, Sasaki K, Ito Y, et al. Mesenchymal stem cells that produce neurotrophic factors reduce ischemic damage in the rat middle cerebral artery occlusion model. Mol Ther 2005;11:96-104.

192. Zachos T, Diggs A, Weisbrode S, Bartlett J, Bertone A. Mesenchymal stem cell-mediated gene delivery of bone morphogenetic protein-2 in an articular fracture model. Mol Ther 2007:15:1543-1550.

193. Yu Y, Yao AH, Chen N, Pu LY, Fan Y, Lv L, Sun BC, Li GQ, Wang $\mathrm{XH}$. Mesenchymal stem cells over-expressing hepatocyte growth factor improve small-for-size liver grafts regeneration. Mol Ther 2007;15:1382-1389.

194. Studeny M, Marini FC, Dembinski JL, Zompetta C, Cabreira-Hansen M, Bekele BN, Champlin RE, Andreeff M. Mesenchymal stem cells: potential precursors for tumor stroma and targeted-delivery vehicles for anticancer agents. J Natl Cancer Inst 2004:96:1593-1603.

195. Hall B, Dembinski J, Sasser AK, Studeny M, Andreeff M, Marini F. Mesenchymal stem cells in cancer: tumor-associated fibroblasts and cell-based delivery vehicles. Int J Hematol 2007;86:8-16.

196. Stoff-Khalili MA, Rivera AA, Mathis JM, Banerjee NS, Moon AS, Hess A, Rocconi RP, Numnum TM, Everts M, Chow LT, et al. Mesenchymal stem cells as a vehicle for targeted delivery of CRAds to lung metastases of breast carcinoma. Breast Cancer Res Treat 2007; 105:157-167.

197. Miletic H, Fischer Y, Litwak S, Giroglou T, Waerzeggers Y, Winkeler A, Li H, Himmelreich U, Lange C, Stenzel W, et al. Bystander killing of malignant glioma by bone marrow-derived tumor-infiltrating progenitor cells expressing a suicide gene. Mol Ther 2007;15:1373-1381.

198. Xin H, Kanehira M, Mizuguchi H, Hayakawa T, Kikuchi T, Nukiwa T, Saijo Y. Targeted delivery of CX3CL1 to multiple lung tumors by mesenchymal stem cells. Stem Cells 2007;25:1618-1626.

199. Rachakatla RS, Marini F, Weiss ML, Tamura M, Troyer D. Development of human umbilical cord matrix stem cell-based gene therapy for experimental lung tumors. Cancer Gene Ther 2007;14:828-835.

200. Kanehira M, Xin H, Hoshino K, Maemondo M, Mizuguchi H, Hayakawa T, Matsumoto K, Nakamura T, Nukiwa T, Saijo Y. Targeted delivery of NK4 to multiple lung tumors by bone marrow-derived mesenchymal stem cells. Cancer Gene Ther 2007;14:894-903.

201. Hakkarainen T, Sarkioja M, Lehenkari P, Miettinen S, Ylikomi T, Suuronen R, Desmond RA, Kanerva A, Hemminki A. Human mesenchymal stem cells lack tumor tropism but enhance the antitumor activity of oncolytic adenoviruses in orthotopic lung and breast tumors. Hum Gene Ther 2007;18:627-641.

202. Karnoub AE, Dash AB, Vo AP, Sullivan A, Brooks MW, Bell GW, Richardson AL, Polyak K, Tubo R, Weinberg RA. Mesenchymal stem cells within tumour stroma promote breast cancer metastasis. Nature 2007;449:557-563

203. Avital I, Moreira AL, Klimstra DS, Leversha M, Papadopoulos EB, Brennan M, Downey RJ. Donor-derived human bone marrow cells contribute to solid organ cancers developing after bone marrow transplantation. Stem Cells 2007;25:2903-2909.

204. Djouad F, Bony C, Apparailly F, Louis-Plence P, Jorgensen C, Noel D. Earlier onset of syngeneic tumors in the presence of mesenchymal stem cells. Transplantation 2006;82:1060-1066.

205. Houghton J, Stoicov C, Nomura S, Rogers AB, Carlson J, Li H, Cai X, Fox JG, Goldenring JR, Wang TC. Gastric cancer originating from bone marrow-derived cells. Science 2004;306:1568-1571.

206. Cogle CR, Theise ND, Fu D, Ucar D, Lee S, Guthrie SM, Lonergan J, Rybka W, Krause DS, Scott EW. Bone marrow contributes to epithelial cancers in mice and humans as developmental mimicry. Stem Cells 2007;25:1881-1887.

207. Horwitz EM, Prockop DJ, Gordon PL, Koo WW, Fitzpatrick LA, Neel MD, McCarville ME, Orchard PJ, Pyeritz RE, Brenner MK. Clinical responses to bone marrow transplantation in children with severe osteogenesis imperfecta. Blood 2001;97:1227-1231.

208. Spees JL, Gregory CA, Singh H, Tucker HA, Peister A, Lynch PJ, Hsu SC, Smith J, Prockop DJ. Internalized antigens must be removed to prepare hypoimmunogenic mesenchymal stem cells for cell and gene therapy. Mol Ther 2004;9:747-756.

209. Gregory CA, Reyes E, Whitney MJ, Spees JL. Enhanced engraftment of mesenchymal stem cells in a cutaneous wound model by culture in 
allogenic species-specific serum and administration in fibrin constructs. Stem Cells 2006;24:2232-2243.

210. Muller I, Kordowich S, Holzwarth C, Spano C, Isensee G, Staiber A, Viebahn S, Gieseke F, Langer H, Gawaz MP, et al. Animal serum-free culture conditions for isolation and expansion of multipotent mesenchymal stromal cells from human BM. Cytotherapy 2006;8:437-444.

211. Bernardo ME, Avanzini MA, Perotti C, Cometa AM, Moretta A, Lenta E, Del Fante C, Novara F, de Silvestri A, Amendola G, et al. Optimization of in vitro expansion of human multipotent mesenchymal stromal cells for cell-therapy approaches: further insights in the search for a fetal calf serum substitute. J Cell Physiol 2007;211:121-130.

212. Aguilar S, Nye E, Chan J, Loebinger M, Spencer-Dene B, Fisk N, Stamp G, Bonnet D, Janes SM. Murine but not human mesenchymal stem cells generate osteosarcoma-like lesions in the lung. Stem Cells 2007;25:1586-1594.

213. Schrepfer S, Deuse T, Reichenspurner H, Fischbein MP, Robbins RC, Pelletier MP. Stem cell transplantation: the lung barrier. Transplant Proc 2007;39:573-576.

214. Tolar J, Nauta AJ, Osborn MJ, Panoskaltsis Mortari A, McElmurry RT, Bell S, Xia L, Zhou N, Riddle M, Schroeder TM, et al. Sarcoma derived from cultured mesenchymal stem cells. Stem Cells 2007;25: 371-379.

215. Bernardo ME, Zaffaroni N, Novara F, Cometa AM, Avanzini MA, Moretta A, Montagna D, Maccario R, Villa R, Daidone MG, et al. Human bone marrow derived mesenchymal stem cells do not undergo transformation after long-term in vitro culture and do not exhibit telomere maintenance mechanisms. Cancer Res 2007;67:9142-9149.

216. Rubin H. Multistage carcinogenesis in cell culture. Dev Biol (Basel) 2001;106:61-66. [Discussion, pp. 67, 143-160.]

217. Rubio D, Garcia S, Paz MF, De la Cueva T, Lopez-Fernandez LA, Lloyd AC, Garcia-Castro J, Bernad A. Molecular characterization of spontaneous mesenchymal stem cell transformation. PLoS ONE 2008;3:e1398.

218. Rubio D, Garcia-Castro J, Martin MC, de la Fuente R, Cigudosa JC, Lloyd AC, Bernad A. Spontaneous human adult stem cell transformation. Cancer Res 2005;65:3035-3039.

219. Kunisaki SM, Armant M, Kao GS, Stevenson K, Kim H, Fauza DO. Tissue engineering from human mesenchymal amniocytes: a prelude to clinical trials. J Pediatr Surg 2007;42:974-979. [Discussion, pp. 979-980.]

220. Kunisaki SM, Jennings RW, Fauza DO. Fetal cartilage engineering from amniotic mesenchymal progenitor cells. Stem Cells Dev 2006;15: $245-253$.

221. Kunisaki SM, Freedman DA, Fauza DO. Fetal tracheal reconstruction with cartilaginous grafts engineered from mesenchymal amniocytes. J Pediatr Surg 2006;41:675-682. [Discussion, pp. 675-682.]

222. Kunisaki SM, Fuchs JR, Kaviani A, Oh JT, LaVan DA, Vacanti JP, Wilson JM, Fauza DO. Diaphragmatic repair through fetal tissue engineering: a comparison between mesenchymal amniocyte- and myoblast-based constructs. J Pediatr Surg 2006;41:34-39. [Discussion, pp. 34-39.]

223. Fuchs JR, Hannouche D, Terada S, Zand S, Vacanti JP, Fauza DO. Cartilage engineering from ovine umbilical cord blood mesenchymal progenitor cells. Stem Cells 2005;23:958-964.

224. Fuchs JR, Kaviani A, Oh JT, LaVan D, Udagawa T, Jennings RW, Wilson JM, Fauza DO. Diaphragmatic reconstruction with autologous tendon engineered from mesenchymal amniocytes. J Pediatr Surg 2004;39:834-838. [Discussion, pp. 834-838.]

225. Kaviani A, Guleserian K, Perry TE, Jennings RW, Ziegler MM, Fauza DO. Fetal tissue engineering from amniotic fluid. J Am Coll Surg 2003;196:592-597.

226. Kojima K, Ignotz RA, Kushibiki T, Tinsley KW, Tabata Y, Vacanti CA. Tissue-engineered trachea from sheep marrow stromal cells with transforming growth factor beta2 released from biodegradable microspheres in a nude rat recipient. J Thorac Cardiovasc Surg 2004;128:147-153.

227. Mondrinos MJ, Koutzaki S, Lelkes PI, Finck CM. A tissue-engineered model of fetal distal lung tissue. Am J Physiol Lung Cell Mol Physiol 2007;293:L639-L650.

228. Mondrinos MJ, Koutzaki S, Jiwanmall E, Li M, Dechadarevian JP, Lelkes PI, Finck CM. Engineering three-dimensional pulmonary tissue constructs. Tissue Eng 2006;12:717-728.

229. Lin YM, Boccaccini AR, Polak JM, Bishop AE, Maquet V. Biocompatibility of poly-DL-lactic acid (PDLLA) for lung tissue engineering. J Biomater Appl 2006;21:109-118.

230. Choe MM, Sporn PH, Swartz MA. Extracellular matrix remodeling by dynamic strain in a three-dimensional tissue-engineered human airway wall model. Am J Respir Cell Mol Biol 2006;35:306-313.
231. Liu M, Xu J, Souza P, Tanswell B, Tanswell AK, Post M. The effect of mechanical strain on fetal rat lung cell proliferation: comparison of two- and three-dimensional culture systems. In Vitro Cell Dev Biol Anim 1995;31:858-866.

232. Liu M, Tanswell AK, Post M. Mechanical force-induced signal transduction in lung cells. Am J Physiol 1999;277:L667-L683.

233. Liu M, Post M. Invited review: mechanochemical signal transduction in the fetal lung. J Appl Physiol 2000;89:2078-2084.

234. Andrade CF, Wong AP, Waddell TK, Keshavjee S, Liu M. Cell-based tissue engineering for lung regeneration. Am J Physiol Lung Cell Mol Physiol 2007;292:L510-L518.

235. Cortiella J, Nichols JE, Kojima K, Bonassar LJ, Dargon P, Roy AK, Vacant MP, Niles JA, Vacanti CA. Tissue-engineered lung: an in vivo and in vitro comparison of polyglycolic acid and pluronic F-127 hydrogel/somatic lung progenitor cell constructs to support tissue growth. Tissue Eng 2006;12:1213-1225.

236. Borthwick DW, Shahbazian M, Krantz QT, Dorin JR, Randell SH. Evidence for stem-cell niches in the tracheal epithelium. Am J Respir Cell Mol Biol 2001;24:662-670.

237. Schoch KG, Lori A, Burns KA, Eldred T, Olsen JC, Randell SH. A subset of mouse tracheal epithelial basal cells generates large colonies in vitro. Am J Physiol Lung Cell Mol Physiol 2004;286:L631-L642.

238. Engelhardt JF, Schlossberg H, Yankaskas JR, Dudus L. Progenitor cells of the adult human airway involved in submucosal gland development. Development 1995;121:2031-2046.

239. Hong KU, Reynolds SD, Giangreco A, Hurley CM, Stripp BR. Clara cell secretory protein-expressing cells of the airway neuroepithelial body microenvironment include a label-retaining subset and are critical for epithelial renewal after progenitor cell depletion. Am J Respir Cell Mol Biol 2001;24:671-681.

240. Giangreco A, Reynolds SD, Stripp BR. Terminal bronchioles harbor a unique airway stem cell population that localizes to the bronchoalveolar duct junction. Am J Pathol 2002;161:173-182.

241. Reynolds SD, Giangreco A, Power JH, Stripp BR. Neuroepithelial bodies of pulmonary airways serve as a reservoir of progenitor cells capable of epithelial regeneration. Am J Pathol 2000;156:269-278.

242. Hollande E, Cantet S, Ratovo G, Daste G, Bremont F, Fanjul M. Growth of putative progenitors of type II pneumocytes in culture of human cystic fibrosis alveoli. Biol Cell 2004;96:429-441.

243. Pan J, Bear C, Farragher S, Cutz E, Yeger H. Cystic fibrosis transmembrane conductance regulator modulates neurosecretory function in pulmonary neuroendocrine cell-related tumor cell line models. $A m$ J Respir Cell Mol Biol 2002;27:553-560.

244. Yeger H, Pan J, Fu XW, Bear C, Cutz E. Expression of CFTR and $\mathrm{Cl}(-)$ conductances in cells of pulmonary neuroepithelial bodies. $\mathrm{Am}$ J Physiol Lung Cell Mol Physiol 2001;281:L713-L721.

245. Pan J, Luk C, Kent G, Cutz E, Yeger H. Pulmonary neuroendocrine cells, airway innervation, and smooth muscle are altered in Cftr null mice. Am J Respir Cell Mol Biol 2006;35:320-326.

246. Kim CF, Jackson EL, Woolfenden AE, Lawrence S, Babar I, Vogel S, Crowley D, Bronson RT, Jacks T. Identification of bronchioalveolar stem cells in normal lung and lung cancer. Cell 2005;121:823-835.

247. Besson A, Hwang HC, Cicero S, Donovan SL, Gurian-West M, Johnson D, Clurman BE, Dyer MA, Roberts JM. Discovery of an oncogenic activity in p27Kip1 that causes stem cell expansion and a multiple tumor phenotype. Genes Dev 2007;21:1731-1746.

248. Ventura JJ, Tenbaum S, Perdiguero E, Huth M, Guerra C, Barbacid M, Pasparakis M, Nebreda AR. p38alpha MAP kinase is essential in lung stem and progenitor cell proliferation and differentiation. Nat Genet 2007;39:750-758.

249. Yanagi S, Kishimoto H, Kawahara K, Sasaki T, Sasaki M, Nishio M, Yajima N, Hamada K, Horie Y, Kubo H, et al. Pten controls lung morphogenesis, bronchioalveolar stem cells, and onset of lung adenocarcinomas in mice. J Clin Invest 2007;117:2929-2940.

250. Ling TY, Kuo MD, Li CL, Yu AL, Huang YH, Wu TJ, Lin YC, Chen $\mathrm{SH}, \mathrm{Yu}$ J. Identification of pulmonary Oct-4+ stem/progenitor cells and demonstration of their susceptibility to SARS coronavirus (SARSCoV) infection in vitro. Proc Natl Acad Sci USA 2006;103:9530-9535.

251. Ratajczak MZ, Machalinski B, Wojakowski W, Ratajczak J, Kucia M. A hypothesis for an embryonic origin of pluripotent Oct-4(+) stem cells in adult bone marrow and other tissues. Leukemia 2007;21:860-867.

252. Blanpain C, Horsley V, Fuchs E. Epithelial stem cells: turning over new leaves. Cell 2007;128:445-458.

253. Willis BC, Borok Z. TGF-beta-induced EMT: mechanisms and implications for fibrotic lung disease. Am J Physiol Lung Cell Mol Physiol 2007;293:L525-L534. 
254. Willis BC, duBois RM, Borok Z. Epithelial origin of myofibroblasts during fibrosis in the lung. Proc Am Thorac Soc 2006;3:377-382.

255. Demayo F, Minoo P, Plopper CG, Schuger L, Shannon J, Torday JS. Mesenchymal-epithelial interactions in lung development and repair: are modeling and remodeling the same process? Am J Physiol Lung Cell Mol Physiol 2002;283:L510-L517.

256. Park KS, Wells JM, Zorn AM, Wert SE, Laubach VE, Fernandez LG, Whitsett JA. Transdifferentiation of ciliated cells during repair of the respiratory epithelium. Am J Respir Cell Mol Biol 2006;34:151-157.

257. Wu R, Harper R, Kao CY, Thai P, Wu D, Chen Y, Chang MMJ. New insights into airway mucous cell differentiation. Journal of Organ Dysfunction 2006;2:30-36.

258. Wang J, Edeen K, Manzer R, Chang Y, Wang S, Chen X, Funk CJ, Cosgrove GP, Fang X, Mason RJ. Differentiated human alveolar epithelial cells and reversibility of their phenotype in vitro. Am J Respir Cell Mol Biol 2007;36:661-668.

259. Morrison SJ. Cancer stem cells. Clin Adv Hematol Oncol 2005;3:171172.

260. Reya T, Morrison SJ, Clarke MF, Weissman IL. Stem cells, cancer, and cancer stem cells. Nature 2001;414:105-111.

261. Eramo A, Lotti F, Sette G, Pilozzi E, Biffoni M, Di Virgilio A, Conticello C, Ruco L, Peschle C, De Maria R. Identification and expansion of the tumorigenic lung cancer stem cell population. Cell Death Differ 2008;15:504-514.

262. Ho MM, Ng AV, Lam S, Hung JY. Side population in human lung cancer cell lines and tumors is enriched with stem-like cancer cells. Cancer Res 2007:67:4827-4833.

263. Tian J, Mahmood R, Hnasko R, Locker J. Loss of Nkx2.8 deregulates progenitor cells in the large airways and leads to dysplasia. Cancer Res 2006;66:10399-10407.

264. Sicinski P, Zacharek S, Kim C. Duality of p27Kip1 function in tumorigenesis. Genes Dev 2007;21:1703-1706.

265. Watkins DN, Berman DM, Burkholder SG, Wang B, Beachy PA, Baylin SB. Hedgehog signalling within airway epithelial progenitors and in small-cell lung cancer. Nature 2003;422:313-317.

266. Pei XH, Bai F, Smith MD, Xiong Y. p18Ink4c collaborates with Men1 to constrain lung stem cell expansion and suppress non-small-cell lung cancers. Cancer Res 2007;67:3162-3170.

267. Seo DC, Sung JM, Cho HJ, Yi H, Seo KH, Choi IS, Kim DK, Kim JS, El-Aty AA, Shin HC. Gene expression profiling of cancer stem cell in human lung adenocarcinoma A549 cells. Mol Cancer 2007;6:75.

268. Zhang X, Zhao P, Kennedy C, Chen K, Wiegand J, Washington G, Marrero L, Cui Y. Treatment of pulmonary metastatic tumors in mice using lentiviral vector-engineered stem cells. Cancer Gene Ther 2008;15:73-84.

269. Samadikuchaksaraei A, Bishop AE. Derivation and characterization of alveolar epithelial cells from murine embryonic stem cells in vitro. Methods Mol Biol 2006;330:233-248.

270. Rippon HJ, Polak JM, Qin M, Bishop AE. Derivation of distal lung epithelial progenitors from murine embryonic stem cells using a novel three-step differentiation protocol. Stem Cells 2006;24:1389-1398.

271. Denham M, Cole TJ, Mollard R. Embryonic stem cells form glandular structures and express surfactant protein $\mathrm{C}$ following culture with dissociated fetal respiratory tissue. Am J Physiol Lung Cell Mol Physiol 2006;290:L1210-L1215.

272. Coraux C, Nawrocki-Raby B, Hinnrasky J, Kileztky C, Gaillard D, Dani C, Puchelle E. Embryonic stem cells generate airway epithelial tissue. Am J Respir Cell Mol Biol 2005;32:87-92.

273. Wang D, Haviland DL, Burns AR, Zsigmond E, Wetsel RA. A pure population of lung alveolar epithelial type II cells derived from human embryonic stem cells. Proc Natl Acad Sci USA 2007;104:4449-4454.

274. Samadikuchaksaraei A, Cohen S, Isaac K, Rippon HJ, Polak JM, Bielby RC, Bishop AE. Derivation of distal airway epithelium from human embryonic stem cells. Tissue Eng 2006;12:867-875.

275. Denham M, Conley BJ, Olsson F, Gulluyan L, Cole TJ, Mollard R. A murine respiratory-inducing niche displays variable efficiency across human and mouse embryonic stem cell species. Am J Physiol Lung Cell Mol Physiol 2007;292:L1241-L1247.

276. Pickering SJ, Minger SL, Patel M, Taylor H, Black C, Burns CJ, Ekonomou A, Braude PR. Generation of a human embryonic stem cell line encoding the cystic fibrosis mutation deltaF508, using preimplantation genetic diagnosis. Reprod Biomed Online 2005;10:390-397.

277. Mateizel I, De Temmerman N, Ullmann U, Cauffman G, Sermon K, Van de Velde H, De Rycke M, Degreef E, Devroey P, Liebaers I, et al. Derivation of human embryonic stem cell lines from embryos obtained after IVF and after PGD for monogenic disorders. Hum Reprod 2006;21:503-511.
278. Takahashi K, Yamanaka S. Induction of pluripotent stem cells from mouse embryonic and adult fibroblast cultures by defined factors. Cell 2006;126:663-676.

279. Takahashi K, Tanabe K, Ohnuki M, Narita M, Ichisaka T, Tomoda K, Yamanaka S. Induction of pluripotent stem cells from adult human fibroblasts by defined factors. Cell 2007;131:861-872.

280. Yu J, Vodyanik MA, Smuga-Otto K, Antosiewicz-Bourget J, Frane JL, Tian S, Nie J, Jonsdottir GA, Ruotti V, Stewart R, et al. Induced pluripotent stem cell lines derived from human somatic cells. Science 2007;318:1917-1920.

281. Nakagawa M, Koyanagi M, Tanabe K, Takahashi K, Ichisaka T, Aoi T, Okita K, Mochiduki Y, Takizawa N, Yamanaka S. Generation of induced pluripotent stem cells without Myc from mouse and human fibroblasts. Nat Biotechnol 2008;26:101-106.

282. Maeda Y, Dave V, Whitsett JA. Transcriptional control of lung morphogenesis. Physiol Rev 2007;87:219-244.

283. Sekine K, Ohuchi H, Fujiwara M, Yamasaki M, Yoshizawa T, Sato T, Yagishita N, Matsui D, Koga Y, Itoh N, et al. Fgf10 is essential for limb and lung formation. Nat Genet 1999;21:138-141.

284. Lu J, Izvolsky KI, Qian J, Cardoso WV. Identification of FGF10 targets in the embryonic lung epithelium during bud morphogenesis. $J$ Biol Chem 2005;280:4834-4841.

285. Lu J, Qian J, Keppler D, Cardoso WV. Cathespin H is an Fgf10 target involved in Bmp4 degradation during lung branching morphogenesis. J Biol Chem 2007;282:22176-22184.

286. Pogach MS, Cao Y, Millien G, Ramirez MI, Williams MC. Key developmental regulators change during hyperoxia-induced injury and recovery in adult mouse lung. J Cell Biochem 2007;100:14151429.

287. Clark JC, Tichelaar JW, Wert SE, Itoh N, Perl AK, Stahlman MT, Whitsett JA. FGF-10 disrupts lung morphogenesis and causes pulmonary adenomas in vivo. Am J Physiol Lung Cell Mol Physiol 2001; 280:L705-L715.

288. Vos JB, van Sterkenburg MA, Rabe KF, Schalkwijk J, Hiemstra PS, Datson NA. Transcriptional response of bronchial epithelial cells to Pseudomonas aeruginosa: identification of early mediators of host defense. Physiol Genomics 2005;21:324-336.

289. Riss J, Khanna C, Koo S, Chandramouli GVR, Yang HH, Ha Y, Kleiner DE, Rosenwald A, Schaefer CF, et al. Cancers as wounds that do not heal: differences and similarities between renal regeneration/ repair and renal cell carcinoma. Cancer Res 2006;66:7216-7224.

290. Desai TJ, Malpel S, Flentke GR, Smith SM, Cardoso WV. Retinoic acid selectively regulates Fgf10 expression and maintains cell identity in the prospective lung field of the developing foregut. Dev Biol 2004; 273:402-415.

291. Tabata C, Kadokawa Y, Tabata R, Takahashi M, Okoshi K, Sakai Y, Mishima M, Kubo H. All-trans-retinoic acid prevents radiation- or bleomycin-induced pulmonary fibrosis. Am J Respir Crit Care Med 2006;174:1352-1360.

292. McGowan SE, Holmes AJ. Vitamin A deficiency alters pulmonary parenchymal collagen and tissue mechanics. Respir Physiolo Neurobiol 2007;156:312-319.

293. Zimova M, Myslivecek J, Potmesil P. Retinoic acid attenuates the mild hyperoxic lung injury in newborn mice. Physiol Res 2008;57:33-40.

294. Ingber DE, Levin M. What lies at the interface of regenerative medicine and developmental biology? Development 2007;134:2541-2547.

295. Radtke F, Clevers H. Self-renewal and cancer of the gut: two sides of a coin. Science 2005;307:1904-1909.

296. Randell SH. Airway epithelial stem cells and the pathophysiology of chronic obstructive pulmonary disease. Proc Am Thorac Soc 2006;3: 718-725.

297. Fuchs E, Tumbar T, Guasch G. Socializing with the neighbors: stem cells and their niche. Cell 2004;116:769-778.

298. Shackleton M, Vaillant F, Simpson KJ, Stingl J, Smyth GK, AsselinLabat ML, Wu L, Lindeman GJ, Visvader JE. Generation of a functional mammary gland from a single stem cell. Nature 2006;439: 84-88.

299. Nelson CM, Bissell MJ. Of extracellular matrix, scaffolds, and signaling: tissue architecture regulates development, homeostasis, and cancer. Ann Rev Cell Dev Biol 2006;22:287-309.

300. Meuwissen R, Linn SC, Linnoila RI, Zevenhoven J, Mooi WJ, Berns A. Induction of small cell lung cancer by somatic inactivation of both Trp53 and Rb1 in a conditional mouse model. Cancer Cell 2003;4: 181-189.

301. Linnoila RI, Sahu A, Miki M, Ball DW, DeMayo FJ. Morphometric analysis of CC10-hASH1 transgenic mouse lung: a model for bron- 
chiolization of alveoli and neuroendocrine carcinoma. Exp Lung Res 2000;26:595-615.

302. Summer R, Kotton DN, Sun X, Ma B, Fitzsimmons K, Fine A. Side population cells and Bcrp1 expression in lung. Am J Physiol Lung Cell Mol Physiol 2003;285:L97-L104.

303. Bertoncello I. Status of high proliferative potential colony-forming cells in the hematopoietic stem cell hierarchy. Curr Top Microbiol Immunol 1992;177:83-94.

304. Bertoncello I, Bradford GB. Surrogate assays for hematopoietic stem cell activity. In: Garland J, Quesenberry P, Hilton D. Colonystimulating factors, 2nd ed. New York: Marcel Dekker; 1997. pp. $35-47$.
305. Phinney DG, Kopen G, Isaacson RL, Prockop DJ. Plastic adherent stromal cells from the bone marrow of commonly used strains of inbred mice: variations in yield, growth, and differentiation. $J$ Cell Biochem 1999;72:570-585.

306. Assmus BH, Honold J, Shächinger V, Britten MB, Fischer-Rasokat U, Lehmann R, Teupe C, Pistorius K, Martin H, Abolmaali ND, et al. Transcoronary transplantation of progenitor cells after myocardial infarction. N Engl J Med 2006;355:1222-1232.

307. Stripp BR, Reynolds SD. Maintenance and repair of the bronchiolar epithelium. Proc Am Thorac Soc 2008;5:328-333.

308. Jaenisch R, Young Y. Stem cells, the molecular circuitry of pluripotency and nuclear reprogramming. Cell 2008;132:567-582. 